Florida International University

FIU Digital Commons

FIU Electronic Theses and Dissertations

University Graduate School

3-21-1996

\title{
The effects of a holistic-graphophonic intervention on the decoding performance of children with reading disabilities
}

E. Judith Krisman Cohen
Florida International University

DOI: $10.25148 /$ etd.FI14060868

Follow this and additional works at: https://digitalcommons.fiu.edu/etd

Part of the Special Education and Teaching Commons

\section{Recommended Citation}

Cohen, E. Judith Krisman, "The effects of a holistic-graphophonic intervention on the decoding performance of children with reading disabilities" (1996). FIU Electronic Theses and Dissertations. 2397.

https://digitalcommons.fiu.edu/etd/2397

This work is brought to you for free and open access by the University Graduate School at FIU Digital Commons. It has been accepted for inclusion in FIU Electronic Theses and Dissertations by an authorized administrator of FIU Digital Commons. For more information, please contact dcc@fiu.edu. 


\section{FLORIDA INTERNATIONAL UNIVERSITY \\ Miami, Florida}

THE EFFECTS OF A HOLISTIC-GRAPHOPHONIC INTERVENTION ON THE DECODING PERFORMANCE OF CHILDREN WITH READING DISABILITIES

A dissertation submitted in partial satisfaction of the requirements for the degree of DOCTOR OF EDUCATION

IN

EXCEPTIONAL STUDENT EDUCATION

by

E. Judith Krisman Cohen 


\section{DISSERTATION COMMITTEE APPROVAL SHEET}

To: Dean Ira Goldenberg

College of Education

This dissertation, written by E. Judith Krisman Cohen, and entitled The Effects of a Holistic-Graphophonic Intervention on the Decoding Performance of Children with Reading Disabilities, having been approved in respect to style and intellectual content, is referred to you for judgment.

We have read this dissertation and recommend that it be approved.

Wendy Cheyney

Stephen Fain

Michael P. Brady, Major Professor

Date of Defense: March 21, 1996

The dissertation of $\mathrm{E}$. Judith Krisman Cohen is approved.

Dean Ira Goldenberg

College of Education

Dr. Richard L. Campbel

Dean of Graduate Studies

Florida International University, 1996 
${ }^{\circ}$ COPYRIGHT 1996 by E. Judith Krisman Cohen

All rights reserved 


\section{DEDICATION}

To my wonderful family and friends, to my exceptional committee, and to

all my students, especially Christie, Laurie, Eddie, Mike, and Ricky, I dedicate this dissertation, with thanks and love. This HUG's for you! 


\section{ACKNOWLEDGMENTS}

Many people have played a part in the realization and completion of this dissertation. I would like to express my sincere appreciation to my dissertation committee, colleagues, students, friends, and family.

With deepest admiration, I offer immeasurable thanks to my major professor, Dr. Michael P. Brady. As a result of his wisdom, guidance, time, and research expertise, this dissertation has become a reality. For his genuine interest in this study, and confidence in me, I am forever grateful. To Dr. Wendy Cheyney, my long-time advisor, mentor, and friend, I extend my heartfelt appreciation. Throughout all my years at F.I.U., she has been a constant source of inspiration and encouragement. Thanks to her example, direction, and many challenges, I began, and completed, this doctoral program. To Dr. Stephen Fain, who has always provided a sense of purpose, as well as humor, I offer sincere thanks. His knowledge and enthusiasm in the field of curriculum has been contagious.

In addition to my outstanding committee, I want to express my gratitude to the excellent faculty of the Department of Educational Psychology and Special Education at Florida International University, for creating an environment of intellectual curiosity, that fostered my academic and professional growth. Special thanks go to Dr. Kim Weber for her thoughtful comments and suggestions during data collection and analysis.

Next, I would like to thank Mrs. Frances McGlannan and all my colleagues, friends, and students at The McGlannan School, for their flexibility, concern, and understanding during this research project. I extend special thanks to my data collectors, Julee Barbour and Nancy Sherar, for their daily observations and 
assistance throughout the study. I am also very grateful to all the children in my reading class, especially the five participants and their parents, for their interest, cooperation, and enthusiasm.

I would also like to thank my friends, and fellow doctoral candidates, Kelly Meyers-Sinett and Sharon McGee, for sharing the "doctoral experience" with me. They provided support and understanding in times of stress and anxiety, as well as in moments of excitement and joy.

Finally, and most importantly, I would like to thank my family for their constant love and faith in me. To my husband, Ken, I offer heartfelt thanks. For many years of patience and encouragement, and in a very special way, for his computer expertise, advice, and assistance (particularly with the graphs and tables), I am truly grateful. Very special thanks go to my children, Julie and David, for their understanding and tolerance. I hope I can make up some lost time in the years ahead. I also want to thank my brothers, Ed and Eric, for their continual support and concern. Above all, I wish to express my gratitude to the best parents ever, Eleanor and Edward Krisman, whose constant love, encouragement, and confidence in me helped me reach for and achieve this very important goal. For always being there, to listen, discuss, and advise, I am forever grateful.

To each of you, who have shared this process with me, in one way or another, thank you. 


\title{
ABSTRACT OF THE DISSERTATION \\ THE EFFECTS OF A HOLISTIC-GRAPHOPHONIC INTERVENTION ON THE DECODING PERFORMANCE OF CHILDREN WITH READING DISABILITIES
}

\author{
by \\ E. Judith Krisman Cohen \\ Florida International University, 1996 \\ Professor Michael P. Brady, Major Professor
}

The purpose of this study was to investigate the effects of an intervention combining holistic and graphophonic methods on the decoding performance of children with reading disabilities. The impact of this synthesis of teaching methods was evaluated by examining five students' abilities to decode a set of training words using three common vowel patterns. Words containing these magic e, double vowel, and closed vowel patterns were presented in isolation and in context. Additional sets of novel words and nonsense words using the same vowel patterns were used to evaluate generalization.

The study incorporated single-subject experimental research methods, using a multiple baseline design across vowel patterns. Data were collected and analyzed daily. The results of this study indicated that all five second-graders, three boys and two girls, demonstrated substantial gains in decoding ability on all three vowel patterns. The students increased their accuracy on training words in isolation, as well as in context. In addition, students increased their decoding accuracy on generalization words, in both novel and nonsense words. These increases in decoding accuracy were maintained during post-intervention probes and during the 7-week follow-up phase of the study. 


\section{TABLE OF CONTENTS}

CHAPTER

PAGE

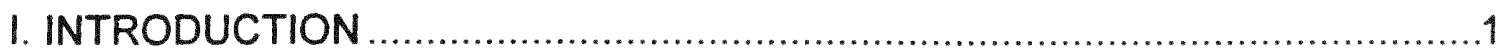

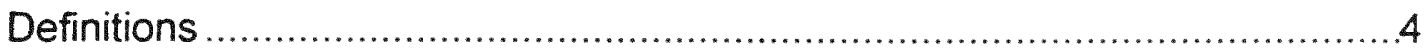

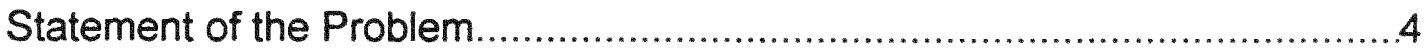

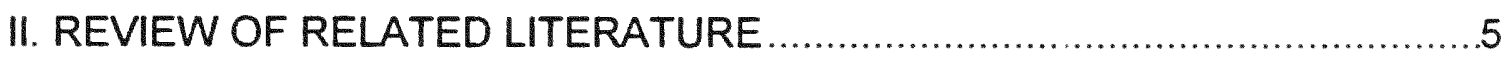

Whole Language Approaches to Reading …...........................................5

Phonetic Approaches to Reading ........................................................ 8

The Research Bases of Whole Language and Phonics..........................11

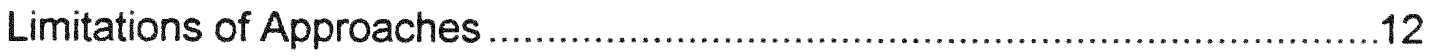

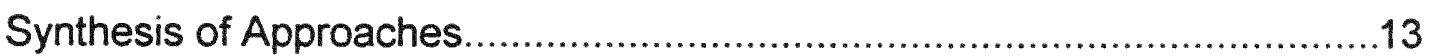

Research Questions........................................................................

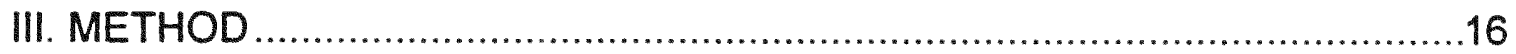

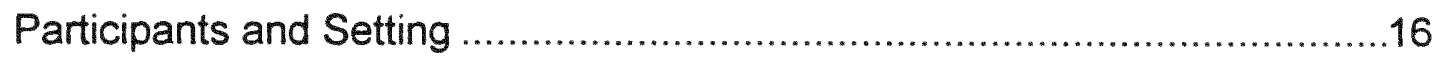

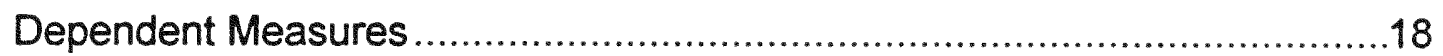

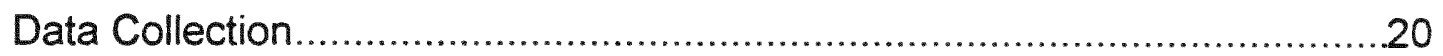

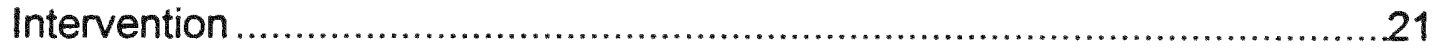

Research Design and Data Analysis ................................................23

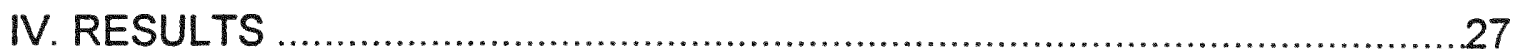

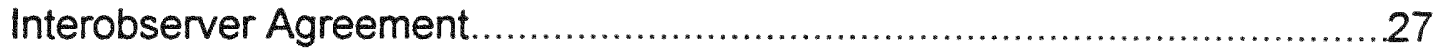

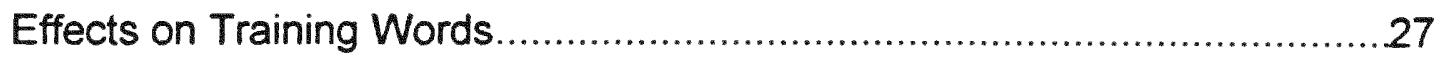

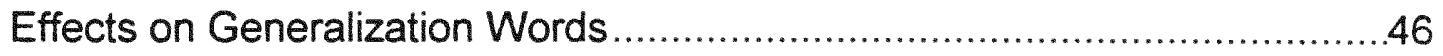

Effects on Standardized Test Measures ..............................................62

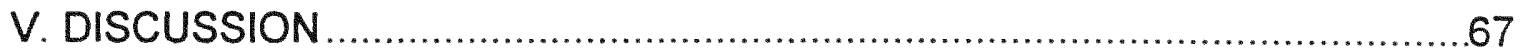

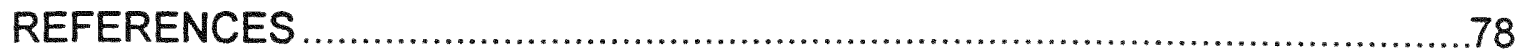

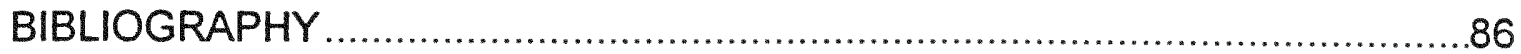


Appendix A List of Words Used in Study Arranged by Vowel Patterns Alphabetical by Phonogram (Rime)

Training Words .92

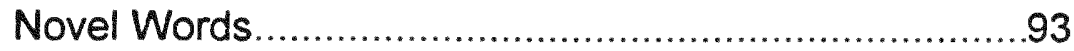

Nonsense Words ..................................................94

Appendix B Sample Data Sheets

Daily Reading Accuracy Data Sheet ..........................96

Consonant Test Used to Establish Reading Criteria ......97

Phonics Pattern Subtest of the Decoding Skills Test .....98

Appendix C List of Literature Books Used in Intervention ......................99

Appendix D Vowel Patterns Classified by Literature Books .................101

Appendix E Intervention Procedure .............................................106

Appendix F Vowel Patterns Chart ..............................................108

Appendix G F.I.U. Institutional Review Board Approval Form .............110

Appendix $\mathrm{H} \quad$ Parental Consent Form and Accompanying Letter ...........112

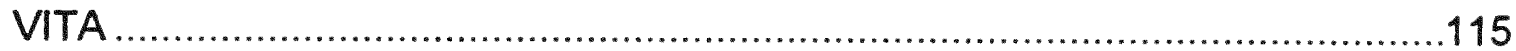




\section{LIST OF TABLES}

PAGE

Table 1 Participant Characteristics 16

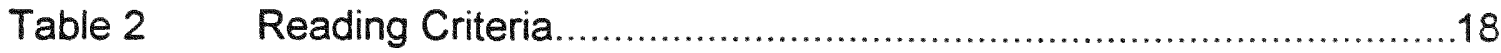

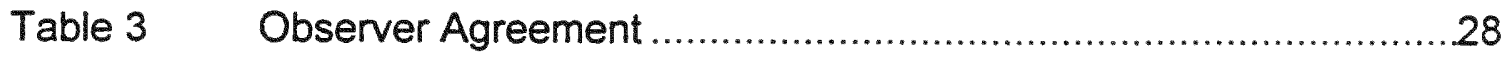

Table 4 Reading Accuracy: Magic e Vowel Pattern Training Words ...........35

Table 5 Reading Accuracy: Double Vowel Pattern Training Words ............36

Table 6 Reading Accuracy: Closed Vowel Pattern Training Words.............37

Table 7 Training Word Accuracy: Group Means .....................................38

Table 8 Reading Generalization: Magic e Vowel Pattern Words................52

Table 9 Reading Generalization: Double Vowel Pattern Words .................53

Table 10 Reading Generalization: Closed Vowel Pattern Words .................54

Table 11 Generalization Word Accuracy: Group Means ............................55

Table 12 Effects on Standardized Test Measures:

Woodcock Reading Mastery Tests - Revised 63 


\section{LIST OF FIGURES}

PAGE

Figure $1 \quad$ Eddie's Results on Training Words ........................................30

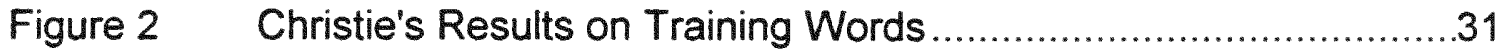

Figure 3 Laurie's Results on Training Words ......................................32

Figure $4 \quad$ Mike's Results on Training Words .........................................33

Figure $5 \quad$ Ricky's Results on Training Words .........................................34

Figure $6 \quad$ Eddie's Results on Generalization Words .............................47

Figure $7 \quad$ Christie's Results on Generalization Words ............................48

Figure $8 \quad$ Laurie's Results on Generalization Words ...............................49

Figure 9 Mike's Results on Generalization Words...................................50

Figure 10 Ricky's Results on Generalization Words .................................51 


\section{CHAPTER I}

Introduction

In the field of education, various philosophies have come and gone, but not without making an impact on the community of educators of the time. Their residual effects continue to influence contemporary education. Similarly, in the area of reading instruction, a variety of models, methods and approaches, all based on different philosophies, have influenced present-day reading educators. Much research has been conducted on these methods and approaches for reading acquisition, for both typical and disabled learners. The results, although controversial, oppositional, and confusing at times, have led reading educators and researchers to re-evaluate current trends and to proceed with yet newer insights and understandings. At the present time, for example, an important concern is the role of phonics in reading instruction. Studies that question the quantity and quality of phonics instruction ("how much" and "what kind") are more relevant than those that compare phonics with other approaches, in an "either-or" proposition. Historically, this notion of an "either-or" way of thinking has been common in education. Advocates of certain beliefs tend to profess extreme, polarized views, such as behaviorism OR constructivism; holistic OR traditional models; bottom-up OR top-down theories; meaning-based OR code-based approaches, etc. The "Great Debate" involving "whole word" OR "phonics" still lingers today. With the popularity of the Whole Language movement, the role of phonics in reading instruction continues to receive attention. These and similar concepts have provoked many academic discussions, arguments, debates, and commentaries.

Rather than conforming to a one-sided view of reading instruction, this study proposes an eclectic, balanced approach, systematically integrating 
meaning AND structure. Although based on a holistic model, this intervention emphasizes the significant role of phonics in the acquisition of reading.

Specifically, phonics is taught in context (i.e., through real stories), and directly (using vowel patterns and rules). The term graphophonics is used because the focus is on the visual representation of a word as a pattern of letters and their corresponding sounds (as in analytic phonics).

The Whole Language movement has led reading educators to ask new and important questions about the reading process, particularly about the role of phonics in reading instruction. The definition of whole language, however, has been problematic in recent years. Bergeron (1990) examined 64 journal articles published between 1979 and 1989 that used the term "whole language" and found marked differences between the many definitions. In addition, confusion results when terms such as "philosophy," "model," "method," and "approach" are used interchangeably. Bergeron (1990) proposed the following definition:

Whole Language is a concept that embodies both a philosophy of language development and the instructional approaches embedded within, and supportive of, that philosophy. This concept includes the use of real literature and writing in the context of meaningful, functional, and cooperative experiences in order to develop in students motivation and interest in the process of learning. (p. 319)

To avoid any confusion, the above definition of whole language is used throughout this study.

The diagnosis and remediation of reading disorders are also in a state of change. In the past, a "bottom up," or deficit model, characterized the remediation approach suggested for children with reading disabilities (RD). This model utilizes a part to whole, synthetic approach to reading. Skills are taught in isolation, 
building up from sounds and letters, to words, to sentences, and finally, to paragraphs and stories.

"Top-down" models, on the other hand, stress reading for meaning. The use of context and schema are used to make sense of a printed passage. The emphasis is on creating an authentic, literate environment. This model utilizes a whole to part approach to reading, and is consistent with the whole language philosophy. The focus is on meaning, and skills are only taught indirectly.

However, since children with reading disabilities have difficulty learning the structure, or code, of our language, a more balanced, integrated intervention model seems necessary. Interactive models combine top-down and bottom-up approaches, integrating schema, semantics, syntax, and graphophonics, to process a printed message and understand its meaning. This model suggests that readers use the various cueing systems simultaneously and "interactively."

Although the various models of reading instruction for both typical and disabled learners are continuously changing and improving, this study has incorporated certain elements from two bodies of knowledge, namely, whole language and phonics. The purpose was not to compare or contrast, but rather to transcend what has come before, and, in the spirit of the "new eclecticism" (Manzo \& Manzo, 1993), "learn from past traditions ... in the process of charting change" (p. 33).

Therefore, the intervention presented in this study combines the meaningbased strategies consistent with the philosophy of whole language with the codebased strategies of graphophonics. This integrative approach is designed to insure a more balanced reading program. In this model, skills are taught directly, in the context of real reading, thereby balancing meaning and structure. This is accomplished through shared reading and vowel pattern analysis. 


\section{Definitions}

Reading disabilities. Difficulties with the process of reading; may be associated with learning disabilities or dyslexia.

Whole Language. A meaning-based philosophy of teaching that integrates listening, speaking, reading, and writing.

Phonics. A code-based approach to reading instruction based on phoneme-grapheme relationships.

Holistic. A whole to part contextual approach to reading.

Graphophonics. One of the four reading cueing systems that focuses on the visual representation of the word as groups or patterns of letters and their corresponding sounds.

Vowel Patterns. Letter groups based on the position of the vowel and its surrounding consonants; syllables; spelling patterns.

Closed syllable. A syllable containing one vowel, ending with a consonant, and the vowel is short, (e.g., cat).

Magic e syllable. A syllable ending in e, containing one consonant before the ending e, one vowel before the consonant, and the vowel is long, (e.g., ride).

Double Vowel syllable. A syllable containing two adjacent vowels, and the first vowel is long, (e.g., boat).

Statement of the Problem

Some learners are resistant to learning via traditional methods of reading instruction. A balanced combination of meaning and structure may assist these students with reading disabilities to acquire reading. The purpose of this study was to investigate the effects of an intervention combining holistic and graphophonic methods on the decoding performance of children with reading disabilities. 


\section{CHAPTER ॥}

Review of Related Literature

\section{Whole Language Approaches to Reading}

A recent issue in the field of reading and learning disabilities (LD) is the relevance of the "whole language" approach to reading. Much has been written both for and against the use of whole language with children who have reading disabilities. Although many practitioners view this change as positive, some question its effect on the reading development of children with learning disabilities.

Whole language is a philosophy that views reading as an interactive process that integrates the oral aspects of language -- listening and speaking, with the written aspects - reading and writing. It encourages the simultaneous use of the four reading cueing systems: schemata, semantics, syntax, and graphophonics. Goodman (1986) summarizes the logic of this approach when he states that language should be "whole, meaningful, and relevant to the learners" (p. 9). Reading should be a communication between the reader and the author, as natural as speaking and listening. It has been said that the whole is worth more than the sum of its parts. Goodman (1986) believes that, "Whole language is firmly supported by four humanistic-scientific pillars: a strong theory of learning, a theory of language, a basic view of teaching and the role of teachers, and a language-centered view of curriculum" (p. 26).

The use of varied strategies in a whole language classroom utilizes meaningful language passages in the context of real literacy events. This is in direct contrast to the use of isolated skills and drills. The theme of natural, meaningful learning drives the whole language approach. The focus is on the process of reading and the meaning of language. 
Hollingsworth and Reutzel (1988) discuss the use of whole language with children with learning disabilities, suggesting that the "language-learning disabled child learns naturally from exposure and use rather than from isolated instructional drills ... learning occurs best where there is active involvement in an interesting and functionally relevant language-learning opportunity" (p.479). The authors explain various practices consistent with whole language theory, such a shared reading, language experience, writing process, oral reading variations, and the impress method. They agree with Goodman when they state that "learning progresses from the meaningful whole of language to an understanding of the parts of the language transaction" (p. 479).

Reading is a transactive process in which people use active strategies for constructing meaning as they interact with print. These strategies -- predicting, confirming, and integrating -- are used by readers to process language cues (Rhodes \& Dudley-Marling, 1988). Phinney (1988) explains how she uses prediction, confirmation, and integration in her work with children. She states that prediction "involves setting expectations for the meaning a particular text will provide" (p. 7); confirmation is the "process of checking predictions against the text" (p. 8); and integration is the "process of choosing and incorporating information from the text into our store of knowledge and ideas" (p. 9).

The practical application of these operations during reading needs to be encouraged with the use of specific plans of action, or strategies, by the reader when an unfamiliar word arises, or confusion occurs. The focus is on understanding and comprehension, not on "sounding out." Some examples of strategies that primary children can learn to use effectively are (a) cloze or "blanking", which is reading ahead, and then going back to try out possibilities that might fit; (b) re-reading a phrase or sentence or part of a page to re-establish 
the flow of the passage; (c) substitutions, or using a good guess to fit in, that will make sense, (e.g., house for home, mom for mother); (d) picture clues to get a sense of what the passage is about; and (e) pointing, to keep the place and focus on initial parts of words.

Whole language alternatives for students with learning disabilities require a holistic view of learning, based on student strengths and abilities. This has been contrasted with a reductionist perspective of remediating deficits (Chiang \& Ford, 1990). Poplin (1988b) considers the four models of LD since 1950, (i.e., the medical, psychological processes, behavioral, and cognitive strategy models), and suggests that they are all drawn from reductionist learning theory. She proposes a new "holistic/constructivist" model, which, she believes, fosters transferability, global thinking, and interactive learning. In discussing this model, she compares her theory of "whole-part-whole" to Whitehead's (1929) theory of "romance, precision, and generalization" (Poplin, 1988a, p. 408). In reading instruction, this concept might involve (a) reading a new story, focusing on its meaning, (b) analyzing its parts (words and syllables), and (c) rereading with new insights and understandings. The interaction of whole and part is further explained by Caine and Caine (1991). They state, "People have enormous difficulty in learning when either parts or wholes are overlooked ... parts and wholes are conceptually interactive. They derive meaning from and give it to each other" (p. 83).

The concept of constructivism is further explored by Brooks and Brooks (1993). They state that this theory about knowledge and learning is based on the way we "construct our own understandings of the world in which we live " (p. 4). This blending of previous experiences and background knowledge helps to interpret new and unfamiliar information. In constructivist education, teachers 
encourage interaction, focusing on learning for understanding. Gardner (1991) also affirms the importance of genuine understanding when he states, "The understandings of the disciplines represent the most important cognitive achievements of human beings. It is necessary to come to know these understandings if we are to be fully human, to live in our time, ... and to build upon it" (p. 11).

Reid (1988) suggests that a gradual evolution, rather than a revolution, might be more successful in changing the LD model to a more holistic one. She believes that in the field of special education in particular, conservatism prevails, and new concepts or theories need to be introduced slowly and carefully. Chiang and Ford (1990) tend to agree with this line of thinking when they advocate moving toward a balance in using holistic and reductionist viewpoints.

\section{Phonetic Approaches to Reading}

Another object of controversy in current educational circles is phonics. It seems to elicit fear in some and rage in others. However, it is impossible to comprehend the reading process without an understanding of phonics. Dechant (1993) suggests that phonics is a way to help children understand and internalize the alphabetic principle as it occurs in our language system. It provides an insight into why words are pronounced the way they are, as well as a strategy to unlock a word when prediction through schema and syntax will not work. "In learning the graphophonological code, children learn that the visual/auditory association follows certain internal consistencies or probabilities" (Dechant, 1993, p. 297). It allows readers to verify their predictions.

Whole language advocates differ in their acceptance of phonics in reading instruction. Some believe phonics should not be taught at all; students will somehow infer letter-sound correspondences from being exposed to a print-rich 
environment. Others, however, believe that indirect phonics instruction is acceptable, as long as it occurs within a meaningful context. Goodman himself states, "Whole language teachers don't reject phonics; what they do is put it in its proper place" (1993, p. 108). For some children, this may be enough. Children with reading disabilities, however, need direct phonics instruction. Phonics advocates suggest that there is "strong support for early, intensive instruction in phonic analysis to help students achieve independence in word recognition" (Trachtenburg, 1990, p. 648).

It should be kept in mind that the purpose of phonics instruction is to provide a strategy for fluency. Phonics is not an end, but a means to an end, which is reading for understanding. Graphophonics is just one of four reading cueing systems. It needs to be kept in proper perspective and used simultaneously with the other three systems: schema, semantics, and syntax.

Another factor influencing phonics is the way in which it is taught. Analytic phonics stresses the symbol-sound relationship within a whole word. It is considered a whole to part approach and is suggested by many phonics advocates. Synthetic phonics, on the other hand, emphasizes the individual letters and sounds that eventually blend into a word. This is considered a part to whole approach and is used by many reading disability specialists.

Phonemic awareness and phonological processing are factors influencing the reading process. The majority of children with reading disabilities experience difficulty with decoding, or word recognition (Stanovich, 1988). Research suggests that these poor readers have difficulty using the sounds of the language in processing written and oral information. They cannot detect and manipulate the sounds within words. Spector (1995) suggests that children with reading, writing, 
and learning disabilities may especially need systematic instruction to ensure the development of phonemic awareness.

Graphophonic analysis is a concept that is becoming popular in reading instruction. It is a process of decoding new words by means of recognizable or spelling patterns in known words (May, 1986). One way this can be incorporated into teaching is through the vowel pattern method. This method emphasizes the position of vowels within words, which utilizes the visual modality (a strength for many children with reading disabilities), rather than a rule-oriented method, which uses the auditory modality (a deficit for many children with reading disabilities). May (1986) suggests that graphophonic analysis should be "carried on in the context of regular reading, guided by a skillful teacher" (p. 159).

Another approach to phonics instruction is the onset-rime approach. Research suggests that it is easier for students to recognize whole rimes than individual phonemes, and that only 37 rimes make up approximately 500 primary grade words (Adams, 1990; Gaskins, Gaskins, \& Gaskins, 1991; Goswami \& Mead, 1992). Gunning (1995) describes a word building approach based on students' natural tendency to seek out pronounceable word parts. It incorporates the use of word patterns, onsets and rimes, and an analogy strategy. In this approach, students decode new words based on identical patterns of known words.

Opponents of code-emphasis approaches claim that it is a bottom-up approach to reading, which emphasizes word recognition rather than understanding the author's message. Fleischner (1995) notes that "many students who succeed in learning to read through code-emphasis programs have not succeeded through other instructional approaches" (p. S82). 
Stahl (1992), however, suggests that exemplary phonics instruction "should be a part of a reading program, integrated and relevant to the reading and writing of actual texts, based on and building upon children's experiences with texts" (p. 625).

\section{The Research Bases of Whole Language and Phonics}

Research in whole language has been descriptive and naturalistic, documenting what happens and how children learn in whole language classrooms. This research provided rationales and models for new whole language programs. Few studies have compared the effectiveness of whole language programs with skills-based programs. This can be attributed to the difference in goals of the whole language research. Instead of achievement, attitudes toward reading are the focus of some studies (Stahl, McKenna, \& Pagnucco, 1994). Ribowsky (1986), compared two kindergartens, one with a whole language approach and one with a code-emphasis approach, in an all-girl, parochial school. Students in the whole language classroom performed significantly better on all tasks than the students in the skills-based classroom. Reutzel and Cooter (1990) found a moderate effect favoring whole language over a basal reader approach in first grade. In general, however, the consensus on whole language research indicates (a) mild, positive effects on comprehension, (b) significant effects when used in kindergarten, and (c) no differences on attitude measures (Stahl, McKenna, \& Pagnucco, 1994, p. 181).

The research literature supporting phonics definitively outweighs that of whole language (Adams, 1990; Chall, 1989; McKenna, Robinson, \& Miller, 1994). In 1967, Chall conducted an extensive review of research and recommended a change from meaning-based (sight words) to code-emphasis (phonics) programs. In 1983, after a further review of research, Chall again concluded that initial 
phonics instruction is effective. Some phonics advocates suggest that whole language and other meaning-based methods may be disastrous for students who do not intuitively grasp the alphabetic principle and that reading acquisition is not as natural as learning to speak; that written language is different than oral language, and must be learned (Chall, 1989; Liberman \& Liberman, 1990; Mather, 1992; Samuels, 1986). The overall evidence indicates that phonics instruction increases children's decoding ability, phonemic awareness, and generalization skills.

Research in the area of phonological awareness is also quite comprehensive. The relationship between beginning reading and phonological processing is directly related (Ball \& Blachman, 1991; Felton, 1993; Foorman, Novy, Francis, \& Liberman, 1991; Majsterek \& Ellenwood, 1995). Phonological processing involves blending and segmenting of sounds and words. Recent studies have demonstrated that instruction in phonological awareness combined with explicit phonics instruction is effective in developing beginning reading and spelling skills (Ball \& Blachman, 1991; McGuinness, McGuinness, \& Donohue, 1995). Ball and Blachman (1991) found that kindergarten children can be taught to segment words into phonemes, and to generalize the segmentation training to novel words (p. 62). In a study involving first-grade children, McGuinness, McGuinness, and Donohue (1995) discovered that early phonological processing skill and reading are interrelated and that "phoneme awareness must be connected in a coherent way to graphemes ... to grasp the logic of the alphabet principle and learn accurate and fluent decoding skills" (p. 851).

\section{Limitations of Approaches}

The use of only one approach to reading instruction is limited and restrictive. The meaning-based approach disregards the importance of the 
alphabetic principle that is especially needed by students with reading disabilities. For meaning and comprehension to occur, children must be able to decode.

Similarly, the code-emphasis approach, if taught explicitly, disregards the primary reason for reading, namely, meaning. If children rely exclusively on the graphophonics cueing system, the purpose of reading may be misunderstood. A dichotomy between meaning- and code-based reading instruction for beginning readers still lingers. This may be the result of strong political and philosophical beliefs of staunch proponents. Nevertheless, the dichotomy exists and continues to permeate the reading literature. As evidence of this apparent incompatibility, Stanovich (1990) published an article entitled, "A Call for an End to the Paradigm Wars in Reading Research" in which he argues for "logical compatibility" and "peaceful co-existence" (p. 221) among researchers of all perspectives.

Synthesis of Approaches

Recently, a more eclectic, integrated approach to reading instruction is becoming evident. In fact, Vellutino (1991), suggests instruction that combines the alphabetic principle and reading for meaning, stating, "Research findings tend to favor the major theoretical premises on which code-emphasis approaches to reading instruction are based and are at variance with the major theoretical premises on which whole language approaches are based. However, the findings do not preclude the compatibility of certain features of both approaches" ( $p .437$ ), and, further, "research supports a balanced approach" (p. 442). Stahl, McKenna, and Pagnucco (1994) assert, "It also could be that combining an explicit phonics program with a program that stresses the use of authentic learning tasks and literature might be the best of both worlds" (p. 181). Several recent studies (Cunningham, Hall, \& Defee, 1991; Eldredge, 1991; Eldredge \& Butterfield, 1986) found that programs that blended phonics instruction with literature-based 
instruction had significant effects on decoding and comprehension (Stahl, McKenna, \& Pagnucco, 1994). Pressley and Rankin (1994) observe, "excellent reading teachers are like the little league coaches, providing authentic literacy experiences to their charges as they build the skills permitting ever more effective participation in more demanding literacy experiences" (p. 166). Therefore, rather than professing a polarized political philosophy of either whole language or phonics, an integration of the two may prove to be beneficial to all children, especially those with reading disabilities. In this way, all the "child-centered," meaning-oriented aspects of whole language would be integrated with the accuracy, automaticity, and fluency that direct phonics instruction provides. The result could be children who read with understanding and fluency. The present study attempted to explore this synthesis of approaches by providing a systematic intervention that bridges the gap between whole language and phonics. Research Questions

It was hypothesized that children with reading disabilities who interact in a reading class that utilizes a holistic-graphophonic intervention will progress significantly on various measures of decoding performance. This hypothesis included progress on the training words, as well as the generalization words. However, greater gains were expected with novel words than with nonsense words and the greatest gains were expected with the training words. Specifically, three questions were addressed.

1. Will students exposed to a holistic-graphophonic intervention increase accuracy in reading a set of training words that contain three common vowel patterns presented in isolation and in context? 
2. Will students exposed to a holistic-graphophonic intervention increase in accuracy of reading novel (untrained) words that contain the same three vowel patterns taught in the set of training words?

3. Will students exposed to a holistic-graphophonic intervention increase in accuracy of reading nonsense words that contain the same three vowel patterns taught in the set of training words? 


\section{CHAPTER III}

\section{Method}

\section{Participants and Setting}

The participants for this study were five children (three boys and two girls), selected from the primary group of a private clinical school for children with learning and language disabilities, located in southwest Miami. These children are generally from an upper middle-class socio-economic background; attendance at the school is contingent upon annual tuition payment. At the time of the study, all the children experienced reading difficulties, and read below grade level. Some of the students were newly enrolled, while others were beginning their second year at the school. None of the participants received medication for attention or behavior problems. The intervention occurred in the students' regular reading classroom. The teacher was the researcher, and the reading class consisted of ten students, ages 7 and 8 . The characteristics of the students who participated in this study are found in Table 1.

Table 1

Participant Characteristics

\begin{tabular}{|c|c|c|c|c|c|c|c|}
\hline \multirow[t]{2}{*}{ Student } & \multirow{2}{*}{$\begin{array}{c}\text { Age } \\
\text { (Yr-Mo) }\end{array}$} & \multirow{2}{*}{ Gender } & \multirow{2}{*}{$\begin{array}{l}\text { Full Scale } \\
\qquad I Q\end{array}$} & \multirow{2}{*}{$\begin{array}{c}\text { Verbal } \\
10\end{array}$} & \multirow{2}{*}{$\begin{array}{c}\text { Perform } \\
10\end{array}$} & \multicolumn{2}{|c|}{ Gates Reading Test } \\
\hline & & & & & & Vocab & Comp \\
\hline Eddie & $7-8$ & $M$ & 104 & 121 & 84 & 1.2 & 1.4 \\
\hline Christie & $8-2$ & $F$ & 103 & 104 & 104 & 1.5 & 1.4 \\
\hline Laurie & $7-8$ & $F$ & 102 & 95 & 110 & 1.3 & 1.4 \\
\hline Mike & $7-10$ & $M$ & 109 & 102 & 115 & 1.0 & $K$ \\
\hline Ricky & $7-11$ & $M$ & 94 & 102 & 86 & 1.6 & 1.5 \\
\hline
\end{tabular}

a Gates-MacGinitie Reading Test scores are grade equivalents based on administration one month prior to baseline. 
The reading criteria used to determine eligibility to participate in the study were the ability to (a) produce consonant sounds when shown letter symbols, with at least $80 \%$ accuracy, (b) match consonant sounds to letter symbols, with at least $80 \%$ accuracy, and (c) score less than $50 \%$ accuracy reading words that contain two or more of the three vowel patterns (i.e., magic e, double vowels, and closed). To demonstrate the first two criteria, a teacher-made consonant symbolsound test was administered individually to each prospective participant. The student was asked to (a) say the appropriate consonant sound when presented with the letter symbol and (b) point to the letter symbol when given the consonant sound. To assess reading accuracy with the three vowel patterns, the monosyllabic real and nonsense words subtest of the Decoding Skills Test (Richardson \& DiBenedetto, 1985) was administered. Students were asked to read monosyllabic real and nonsense words (i.e., words containing short vowels, long vowels with silent $e$, and vowel digraphs) that conform to the three common vowel patterns.

All students produced the consonant sounds when shown letter symbols with at least $80 \%$ accuracy (Mean $=89 \%$, Range $=81 \%$ to $95 \%$ ). All students matched consonant sounds to letter symbols with $100 \%$ accuracy. None of the students read any of the magic e or double vowel pattern words ( $0 \%$ accuracy). For the closed vowel pattern, three students scored $<50 \%$ accuracy (viz., $10 \%$, $30 \%$, and $30 \%$ ) while two students scored $50 \%$ and $80 \%$. Since the reading criteria specified a score of $<50 \%$ accuracy in at least two of the three vowel patterns, all five participants met all the reading eligibility criteria. The reading criteria of the five students are presented in Table 2.

Four additional selection criteria included (a) legal second grade placement, (b) willingness of parent and child to participate in the study, (c) 
regular attendance, and (d) full scale $I Q>90$. Five students met all criteria and all five participated in the study.

Table 2

Reading Criteria

\begin{tabular}{lccccc}
\hline Student & $\begin{array}{c}\text { Produce } \\
\text { Consonant } \\
\text { Sounds }\end{array}$ & $\begin{array}{c}\text { Match } \\
\text { Sounds to } \\
\text { Letters }\end{array}$ & $\begin{array}{c}\text { Accuracy } \\
\text { Magic } \\
\text { Words }\end{array}$ & $\begin{array}{c}\text { Accuracy } \\
\text { Double } \\
\text { Vowels }\end{array}$ & $\begin{array}{c}\text { Accuracy } \\
\text { Closed } \\
\text { Words }\end{array}$ \\
\hline Eddie & $81 \%$ & $100 \%$ & $0 \%$ & $0 \%$ & $10 \%$ \\
Christie & $95 \%$ & $100 \%$ & $0 \%$ & $0 \%$ & $30 \%$ \\
Laurie & $90 \%$ & $100 \%$ & $0 \%$ & $0 \%$ & $50 \%$ \\
Mike & $86 \%$ & $100 \%$ & $0 \%$ & $0 \%$ & $30 \%$ \\
Ricky & $95 \%$ & $100 \%$ & $0 \%$ & $0 \%$ & $80 \%$ \\
\hline
\end{tabular}

\section{Dependent Measures}

Pre-and post-intervention measures. The Woodcock Reading Mastery Tests-Revised was selected as a pre-test / post-test measure for this study. This instrument is an individually administered battery of tests designed to diagnose reading strengths and weaknesses for students in grade $K$ to 12 (Woodcock, 1987). There are two equivalent forms of this test. Form $G$ was used as the pretest and Form $\mathrm{H}$ was used as the posttest. The four subtests include: word identification, word attack, word comprehension, and passage comprehension.

Only the word identification, word attack, and passage comprehension subtests were used for this study. The Woodcock Reading Mastery Tests-Revised has been shown to be a valid and reliable diagnostic reading test and has been utilized in many studies. 
Reading accuracy: Training words. Two procedures were used to measure accuracy in reading the training words. First, accuracy of reading words in isolation was measured. To do this, a master list of 150 training words containing 50 of each of the three vowel patterns was developed (see Appendix A). This was called the "training set." Each day, 5 words representing each vowel pattern was randomly selected from the master list (total 15 words). Each student was asked to read these words as they were individually presented on 3 " $\times 5$ " white index cards in mixed order.

Second, reading accuracy in context was evaluated. To do this, sentence strips containing the "training set" words were developed. These sentences were taken directly from the books used for the training set. The target word(s) were written on the back of each card. Each day, 5 sentence strips using training words from each vowel pattern were randomly selected from the sentence pool (a total of 15 sentences). Students were asked to read each sentence.

\section{Reading generalization: Novel words and nonsense words. Two} procedures were used to measure accuracy of novel words and nonsense words. First, reading accuracy of novel (different than "training set") words were measured. To do this, a master list of 150 novel words containing 50 of each of the three vowel patterns was developed (see Appendix A). Novel words did not rhyme with the "training set" words. Each day, 5 words from each of the three vowel patterns were randomly selected from the master list (a total of 15 generalization novel words). Each student was asked to read these words as they were individually presented on index cards in mixed order.

Second, reading accuracy of nonsense words was evaluated. A list of 150 nonsense words containing 50 of each of the three vowel patterns was developed (see Appendix A). Each day, 5 nonsense words from each of the vowel patterns 
were randomly selected from the master list (a total of 15 generalization nonsense words). Each student was asked to read these words as they were individually presented on index cards in mixed order. The purpose in using novel and nonsense words was to evaluate transfer and generalization of the three vowel patterns.

To determine the order of presentation, a coin was tossed. Words in isolation (training set) and novel words (generalization set) were presented first when "heads" occurred; conversely, words in context (training set) and nonsense words (generalization set) were presented first when "tails" appeared. However, training words were always presented before generalization words.

All the word cards and sentence strips used for daily measurement were computer generated. They were printed with black ink, and the size, shape, and format were consistent. The index cards selected for individual words (training words in isolation, novel words, and nonsense words) measured $3^{\prime \prime} \times 5^{\prime \prime}$ and were white in color. The training words in context were printed on sentence strips, approximately $3 " \times 11^{\prime \prime}$. In addition, all index cards and sentence strips were laminated to preserve the original quality throughout the study.

\section{Data Collection}

Data collectors. There were three data collectors during this study. The first was the teacher-researcher, who was a doctoral candidate with 20 years teaching experience in special education. The second was a Masters level student teacher, who had an undergraduate degree in Psychology. The third was a paraprofessional, who had three years experience working in this setting. Training sessions were conducted before the study began. Each data collector reviewed the master lists for each set of training words, sentences, novel words, and nonsense words. The procedure for recording students reading accuracy on 
the daily data sheet was explained and practiced. Data collectors showed a minimum of $80 \%$ agreement among all observers prior to beginning the study.

Data collection procedure. The word identification, word attack, and passage comprehension subtests of the Woodcock Reading Mastery TestsRevised (i.e., the pre- and post-measures) were individually administered to each participant. Forms $\mathrm{G}$ and $\mathrm{H}$ were used respectively as pre- and posttests, before baseline and during the last week of the study.

For the daily reading accuracy measures, a data sheet for each participant was used to record "correct" and "incorrect" responses for each word and sentence presented (see Appendix B). Data were collected for training words in isolation, training words in context, novel words, and nonsense words. Each student's responses to words using each vowel pattern were (a) tallied separately, (b) converted to percentage correct, and (c) presented daily on individual graphs. Data collection occurred each morning in homeroom, approximately 23 hours after the previous day's reading instruction. Intervention

Each day, during the 60 minute reading class, approximately 20 minutes of instructional time was allocated to each component of the intervention (i.e., holistic and graphophonic). The teacher remained the same throughout the study, and all instruction during the intervention was whole group (ten students). To prevent contamination, all direct reading instruction occurred during this time.

Holistic component. The holistic component involved a shared reading of various Big Books, using quality children's literature. The books selected were from the Story Box (Wright Group, 1980) and Sunshine Books (Wright Group, 1987 ) collections. The "starter set" was a pictured reading book, selected to teach a specific vowel pattern (see Appendixes C \& D). Appendix C provides a 
list of the literature books used in the intervention with the corresponding target vowel pattern. Appendix $D$ includes the specific words from each book, classified by vowel pattern as well as by individual vowel. This part of the intervention procedure consisted of five elements: (a) semantic mapping; (b) reading, rereading, and choral reading; (c) guided questioning; (d) illustrating parts of the story; and (e) a writing response to literature. This was a two-day procedure, activities a, b, and c occurring on day one, and activities b, d, and e occurring on day two (see Appendix E).

Graphophonic component. Each day, the graphophonic component followed the holistic component. This part focused on an analysis of the three common vowel patterns: magic e, "double vowel blockers" (adapted from Crazy Syllables, Hoiland Publications, 1985), and closed vowel patterns. The "starter set" for this component was the vowel pattern chart (developed by the researcher, see Appendix F). Although there are six common vowel patterns, only three were used in this study. To identify words to place on the vowel pattern chart, specific words were selected from each story, and some rhyming words were added. This group constituted the "training set" for each vowel pattern (see Appendix D). These selected words (closed, magic e, or double vowels) were written in black ink on standard white sentence strips (approximately $3 "$ by $8 "$ ). On the training words used in the intervention (not on the daily performance probes for data collection), vowels were color-coded in red, blends in green, and digraphs in blue. Individual children were asked to place word cards in the appropriate vowel pattern box (on large chart on board), while the others wrote the words on individual vowel pattern sheets at their desks. Children were asked to read the words and explain the rationale for each vowel pattern choice. 
The graphophonic intervention procedure included five elements: (a) tracing vowels in red, (b) signing the vowels, (c) analyzing words on the vowel pattern sheet, (d) constructing words with alphabet chips (round, plastic, colorcoded "poker chips"), and (e) guided spelling. This was also a two day intervention procedure. Day one included activities $a, b$, and $c$, and day two included activities $d$ and e (see Appendix E).

Although the intervention procedure included two specific elements (i.e., holistic and graphophonic), it followed a spiral, rather than sequential, model. In other words, the story was initially presented as a meaningful "whole," the words were analyzed into structured "parts," rereading provided a return to the "whole," constructing words practiced the "parts," and the written response confirmed the "whole." The integration and balance of whole and part was the basic premise of the intervention, and the spiral followed the principle of whole-part-whole.

Materials. The materials used in this study included published children's literature books (see Appendix C), and teacher-made items. The teacher-made items included word cards, work sheets, and alphabet chips.

Booster sessions. Additional instructional sessions were initiated for two of the five students (viz., Eddie and Christie) to increase the power of the group intervention. These "Booster Sessions" were begun on Day 15 of the study. They were conducted later in the day, after the group instruction. Christie received 9 booster sessions; Eddie received 15 sessions. The 5-10 minute booster was conducted as a mini-lesson and contained the same story and training words from that day's group lesson.

\section{Research Design and Data Analysis}

Single subject research design "refers to a research strategy developed to document changes in the behavior of the individual subject ... to demonstrate a 
functional relationship between intervention and a change in behavior" (Tawney \& Gast, 1984, p. 10). This design has been used for over 40 years in research involving certain areas of medicine, psychology, and special education. Although only a few examples exist currently in reading research, McCormick (1990) suggests that, "more reading researchers add this methodology to their repertoires" (p. 80). In 1995, McCormick states, "time is overdue for literacy investigators to consider single-subject experimental studies as viable options when attempting to answer certain types of instructional questions" (p. 30).

The research design used in this study was a multiple baseline design, with the intervention applied across vowel patterns. Single-subject experimental research was chosen to establish the effects of the intervention on individual students and to provide an opportunity to examine potential replication of effects within each student and across students. "The personalized evaluation inherent in single-subject studies presents good possibilities for furnishing insights to refine our perceptions about delayed readers" (McCormick, 1995, p. 28). Intrasubject replication was seen whenever the experimental effects were witnessed across each of the three vowel patterns within a student. Intersubject replication was observed when similar effects occurred across the five students. Data were collected daily to measure the five students' individual responses to (a) training words in isolation, (b) training words in context, (c) novel words, and (d) nonsense words. These training and generalization words contained the magic $e$, double vowel, or closed vowel pattern. The multiple baseline design across vowel patterns included repeated measures of preintervention (baseline) performance concurrently on the three dependent measures (vowel patterns). When the baseline performance for each participant was stable, the independent variable (holistic-graphophonic reading intervention) was introduced. This was applied to 
the first dependent variable (i.e., magic e vowel pattern), and each student's performance on all dependent variables continued to be measured. When the students responded positively to the intervention with the first dependent variable, the intervention was introduced to the second dependent variable (double vowel pattern), and ultimately, to the third dependent variable (closed vowel pattern). Post-intervention measures were analyzed to assess retention of each vowel pattern while subsequent patterns were introduced. Finally, follow-up probes were conducted to determine whether potential increases in decoding skills were maintained.

The multiple baseline design across vowel patterns provided an effective way to study each student's response to the independent variable (intervention), as it was introduced with each dependent measure (i.e., vowel pattern). The use of training words in isolation and in context offered an opportunity to examine any possible differences between each group (i.e., isolation and context). The utilization of novel and nonsense words provided a way to assess generalization and transfer of the dependent measures with unknown words. In addition, any differences between unknown real words (novel words) and unknown non-words (nonsense words) could be analyzed.

The pre- and posttest scores were analyzed by raw score, standard score, and age-equivalents for each child. Age-based norms were used to obtain standard scores. To control for maturation over time, a derived age-equivalent gain was calculated by subtracting four months (length of the study) from the actual age-equivalent gain. Given the low $N$ (five students), inferential statistics to assess these differences were not used.

The data for daily reading performance measures were analyzed by means of visual inspection. Graphs indicate each dependent variable for each student. 
The training words in isolation and in context are presented separately from the generalization measures (i.e., novel words and nonsense words). Graphs representing individual student performance on the training words (in isolation and in context) are shown in one set of figures (1 - 5). Graphs indicating individual student performance on the generalization words (novel and nonsense words) are shown in a separate set of figures $(6-10)$.

An increase in the percentage of words read correctly after the reading intervention is applied would be evidence of successful intervention for the training words (Research Question \# 1). An increase in the percentage of novel and nonsense words read correctly after the reading intervention is applied would be evidence of successful transfer and generalization of the vowel patterns taught in the set of training words (Research Questions \# 2 and \# 3). 


\section{CHAPTER IV}

\section{Results}

\section{Interobserver Agreement}

To establish agreement on the observers' accuracy of recording students' reading correctness, the following procedure was used. While one observer scored each word, a second observer was positioned between and to the side of the primary observer and the student, such that she could view each word card that was presented by the primary observer, but could not view the data collection sheet held by the primary observer. This procedure was conducted on $9 \%$ of all observations.

Interobserver agreement checks were calculated by each category. That is, agreement coefficients were established for magic e words in isolation, magic e words in context, double vowel words in isolation, double vowel words in context, closed words in isolation, closed words in context, novel magic e words, nonsense magic e words, novel double vowel words, nonsense double vowel words, novel closed words, and nonsense closed words. To determine the percentage of agreement, the following formula was used: agreements / agreements + disagreements $\times 100=\%$. The agreement coefficients for each category are presented in Table 3.

On $43 \%$ of the study days, at least one student participated in an interobserver agreement check. Eddie, Christie, and Mike had the lowest percent of observations with agreement checks (9\%). Laurie and Ricky had the highest percent of observations with checks (11\%).

\section{Effects on Training Words}

The effects on training words are presented graphically and independently for each student. The individual graphs that show the impact of the intervention 
Table 3

Observer Agreement

\begin{tabular}{|c|c|c|c|c|}
\hline Participant & Magic e & Double Vowel & Closed & Total \\
\hline & \multicolumn{4}{|c|}{ Training Words } \\
\hline Eddie & & & & \\
\hline Isolation & $100 \%$ & $100 \%$ & $100 \%$ & $100 \%$ \\
\hline Context & $100 \%$ & $91 \%$ & $94 \%$ & $95 \%$ \\
\hline \multicolumn{5}{|l|}{ Christie } \\
\hline Isolation & $100 \%$ & $100 \%$ & $100 \%$ & $100 \%$ \\
\hline Context & $100 \%$ & $87 \%$ & $100 \%$ & $96 \%$ \\
\hline \multicolumn{5}{|l|}{ Laurie } \\
\hline Isolation & $100 \%$ & $100 \%$ & $100 \%$ & $100 \%$ \\
\hline Context & $97 \%$ & $100 \%$ & $100 \%$ & $99 \%$ \\
\hline \multicolumn{5}{|l|}{ Mike } \\
\hline Isolation & $100 \%$ & $100 \%$ & $100 \%$ & $100 \%$ \\
\hline Context & $100 \%$ & $100 \%$ & $97 \%$ & $99 \%$ \\
\hline \multicolumn{5}{|l|}{ Ricky } \\
\hline Isolation & $100 \%$ & $100 \%$ & $100 \%$ & $100 \%$ \\
\hline Context & $100 \%$ & $100 \%$ & $100 \%$ & $100 \%$ \\
\hline \multicolumn{5}{|l|}{ Total } \\
\hline Isolation & $100 \%$ & $100 \%$ & $100 \%$ & $100 \%$ \\
\hline Context & $99 \%$ & $96 \%$ & $98 \%$ & $98 \%$ \\
\hline & \multicolumn{4}{|c|}{ Generalization Words } \\
\hline \multicolumn{5}{|l|}{ Eddie } \\
\hline Novel & $100 \%$ & $100 \%$ & $100 \%$ & $100 \%$ \\
\hline Nonsense & $100 \%$ & $100 \%$ & $100 \%$ & $100 \%$ \\
\hline \multicolumn{5}{|l|}{ Christie } \\
\hline Novel & $95 \%$ & $100 \%$ & $95 \%$ & $97 \%$ \\
\hline Nonsense & $90 \%$ & $100 \%$ & $100 \%$ & $97 \%$ \\
\hline \multicolumn{5}{|l|}{ Laurie } \\
\hline Novel & $100 \%$ & $100 \%$ & $95 \%$ & $98 \%$ \\
\hline Nonsense & $100 \%$ & $100 \%$ & $95 \%$ & $98 \%$ \\
\hline \multicolumn{5}{|l|}{ Mike } \\
\hline Novel & $100 \%$ & $95 \%$ & $95 \%$ & $97 \%$ \\
\hline Nonsense & $100 \%$ & $95 \%$ & $100 \%$ & $98 \%$ \\
\hline \multicolumn{5}{|l|}{ Ricky } \\
\hline Novel & $100 \%$ & $90 \%$ & $85 \%$ & $92 \%$ \\
\hline Nonsense & $100 \%$ & $100 \%$ & $100 \%$ & $100 \%$ \\
\hline \multicolumn{5}{|l|}{ Total } \\
\hline Novel & $99 \%$ & $97 \%$ & $94 \%$ & $97 \%$ \\
\hline Nonsense & $98 \%$ & $99 \%$ & $99 \%$ & $99 \%$ \\
\hline
\end{tabular}


on each student's training words are found in Figures 1 - 5. Each vowel pattern was analyzed separately for words presented in isolation and in context. Mean scores for each student were calculated for each vowel pattern, during each phase of the study (i.e., baseline, intervention, post-intervention, and follow-up). These individual results are provided in Tables 4, 5, and 6, for the magic e, double vowel, and closed vowel patterns, respectively. Group mean scores for each vowel pattern in the training words are presented in Table 7.

Magic e vowel pattern. The individual and group results are presented in Tables 4 and 7 respectively. Daily student performance on the magic e words is found on the top graphs of Figures 1 - 5. Overall, the five students showed a low, stable level during baseline (Days 1 - 6). Accuracy for words presented in isolation was consistently lower than for words in context. The means for individual students varied from $0 \%$ to $28 \%$, with an overall mean of $13 \%$ for words in isolation. For words in context, from $27 \%$ to $60 \%$, with an overall mean of $38 \%$.

During baseline, Eddie's mean score for words in isolation was $7 \%$ with a range of $0 \%$ (low score) to $20 \%$ (high score). For words in context, his mean score was $35 \%$ with a range of $0 \%$ to $100 \%$. Christie's mean score for words in isolation was $12 \%$ (range of $0 \%$ to $20 \%$ ). For words in context, her mean score was $60 \%$ ( $38 \%$ to $100 \%$ ). Laurie's mean score for words in isolation was $28 \%$ (range of $20 \%$ to $40 \%$ ). For words in context, her mean score was $31 \%$ (0\% to $60 \%$ ). Mike's mean score (and range) for words in isolation was $0 \%$. For words in context, his mean score was $27 \%$ (0\% to $60 \%$ ). Ricky's mean score for words in isolation was $20 \%$, with all scores at $20 \%$. For words in context, Ricky's mean score was $36 \%$ ( $17 \%$ to $57 \%$ ).

The intervention for the Magic e vowel pattern was implemented on Day 7 and continued until Day 22. Between Days 7 and 22, the results were notable. 


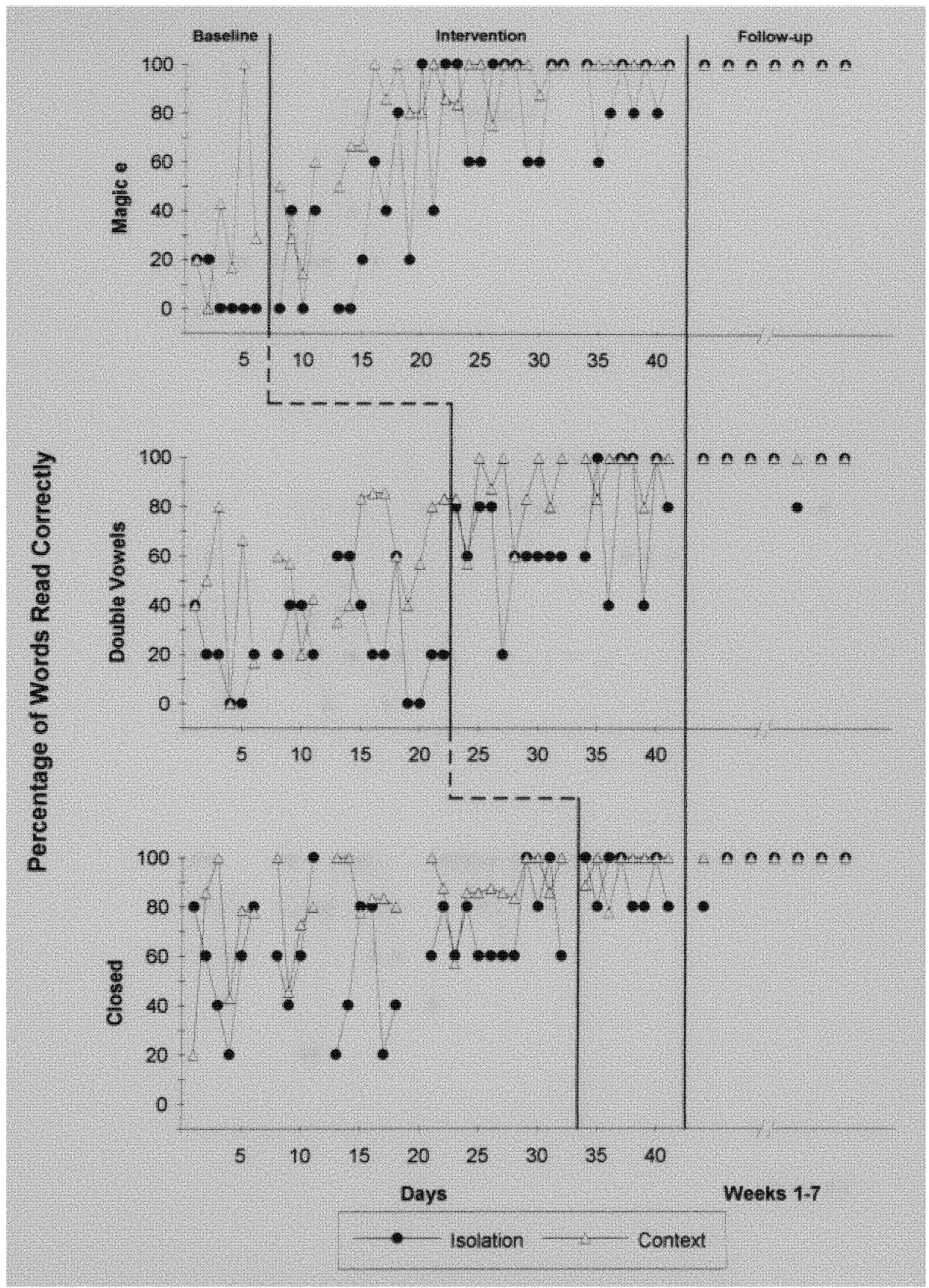

Figure 1. Eddie's Results on Training Words 


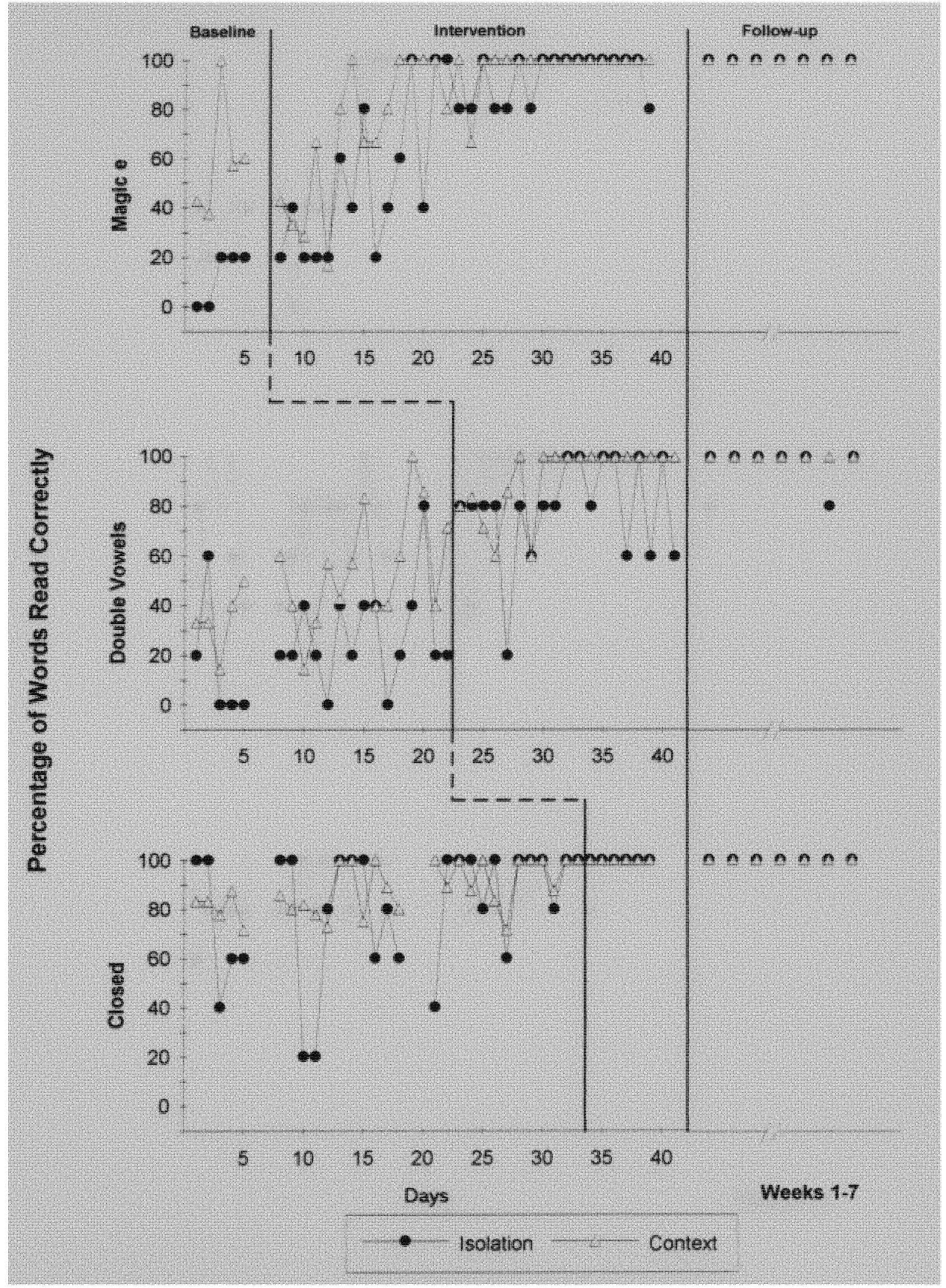

Figure 2. Christie's Results on Training Words 


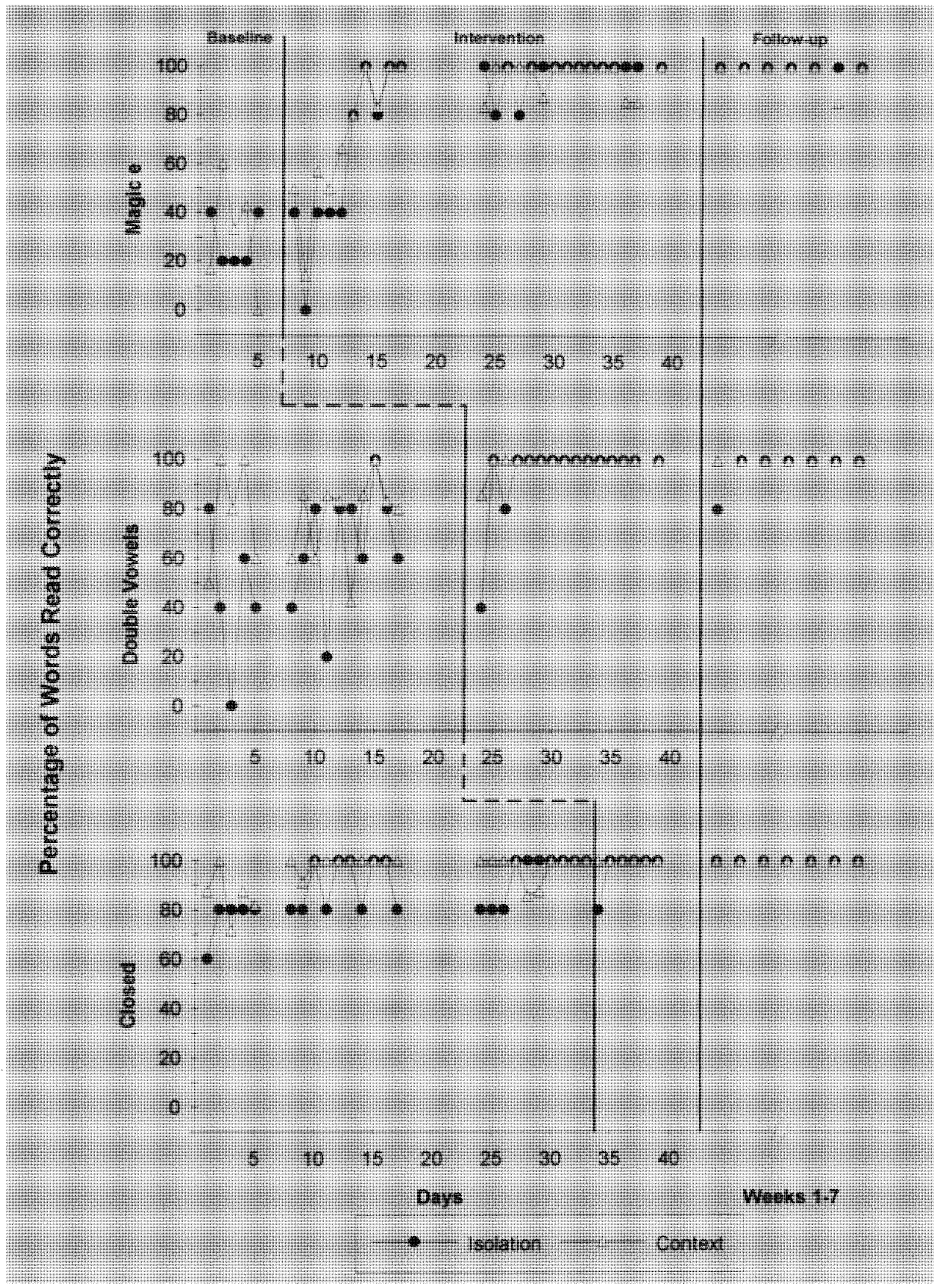

Figure 3. Laurie's Results on Training Words 


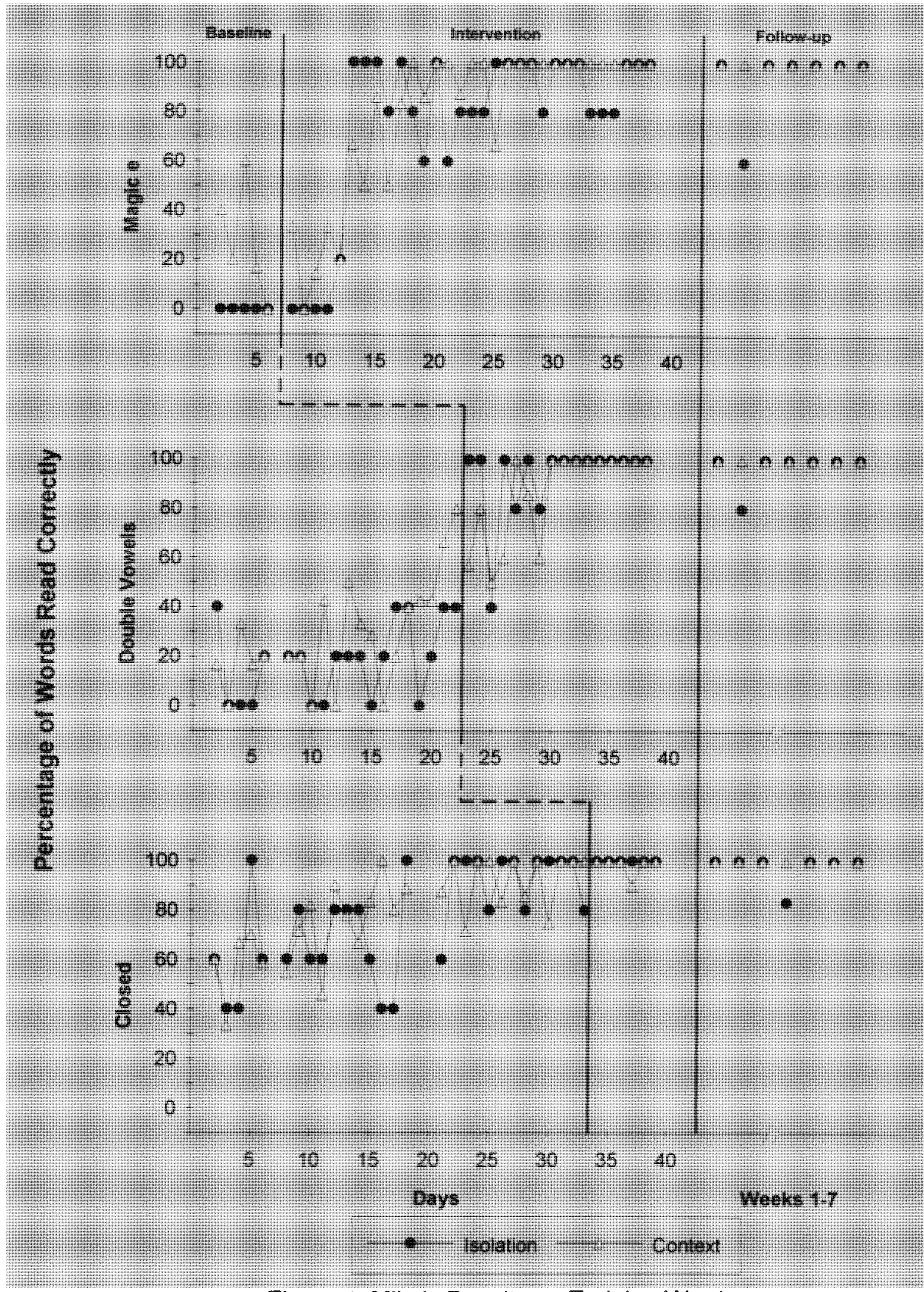

Figure 4. Mike's Results on Training Words 
Figure 5. Ricky's Results on Training Words 
Table 4

Reading Accuracy: Magic e Vowel Pattern Training Words

\begin{tabular}{lcccc}
\hline Participant & Baseline & Intervention & Post Interva & Follow-up \\
(Days 1-6) & (Days 8-22) & (Days 23-41) & (7/7 weeks)
\end{tabular}

Words in Isolation

$\begin{array}{ccccc}\begin{array}{c}\text { Eddie } \\ \text { Mean }\end{array} & 7 \% & 39 \% & 86 \% & 100 \% \\ \text { Range } & 0 \%-20 \% & 0 \%-100 \% & 60 \%-100 \% & 100 \% \\ \begin{array}{c}\text { Christie } \\ \text { Mean }\end{array} & 12 \% & 51 \% & 93 \% & 100 \% \\ \text { Range } & 0 \%-20 \% & 20 \%-100 \% & 80 \%-100 \% & 100 \% \\ \text { Laurie } & & & & \\ \text { Mean } & 28 \% & 62 \% & 97 \% & 100 \% \\ \text { Range } & 20 \%-40 \% & 0 \%-100 \% & 80 \%-100 \% & 100 \%\end{array}$

Mike

$\begin{array}{lcccc}\text { Mean } & 0 \% & 59 \% & 93 \% & 94 \% \\ \text { Range } & 0 \% & 0 \%-100 \% & 80 \%-100 \% & 60 \%-100 \%\end{array}$

Ricky

$\begin{array}{lcccc}\text { Mean } & 20 \% & 67 \% & 96 \% & 97 \% \\ \text { Range } & 20 \% & 20 \%-100 \% & 80 \%-100 \% & 80 \%-100 \%\end{array}$

Words in Context

Eddie

$\begin{array}{lcccc}\text { Mean } & 35 \% & 69 \% & 97 \% & 100 \% \\ \text { Range } & 0 \%-100 \% & 14 \%-100 \% & 75 \%-100 \% & 100 \% \\ \text { Chistie } & & & & \\ \text { Mean } & 60 \% & 71 \% & 98 \% & 100 \% \\ \text { Range } & 38 \%-100 \% & 17 \%-100 \% & 67 \%-100 \% & 100 \% \\ \text { urie } & & & & \\ \text { Mean } & 31 \% & 70 \% & 96 \% & 98 \% \\ \text { Range } & 0 \%-60 \% & 14 \%-100 \% & 83 \%-100 \% & 86 \%-100 \%\end{array}$

Mike

$\begin{array}{lcccc}\text { Mean } & 27 \% & 61 \% & 98 \% & 100 \% \\ \text { Range } & 0 \%-60 \% & 0 \%-100 \% & 67 \%-100 \% & 100 \%\end{array}$

Ricky

Mean

Range

$36 \%$
$17 \%-57 \%$

$81 \%$

$95 \%$

$100 \%$

$29 \%-100 \% \quad 67 \%-100 \% \quad 100 \%$

apost Intervention refers to cessation of intervention on one vowel pattern and introduction of intervention on the subsequent vowel pattern. 
Table 5

Reading Accuracy: Double Vowel Pattern Training Words

\begin{tabular}{lcccc}
\hline Participant & $\begin{array}{c}\text { Baseline } \\
\text { (Days 1-22) }\end{array}$ & $\begin{array}{c}\text { Intervention } \\
\text { (Days 23-33) }\end{array}$ & $\begin{array}{c}\text { Post Interva } \\
\text { (Days 34-41) }\end{array}$ & $\begin{array}{c}\text { Follow-up } \\
\text { (7/7 weeks) }\end{array}$
\end{tabular}

Words in Isolation

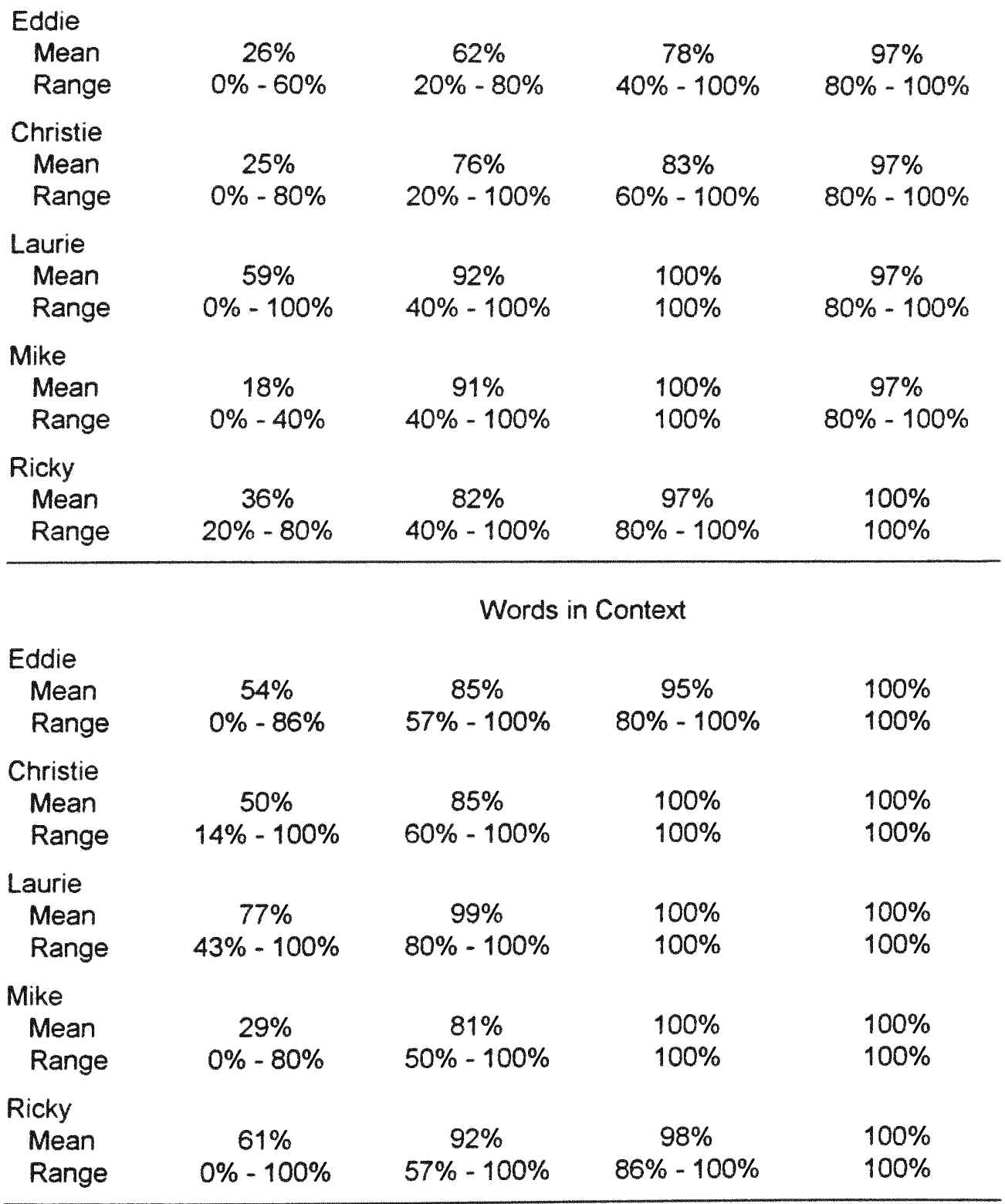

apost Intervention refers to cessation of intervention on one vowel pattern and introduction of intervention on the subsequent vowel pattern. 
Table 6

Reading Accuracy: Closed Vowel Pattern Training Words

\begin{tabular}{|c|c|c|c|c|}
\hline Participant & $\begin{array}{c}\text { Baseline } \\
\text { (Days 1-33) }\end{array}$ & $\begin{array}{l}\text { Intervention } \\
\text { (Days 34-38) }\end{array}$ & $\begin{array}{l}\text { Post Interva } \\
\text { (Days } 39-41 \text { ) }\end{array}$ & $\begin{array}{l}\text { Follow-up } \\
\text { (7/7 weeks) }\end{array}$ \\
\hline
\end{tabular}

Words in Isolation

\begin{tabular}{|c|c|c|c|c|}
\hline \multicolumn{5}{|l|}{ Eddie } \\
\hline Mean & $62 \%$ & $92 \%$ & $87 \%$ & $97 \%$ \\
\hline Range & $20 \%-100 \%$ & $80 \%-100 \%$ & $80 \%-100 \%$ & $80 \%-100 \%$ \\
\hline \multicolumn{5}{|l|}{ Christie } \\
\hline Mean & $81 \%$ & $100 \%$ & $100 \%$ & $100 \%$ \\
\hline Range & $20 \%-100 \%$ & $100 \%$ & $100 \%$ & $100 \%$ \\
\hline \multicolumn{5}{|l|}{ Laurie } \\
\hline Mean & $89 \%$ & $96 \%$ & $100 \%$ & $100 \%$ \\
\hline Range & $60 \%-100 \%$ & $80 \%-100 \%$ & $100 \%$ & $100 \%$ \\
\hline \multicolumn{5}{|l|}{ Mike } \\
\hline Mean & $77 \%$ & $100 \%$ & $100 \%$ & $98 \%$ \\
\hline Range & $40 \%-100 \%$ & $100 \%$ & $100 \%$ & $83 \%-100 \%$ \\
\hline \multicolumn{5}{|l|}{ Ricky } \\
\hline Mean & $94 \%$ & $100 \%$ & $100 \%$ & $100 \%$ \\
\hline Range & $60 \%-100 \%$ & $100 \%$ & $100 \%$ & $100 \%$ \\
\hline & \multicolumn{4}{|c|}{ Words in Context } \\
\hline \multicolumn{5}{|l|}{ Eddie } \\
\hline Mean & $82 \%$ & $93 \%$ & $100 \%$ & $100 \%$ \\
\hline Range & $20 \%-100 \%$ & $78 \%-100 \%$ & $100 \%$ & $100 \%$ \\
\hline \multicolumn{5}{|l|}{ Christie } \\
\hline Mean & $88 \%$ & $100 \%$ & $100 \%$ & $100 \%$ \\
\hline Range & $71 \%-100 \%$ & $100 \%$ & $100 \%$ & $100 \%$ \\
\hline \multicolumn{5}{|l|}{ Laurie } \\
\hline Mean & $96 \%$ & $100 \%$ & $100 \%$ & $100 \%$ \\
\hline Range & $71 \%-100 \%$ & $100 \%$ & $100 \%$ & $100 \%$ \\
\hline \multicolumn{5}{|l|}{ Mike } \\
\hline Mean & $80 \%$ & $98 \%$ & $100 \%$ & $100 \%$ \\
\hline Range & $33 \%-100 \%$ & $90 \%-100 \%$ & $100 \%$ & $100 \%$ \\
\hline \multicolumn{5}{|l|}{ Ricky } \\
\hline Mean & $92 \%$ & $93 \%$ & $78 \%$ & $100 \%$ \\
\hline Range & $64 \%-100 \%$ & $78 \%-100 \%$ & $78 \%$ & $100 \%$ \\
\hline
\end{tabular}

apost Intervention refers to cessation of intervention. 
Table 7

Training Word Accuracy: Group Means

\begin{tabular}{|c|c|c|c|c|}
\hline Vowel Pattern & Baseline & Intervention & Post Interv & Follow-up \\
\hline & \multicolumn{4}{|c|}{ Words in Isolation } \\
\hline Magic e & $13 \%$ & $56 \%$ & $93 \%$ & $98 \%$ \\
\hline Double Vowels & $33 \%$ & $81 \%$ & $92 \%$ & $98 \%$ \\
\hline \multirow[t]{2}{*}{ Closed } & $81 \%$ & $98 \%$ & $97 \%$ & $99 \%$ \\
\hline & \multicolumn{4}{|c|}{ Words in Context } \\
\hline Magic e & $38 \%$ & $70 \%$ & $97 \%$ & $100 \%$ \\
\hline Double Vowels & $54 \%$ & $88 \%$ & $99 \%$ & $100 \%$ \\
\hline Closed & $88 \%$ & $97 \%$ & $96 \%$ & $100 \%$ \\
\hline
\end{tabular}


The overall mean score for words in isolation was $56 \%$ (compared to $13 \%$ during baseline) and $70 \%$ for words in context (compared to $38 \%$ during baseline). After four days of intervention (Day 14), three students achieved and maintained scores of $80 \%$ or $100 \%$ with words in isolation. "Booster sessions" were initiated on Day 15 for the two students who experienced more difficulty with these words (see Method page).

During magic e intervention, Eddie's mean score for words in isolation was $39 \%$ with a range of $0 \%$ to $100 \%$. For words in context, his mean score was $69 \%$ (range of $14 \%$ to $100 \%$ ). Christie's mean score for words in isolation was $51 \%$ ( $20 \%$ to $100 \%)$. For words in context, her mean score was $71 \%(17 \%$ to $100 \%)$. Laurie's mean score for words in isolation was $62 \%(0 \%$ to $100 \%)$. For words in context, her mean score was $70 \%$ ( $14 \%$ to $100 \%$ ). Mike's mean score for words in isolation was $59 \%(0 \%$ to $100 \%)$, and for words in context, $61 \%(0 \%$ to $100 \%)$. Ricky's mean score for words in isolation was $67 \%(20 \%$ to $100 \%)$, and for words in context, $81 \%(29 \%$ to $100 \%)$.

When the intervention with the magic e vowel pattern was discontinued, the intervention for the subsequent pattern (i.e., double vowel) was implemented. This allowed the instruction to focus on a single vowel pattern, decreasing potential confusion with the previous vowel pattern. Data continued to be collected to assess possible maintenance effects. This phase was referred to as post-intervention. In general, all five students continued to recognize the magic e pattern. The overall results from Day 23 through 41 were notable. The mean score for words in isolation was $93 \%$ (compared to $13 \%$ during baseline) and $97 \%$ for words in context (compared to $38 \%$ during baseline).

During the post-intervention observations, Eddie's mean score for words in isolation was $86 \%$ (60\% to $100 \%$ ). For words in context, his mean score was $97 \%$ 
( $75 \%$ to $100 \%$ ). Christie's mean score for words in isolation was $93 \%$ ( $80 \%$ to $100 \%$ ). For words in context, her mean score was $98 \%$ (67\% to $100 \%)$. Laurie's mean score for words in isolation was $97 \%$ ( $80 \%$ to $100 \%)$. For words in context, her mean score was $96 \%$ ( $83 \%$ to $100 \%$ ). Mike's mean score for words in isolation was $93 \%(80 \%$ to $100 \%$ ). For words in context, his mean score was $98 \%$ (67\% to $100 \%)$. Ricky's mean score for words in isolation was $96 \%(80 \%$ to $100 \%)$, and for words in context, $95 \%(67 \%$ to $100 \%)$.

Finally, follow-up probes were collected and analyzed after intervention for all three vowel patterns was discontinued. This included seven observations spread across a total of seven weeks. The first three probes were collected the two weeks immediately following the end of intervention and the remaining probes after a two week winter vacation. The overall results during the follow-up period were substantial. The mean score for words in isolation was $98 \%$, and $100 \%$ for words in context. Probe 4 was especially remarkable since it was the first after the two week winter vacation. All five participants scored $100 \%$ for both words in isolation and in context .

During the follow-up phase, Eddie's mean score was $100 \%$ for words in isolation, as well as in context. Christie's mean score was $100 \%$ for words in isolation and in context. Laurie's mean score was $100 \%$ for words in isolation, and $98 \%$ ( $86 \%$ to $100 \%)$ for words in context. Mike's mean score was $94 \%$ ( $60 \%$ to $100 \%$ ) for words in isolation, and $100 \%$ for words in context. Ricky's mean score was $97 \%$ ( $80 \%$ to $100 \%$ ) for words in isolation, and $100 \%$ for words in context.

Double vowel pattern. The individual and group results are provided in Tables 5 and 7 respectively. Daily student performance on the double vowel words is found on the middle graph of Figures $1-5$. Overall, the five students 
showed a higher level of response with more variability, during baseline. The individual means varied from $18 \%$ to $59 \%$, with an overall mean of $33 \%$ for words in isolation, and from $29 \%$ to $77 \%$, with an overall mean of $54 \%$ for words in context. The baseline period included Days 1 through 22 .

During baseline, Eddie's mean score for words in isolation was $26 \%$ with a range of $0 \%$ to $60 \%$. For words in context, his mean score was $54 \%$ with a range of $0 \%$ to $86 \%$. Christie's mean score for words in isolation was $25 \%$ (range of $0 \%$ to $80 \%$ ). For words in context, her mean score was $50 \%$ (14\% to $100 \%)$. Laurie's mean score for words in isolation was $59 \%$ (range of $0 \%$ to $100 \%$ ). For words in context, her mean score was $77 \%$ (43\% to $100 \%)$. Mike's mean score for words in isolation was $18 \%(0 \%$ to $40 \%)$. For words in context, his mean score was $29 \%$ ( $0 \%$ to $80 \%$ ). Ricky's mean score for words in isolation was $36 \%(20 \%$ to $80 \%)$. For words in context, his mean score was $61 \%$ with a range of $0 \%$ to $100 \%$.

The intervention for the double vowel pattern was implemented on Day 22. This intervention continued until Day 33. Between Days 23 and 33, the results were positive. The overall mean score for words in isolation was $81 \%$ (compared to $33 \%$ during baseline) and $88 \%$ for words in context (compared to $54 \%$ during baseline). The change was fairly rapid, taking only three to four days before gains were noticeable. By Day 25, four out of the five students achieved and maintained $80 \%$ or greater in either words in isolation or context, or both.

During double vowel intervention, Eddie's mean score for words in isolation was $62 \%$ with a range of $20 \%$ to $80 \%$. For words in context, his mean score was $85 \%$ (range of $57 \%$ to $100 \%$ ). Christie's mean score for words in isolation was $76 \%$ (20\% to $100 \%)$. For words in context, her mean score was $85 \%(60 \%$ to $100 \%)$. Laurie's mean score for words in isolation was $92 \%$ ( $40 \%$ to $100 \%$ ). For words in context, her mean score was $99 \%$ ( $80 \%$ to $100 \%)$. Mike's 
mean score for words in isolation was $91 \%(40 \%$ to $100 \%)$. For words in context, his mean score was $81 \%$ (50\% to $100 \%$ ). Ricky's mean score for words in isolation was $82 \%$ (40\% to $100 \%$ ). For words in context, his mean score was $92 \%$ (57\% to $100 \%$ ).

When the intervention with the double vowel pattern was discontinued, the intervention for the subsequent pattern (i.e., closed) was implemented. This allowed the instruction to focus on a single vowel pattern, decreasing potential confusion with the previous vowel patterns. Data continued to be collected to assess possible maintenance effects. This was referred to as the postintervention phase. In general, all five students continued to recognize the double vowel pattern. The overall results from Days 34 through 41 were notable. The mean score for words in isolation was $92 \%$ (compared to $33 \%$ during baseline) and $99 \%$ for words in context (compared to $54 \%$ during baseline).

During the post-intervention observations, Eddie's mean score for words in isolation was $78 \%$ (40\% to $100 \%$ ). For words in context, his mean score was $95 \%$ ( $80 \%$ to $100 \%)$. Christie's mean score for words in isolation was $83 \%$ (60\% to $100 \%$ ). For words in context, her mean score (and range) was $100 \%$. Laurie's mean score for words in isolation, as well as in context, was $100 \%$. Mike's mean score for words in isolation and in context was 100\%. Ricky's mean score for words in isolation was $97 \%$ ( $80 \%$ to $100 \%$ ). For words in context, his mean score was $98 \%(86 \%$ to $100 \%)$.

Finally, follow-up probes were collected and analyzed after intervention for all three vowel patterns was discontinued. This included seven observations spread across a total of seven weeks. The first three probes were collected the two weeks immediately following the end of intervention and the remaining four probes after a two week winter vacation. The overall results during the follow-up 
period were notable. The mean score for words in isolation was $98 \%$, and $100 \%$ for words in context. Probe 4 was especially remarkable since it was the first after the two week winter vacation. All 5 participants scored $100 \%$ for both words in isolation and in context.

During the follow-up phase, Eddie's mean score was $97 \%$ ( $80 \%$ to $100 \%)$ for words in isolation, and $100 \%$ for words in context. Christie's mean score was $97 \%(80 \%$ to $100 \%)$ for words in isolation, and $100 \%$ for words in context.

Laurie's mean score was $97 \%(80 \%$ to $100 \%)$ for words in isolation, and $100 \%$ for words in context. Mike's mean score was $97 \%(80 \%$ to $100 \%)$ for words in isolation, and $100 \%$ for words in context. Ricky's mean score was $100 \%$ for words in isolation, as well as in context.

Closed vowel pattern. The individual and group results are presented in Tables 6 and 7 respectively. Daily student performance on the closed words is found on the bottom graph of Figures 1 - 5. Overall, the five students showed a fairly high but inconsistent level during baseline (Days 1 - 33). Again, accuracy for words presented in isolation was consistently lower than for words in context. The means for individual students varied, from $62 \%$ to $94 \%$, with an overall mean score of $81 \%$ for words in isolation. For words in context, from $80 \%$ to $96 \%$, with an overall mean of $88 \%$. The intervention was applied to this third vowel pattern even though students' accuracy had improved somewhat. Although the overall percentage of words read correctly was higher than during baseline, the scores did not demonstrate mastery and stability. Due to the inconsistent level of response and the significantly lower generalization baseline results, the closed vowel intervention was implemented on Day 33.

During baseline, Eddie's mean score for words in isolation was $62 \%$ with a range of $20 \%$ to $100 \%$. For words in context, his mean score was $82 \%$ (range of 
$20 \%$ to $100 \%)$. Christie's mean score for words in isolation was $81 \%(20 \%$ to $100 \%)$. For words in context, her mean score was $88 \%(71 \%$ to $100 \%)$. Laurie's mean score for words in isolation was $89 \%$ (60\% to $100 \%)$. For words in context, her mean score was $96 \%$ ( $71 \%$ to $100 \%)$. Mike's mean score for words in isolation was $77 \%$ (40\% to $100 \%$ ). For words in context, his mean score was $80 \%$ ( $33 \%$ to $100 \%$ ). Ricky's mean score for words in isolation was $94 \%$ (60\% to $100 \%)$. For words in context, his mean score was $92 \%$ (64\% to $100 \%)$.

The intervention for the closed vowel pattern was implemented on Day 33 and continued until Day 38, when all intervention ceased. Between Days 34 and 38 , the results were positive. The overall mean score for words in isolation was $98 \%$ (compared to $81 \%$ during baseline) and $97 \%$ for words in context (compared to $88 \%$ during baseline). The change was rapid. Gains were noticeable almost immediately.

During the closed vowel pattern intervention, Eddie's mean score for words in isolation was $92 \%$ with a range of $80 \%$ to $100 \%$. For words in context, his mean score was $93 \%$ (range of $78 \%$ to $100 \%$ ). Christie's mean score for words in isolation, as well as in context, was $100 \%$. Laurie's mean score for words in isolation was $96 \%(80 \%$ to $100 \%)$. For words in context, her mean score was $100 \%$. Mike's mean score for words in isolation was $100 \%$. For words in context, his mean score was $98 \%$ (90\% to $100 \%)$. Ricky's mean score for words in isolation was $100 \%$. For words in context, his mean score was $93 \%$ ( $78 \%$ to $100 \%)$.

Once the intervention with the closed vowel pattern was discontinued, data collection continued to assess for possible maintenance effects. This phase was referred to as post-intervention. The overall results from Day 39 through 41 were positive. The mean score for words in isolation was $97 \%$ (compared to $81 \%$ 
during baseline) and $96 \%$ for words in context (compared to $88 \%$ during baseline).

During the post-intervention observations, Eddie's mean score for words in isolation was $87 \%$ ( $80 \%$ to $100 \%$ ). For words in context, his mean score was $100 \%$. Christie's mean score for words in isolation, as well as in context, was $100 \%$. Laurie's mean score for words in isolation, and in context, was $100 \%$. Mike's mean score for words in isolation, as well as in context, was $100 \%$. Ricky's mean score for words in isolation was $100 \%$ and for words in context, his mean score was $78 \%$ (only one score was obtained, due to absences). Although this post-intervention period was brief, all but two scores were consistently $100 \%$.

Finally, follow-up probes were collected and analyzed after intervention for all vowel patterns was discontinued. This included seven observations spread across seven weeks. The first three probes were collected the two weeks immediately following the end of intervention and the remaining four probes after a two week winter vacation. The overall results during the follow-up period were positive. The mean score for words in isolation was $99 \%$, and $100 \%$ for words in context. Probe 4 was especially remarkable since it was the first after the two week winter vacation. All 5 participants scored $100 \%$ for words in context. Four out of the five students scored $100 \%$ for words in isolation. The one exception was Mike, who scored $83 \%$ for closed words in isolation.

During the follow-up phase, Eddie's mean score was $97 \%$ ( $80 \%$ to $100 \%$ ) for words in isolation, and $100 \%$ for words in context. Christie's mean score was $100 \%$ for words in isolation, as well as in context. Laurie's mean score was $100 \%$ for words in isolation and in context. Mike's mean score was $98 \%(83 \%$ to $100 \%)$ for words in isolation, and $100 \%$ for words in context. Ricky's mean score was $100 \%$ for words in isolation and in context. 


\section{Effects on Generalization Words}

The effects on generalization words are presented graphically and independently for each student. The individual graphs that show the impact of the intervention on each student's generalization words (i.e., novel and nonsense words) are found in Figures 6 - 10. Mean scores for each student were calculated for each vowel pattern, during each phase of the study (i.e., baseline, intervention, post-intervention, and follow-up). The individual results are provided in Tables 8, 9, and 10, for the magic e, double vowel, and closed vowel patterns respectively. Group mean scores for each vowel pattern are presented in Table 11.

Magic e vowel pattern. The individual and group results are presented in Tables 8 and 11 respectively. Daily student performance on the magic e words is found on the top graphs of Figures $6-10$. Overall, the five students showed a low, stable level during baseline (Days 1 - 6). In general, accuracy for novel words was somewhat higher than for nonsense words. The individual means varied from $0 \%$ to $7 \%$, with an overall mean score of $4 \%$ for novel words. For nonsense words, the means varied from $0 \%$ to $8 \%$, with an overall mean of $2 \%$.

During baseline, Eddie's mean score for novel words was $3 \%$ with a range of $0 \%$ (low score) to $20 \%$ (high score). For nonsense words, his mean score was $0 \%$. Christie's mean score for novel words was $4 \%$ (range of $0 \%$ to $20 \%$ ). For nonsense words, her mean score was $8 \%$ (0\% to 20\%). Laurie's mean score for novel words was $4 \%$ ( $0 \%$ to $20 \%$ ). For nonsense words, her mean score was $0 \%$. Mike's mean score for novel words was $0 \%$. For nonsense words, his mean score was $4 \%$ ( $0 \%$ to $20 \%$ ). Ricky's mean score for novel words was $7 \%$ ( $0 \%$ to $20 \%$ ). For nonsense words, his mean score was $0 \%$. 


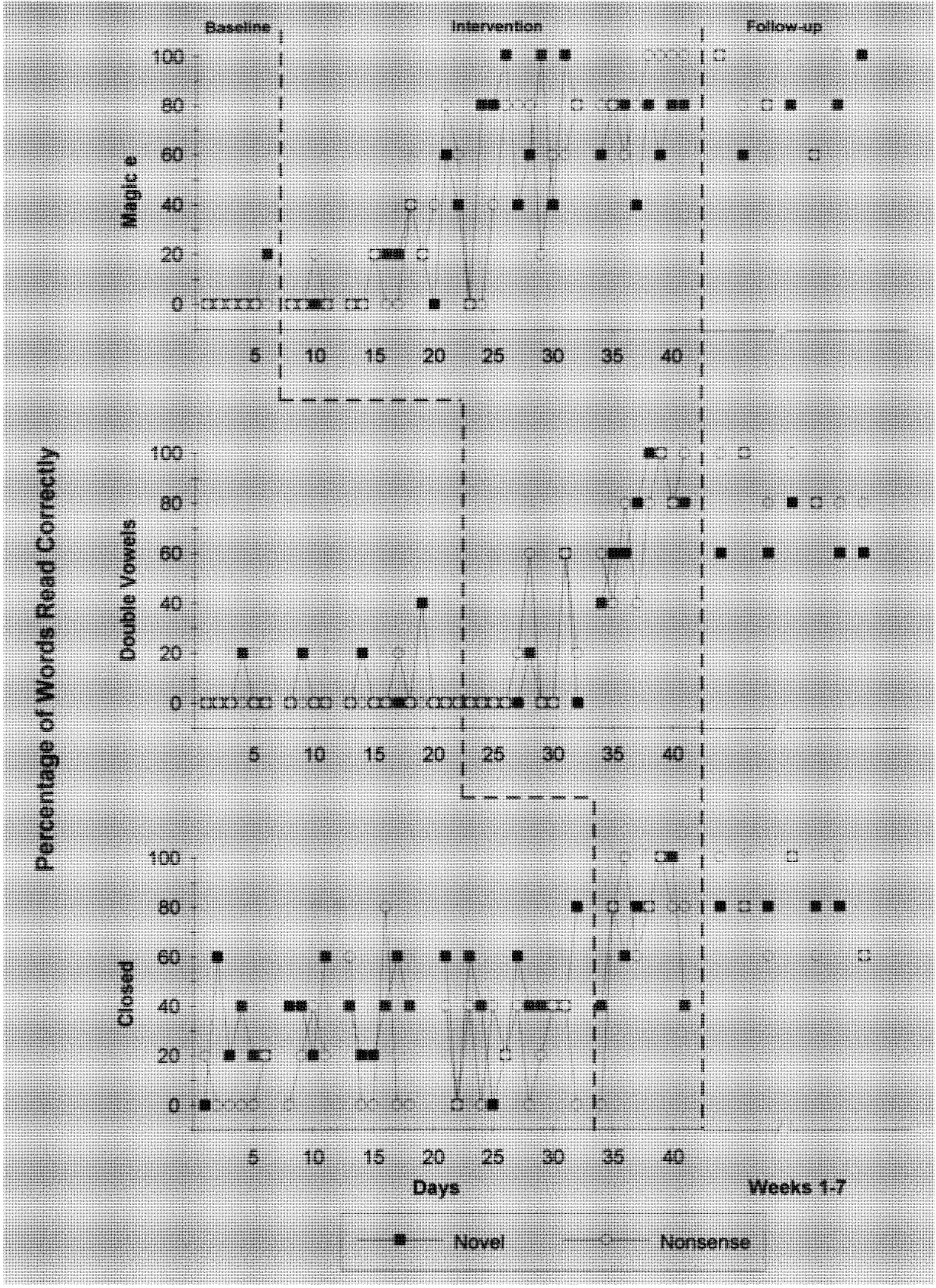

Figure 6. Eddie's Results on Generalization Words 


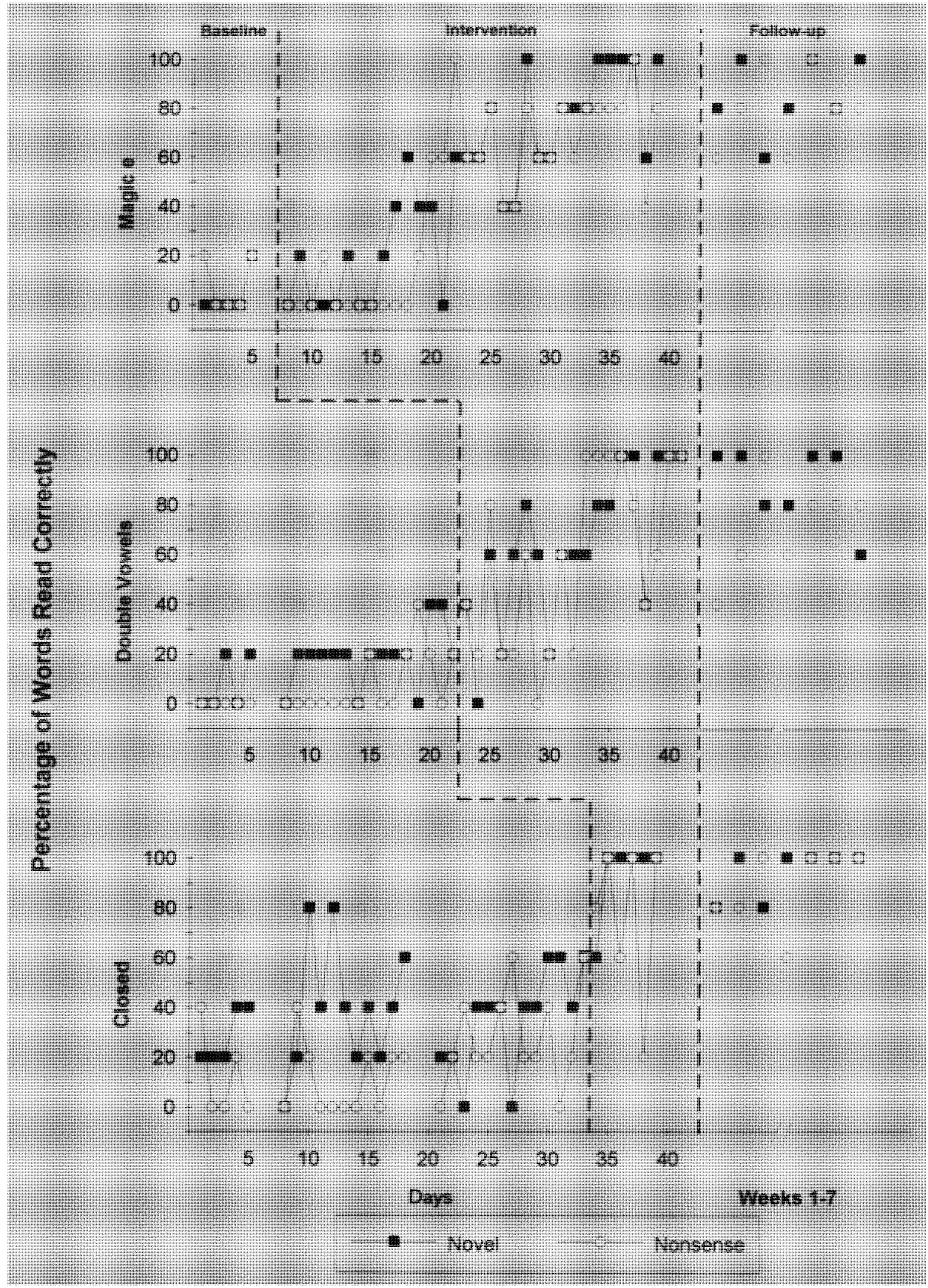

Figure 7. Christie's Results on Generalization Words 


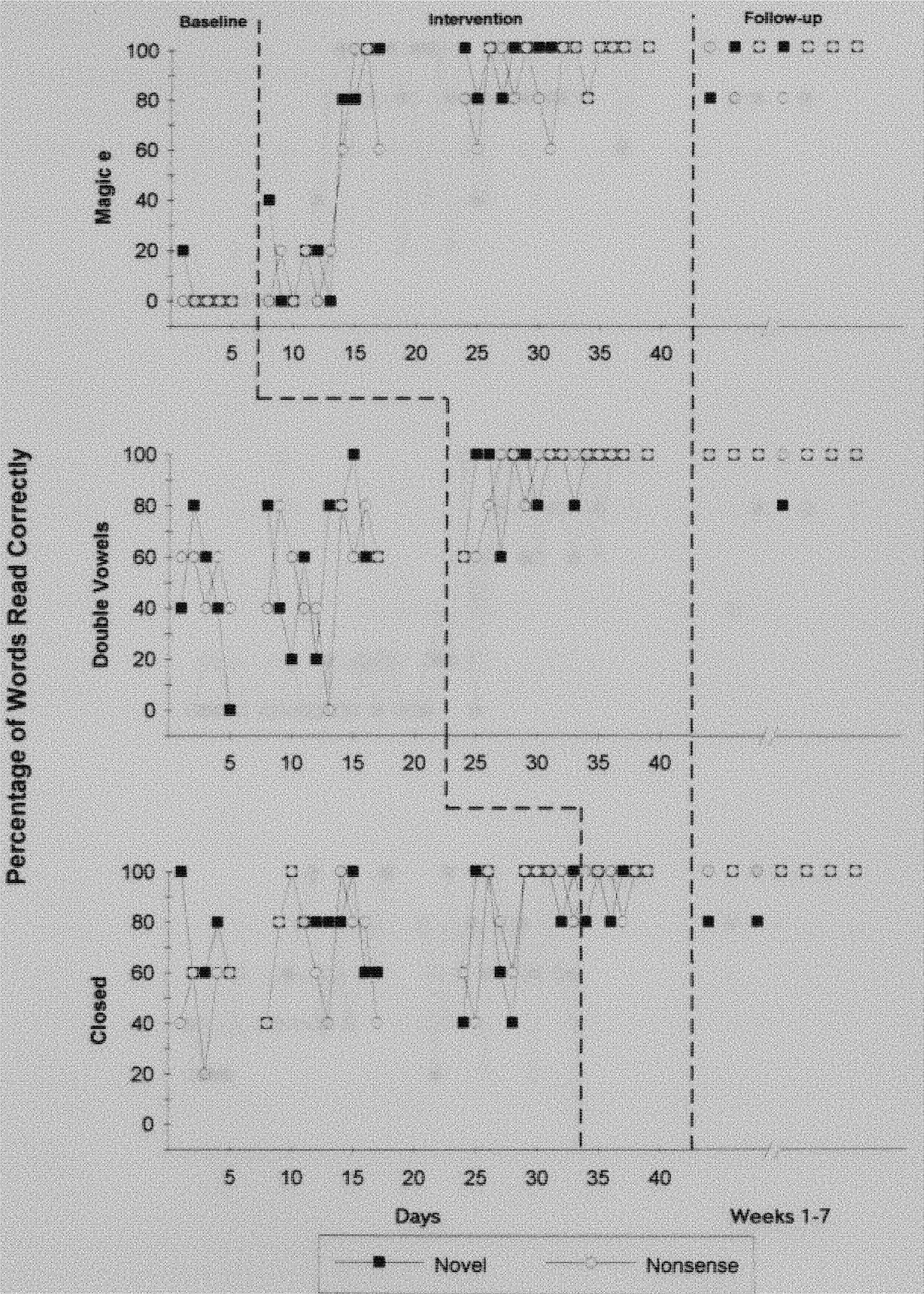

Figure 8. Laurie's Results on Generalization Words 


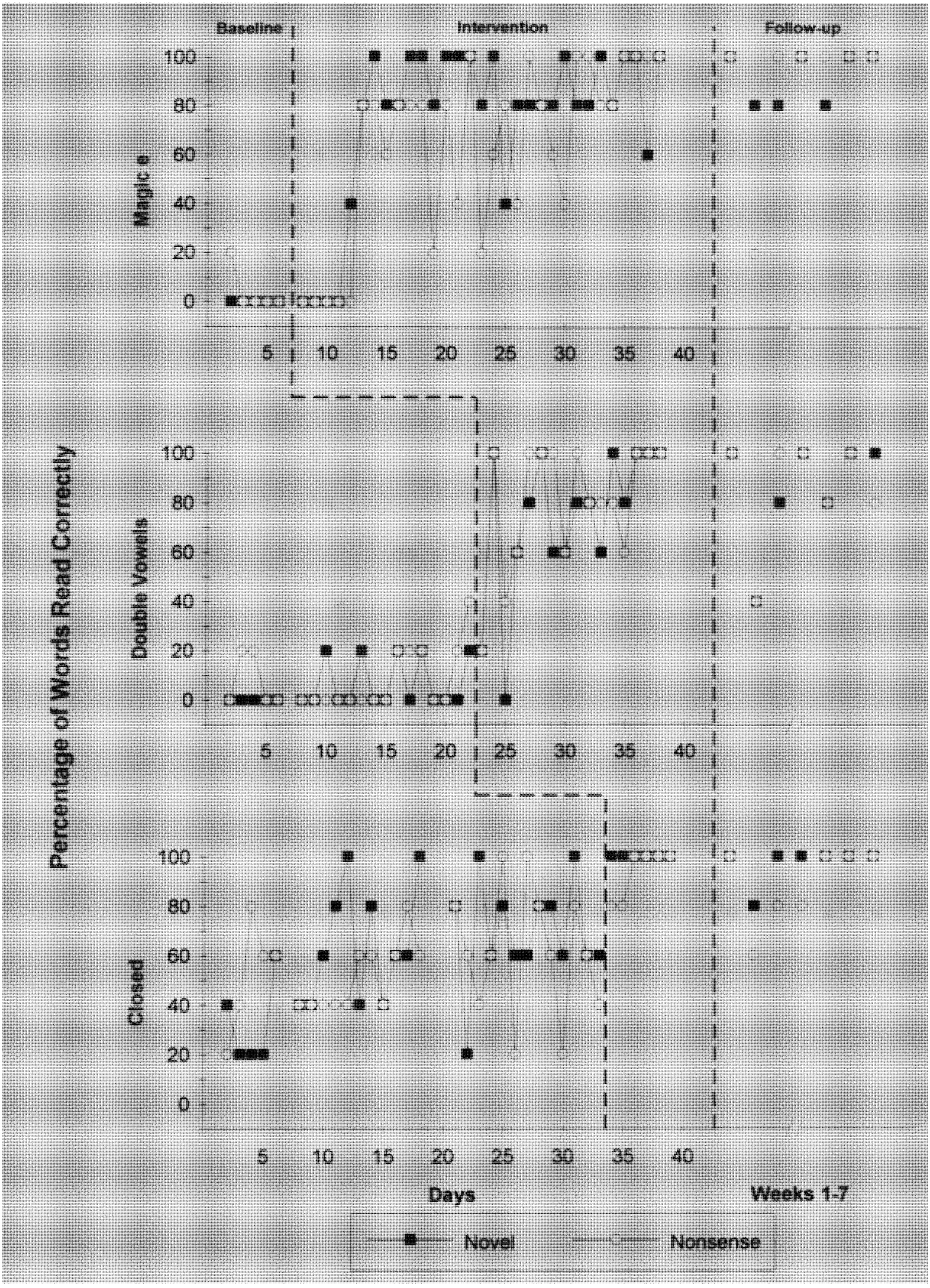

Figure 9. Mike's Results on Generalization Words 


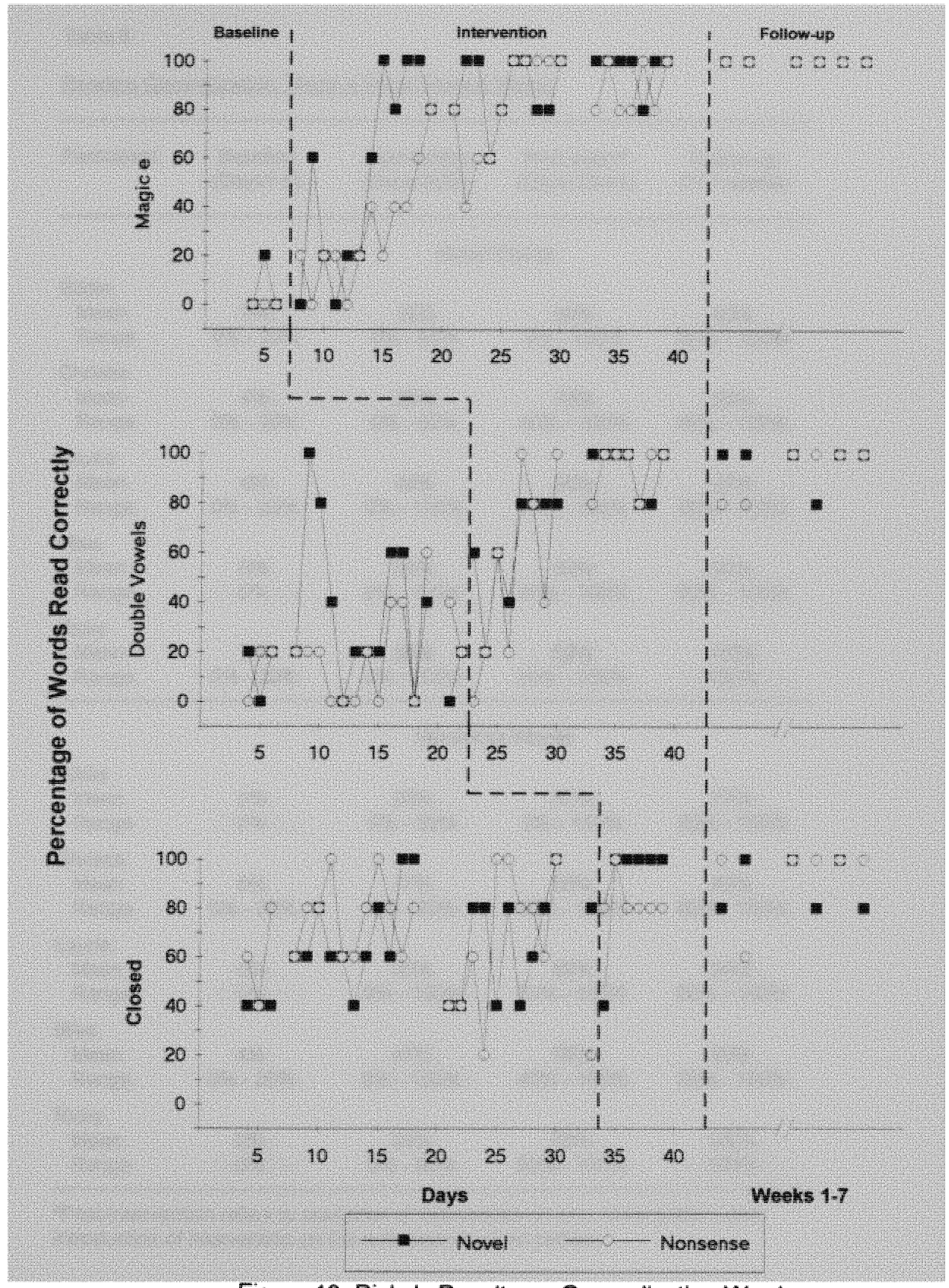

Figure 10. Ricky's Results on Generalization Words 
Table 8

Reading Generalization: Magic e Vowel Pattern Words

\begin{tabular}{|c|c|c|c|c|}
\hline Participant & $\begin{array}{l}\text { Baseline } \\
\text { (Days1-6) }\end{array}$ & $\begin{array}{l}\text { Intervention } \\
\text { (Days 8-22) }\end{array}$ & $\begin{array}{l}\text { Post Interva } \\
\text { (Days 23-41) }\end{array}$ & $\begin{array}{l}\text { Follow-up } \\
\text { (7/7 weeks) }\end{array}$ \\
\hline & \multicolumn{4}{|c|}{ Novel Words } \\
\hline $\begin{array}{l}\text { Eddie } \\
\text { Mean } \\
\text { Range }\end{array}$ & $\begin{array}{c}3 \% \\
0 \%-20 \%\end{array}$ & $\begin{array}{c}16 \% \\
0 \%-60 \%\end{array}$ & $\begin{array}{c}69 \% \\
0 \%-100 \%\end{array}$ & $\begin{array}{c}80 \% \\
60 \%-100 \%\end{array}$ \\
\hline $\begin{array}{c}\text { Christie } \\
\text { Mean } \\
\text { Range }\end{array}$ & $\begin{array}{c}4 \% \\
0 \%-20 \%\end{array}$ & $\begin{array}{c}20 \% \\
0 \%-60 \%\end{array}$ & $\begin{array}{c}76 \% \\
40 \%-100 \%\end{array}$ & $\begin{array}{c}86 \% \\
60 \%-100 \%\end{array}$ \\
\hline $\begin{array}{l}\text { Laure } \\
\text { Mean } \\
\text { Range }\end{array}$ & $\begin{array}{c}4 \% \\
0 \%-20 \%\end{array}$ & $\begin{array}{c}44 \% \\
0 \%-100 \%\end{array}$ & $\begin{array}{c}96 \% \\
80 \%-100 \%\end{array}$ & $\begin{array}{c}97 \% \\
80 \%-100 \%\end{array}$ \\
\hline $\begin{array}{l}\text { Mike } \\
\text { Mean } \\
\text { Range }\end{array}$ & $\begin{array}{l}0 \% \\
0 \%\end{array}$ & $\begin{array}{c}64 \% \\
0 \%-100 \%\end{array}$ & $\begin{array}{c}84 \% \\
40 \%-100 \%\end{array}$ & $\begin{array}{c}91 \% \\
80 \%-100 \%\end{array}$ \\
\hline $\begin{array}{l}\text { Ricky } \\
\text { Mean } \\
\text { Range }\end{array}$ & $\begin{array}{c}7 \% \\
0 \%-20 \%\end{array}$ & $\begin{array}{c}59 \% \\
0 \%-100 \%\end{array}$ & $\begin{array}{c}92 \% \\
60 \%-100 \%\end{array}$ & $\begin{array}{l}100 \% \\
100 \%\end{array}$ \\
\hline & & Nonser & Words & \\
\hline $\begin{array}{l}\text { Eddie } \\
\text { Mean } \\
\text { Range }\end{array}$ & $\begin{array}{l}0 \% \\
0 \%\end{array}$ & $\begin{array}{c}20 \% \\
0 \%-80 \%\end{array}$ & $\begin{array}{c}67 \% \\
0 \%-100 \%\end{array}$ & $\begin{array}{c}77 \% \\
20 \%-100 \%\end{array}$ \\
\hline $\begin{array}{c}\text { Christie } \\
\text { Mean } \\
\text { Range }\end{array}$ & $\begin{array}{c}8 \% \\
0 \%-20 \%\end{array}$ & $\begin{array}{c}17 \% \\
0 \%-60 \%\end{array}$ & $\begin{array}{c}68 \% \\
40 \%-100 \%\end{array}$ & $\begin{array}{c}80 \% \\
60 \%-100 \%\end{array}$ \\
\hline $\begin{array}{l}\text { Laurie } \\
\text { Mean } \\
\text { Range }\end{array}$ & $\begin{array}{l}0 \% \\
0 \%\end{array}$ & $\begin{array}{c}38 \% \\
0 \%-100 \%\end{array}$ & $\begin{array}{c}89 \% \\
60 \%-100 \%\end{array}$ & $\begin{array}{c}94 \% \\
80 \%-100 \%\end{array}$ \\
\hline $\begin{array}{l}\text { Mike } \\
\text { Mean } \\
\text { Range }\end{array}$ & $\begin{array}{c}4 \% \\
0 \%-20 \%\end{array}$ & $\begin{array}{c}47 \% \\
0 \%-100 \%\end{array}$ & $\begin{array}{c}78 \% \\
40 \%-100 \%\end{array}$ & $\begin{array}{c}89 \% \\
20 \%-100 \%\end{array}$ \\
\hline $\begin{array}{l}\text { Ricky } \\
\text { Mean } \\
\text { Range }\end{array}$ & $\begin{array}{l}0 \% \\
0 \%\end{array}$ & $\begin{array}{c}34 \% \\
0 \%-80 \%\end{array}$ & $\begin{array}{c}88 \% \\
60 \%-100 \%\end{array}$ & $\begin{array}{l}100 \% \\
100 \%\end{array}$ \\
\hline
\end{tabular}

apost Intervention refers to cessation of intervention on one vowel pattern and introduction of intervention on the subsequent vowel pattern. 
Table 9

Reading Generalization: Double Vowel Pattern Words

\begin{tabular}{ccccc}
\hline Participant & Baseline & Intervention & Post Interva & Follow-up \\
(Days 1-22) & (Days 23-33) & (Days 34-41) & (7/7 weeks)
\end{tabular}

Novel Words

\begin{tabular}{|c|c|c|c|c|}
\hline \multicolumn{5}{|l|}{ Eddie } \\
\hline Mean & $5 \%$ & $8 \%$ & $75 \%$ & $71 \%$ \\
\hline Range & $0 \%-40 \%$ & $0 \%-60 \%$ & $40 \%-100 \%$ & $60 \%-100 \%$ \\
\hline \multicolumn{5}{|l|}{ Christie } \\
\hline Mean & $16 \%$ & $47 \%$ & $88 \%$ & $89 \%$ \\
\hline Range & $0 \%-40 \%$ & $0 \%-80 \%$ & $40 \%-100 \%$ & $60 \%-100 \%$ \\
\hline \multicolumn{5}{|l|}{ Laurie } \\
\hline Mean & $55 \%$ & $88 \%$ & $100 \%$ & $97 \%$ \\
\hline Range & $0 \%-100 \%$ & $60 \%-100 \%$ & $100 \%$ & $80 \%-100 \%$ \\
\hline \multicolumn{5}{|l|}{ Mike } \\
\hline Mean & $5 \%$ & $64 \%$ & $96 \%$ & $86 \%$ \\
\hline Range & $0 \%-20 \%$ & $0 \%-100 \%$ & $80 \%-100 \%$ & $40 \%-100 \%$ \\
\hline \multicolumn{5}{|l|}{ Ricky } \\
\hline Mean & $31 \%$ & $67 \%$ & $93 \%$ & $97 \%$ \\
\hline Range & $0 \%-100 \%$ & $20 \%-100 \%$ & $80 \%-100 \%$ & $80 \%-100 \%$ \\
\hline
\end{tabular}

Nonsense Words

Eddie

Mean

Range

$1 \%$

$16 \%$

$73 \%$

$89 \%$

Christie

Mean

$6 \%$

$0 \%-60 \%$

$40 \%-100 \%$

$60 \%-100 \%$

Range

$0 \%-40 \%$

$40 \%$

$85 \%$

Laurie

Mean

$53 \%$

$0 \%-100 \%$

$40 \%-100 \%$

$40 \%-100 \%$

Range

$0 \%-80 \%$

$88 \%$

$100 \%$

$100 \%$

$100 \%$

$60 \%-100 \%$

$100 \%$

Mike

Mean

$8 \%$

$76 \%$

$88 \%$

$86 \%$

Range

$0 \%-40 \%$

$20 \%-100 \%$

$60 \%-100 \%$

$40 \%-100 \%$

Ricky

Mean

$19 \%$

$56 \%$

$97 \%$

$93 \%$

Range

$0 \%-60 \%$

$0 \%-100 \%$

$80 \%-100 \%$

$80 \%-100 \%$

a Post Intervention refers to cessation of intervention on one vowel pattern and introduction of intervention on the subsequent vowel pattern. 
Table 10

Reading Generalization: Closed Vowel Pattern Words

\begin{tabular}{|c|c|c|c|c|}
\hline Participant & $\begin{array}{c}\text { Baseline } \\
\text { (Days 1-33) }\end{array}$ & $\begin{array}{l}\text { Intervention } \\
\text { (Days 34-38) }\end{array}$ & $\begin{array}{l}\text { Post Interv } \\
\text { (Days } 39-41 \text { ) }\end{array}$ & $\begin{array}{l}\text { Follow-up } \\
(7 / 7 \text { weeks })\end{array}$ \\
\hline & \multicolumn{4}{|c|}{ Novel Words } \\
\hline $\begin{array}{l}\text { Eddie } \\
\text { Mean } \\
\text { Range }\end{array}$ & $\begin{array}{c}36 \% \\
0 \%-80 \%\end{array}$ & $\begin{array}{c}68 \% \\
40 \%-80 \%\end{array}$ & $\begin{array}{c}80 \% \\
40 \%-100 \%\end{array}$ & $\begin{array}{c}80 \% \\
60 \%-100 \%\end{array}$ \\
\hline $\begin{array}{c}\text { Christie } \\
\text { Mean } \\
\text { Range }\end{array}$ & $\begin{array}{c}36 \% \\
0 \%-80 \%\end{array}$ & $\begin{array}{c}92 \% \\
60 \%-100 \%\end{array}$ & $\begin{array}{l}100 \% \\
100 \%\end{array}$ & $\begin{array}{c}94 \% \\
80 \%-100 \%\end{array}$ \\
\hline $\begin{array}{l}\text { Laurie } \\
\text { Mean } \\
\text { Range }\end{array}$ & $\begin{array}{c}78 \% \\
40 \%-100 \%\end{array}$ & $\begin{array}{c}92 \% \\
80 \%-100 \%\end{array}$ & $\begin{array}{l}100 \% \\
100 \%\end{array}$ & $\begin{array}{c}93 \% \\
80 \%-100 \%\end{array}$ \\
\hline $\begin{array}{l}\text { Mike } \\
\text { Mean } \\
\text { Range }\end{array}$ & $\begin{array}{c}61 \% \\
20 \%-100 \%\end{array}$ & $\begin{array}{l}100 \% \\
100 \%\end{array}$ & $\begin{array}{l}100 \% \\
100 \%\end{array}$ & $\begin{array}{c}97 \% \\
80 \%-100 \%\end{array}$ \\
\hline $\begin{array}{l}\text { Ricky } \\
\text { Mean } \\
\text { Range }\end{array}$ & $\begin{array}{c}64 \% \\
40 \%-100 \%\end{array}$ & $\begin{array}{c}88 \% \\
40 \%-100 \%\end{array}$ & $\begin{array}{l}100 \% \\
100 \%\end{array}$ & $\begin{array}{c}90 \% \\
80 \%-100 \%\end{array}$ \\
\hline
\end{tabular}

Nonsense Words

\begin{tabular}{|c|c|c|c|c|}
\hline \multicolumn{5}{|l|}{ Eddie } \\
\hline Mean & $19 \%$ & $64 \%$ & $87 \%$ & $80 \%$ \\
\hline Range & $0 \%-80 \%$ & $0 \%-100 \%$ & $80 \%-100 \%$ & $60 \%-100 \%$ \\
\hline \multicolumn{5}{|l|}{ Christie } \\
\hline Mean & $19 \%$ & $72 \%$ & $100 \%$ & $80 \%$ \\
\hline Range & $0 \%-60 \%$ & $20 \%-100 \%$ & $100 \%$ & $60 \%-100 \%$ \\
\hline \multicolumn{5}{|l|}{ Laurie } \\
\hline Mean & $70 \%$ & $96 \%$ & $100 \%$ & $100 \%$ \\
\hline Range & $20 \%-100 \%$ & $80 \%-100 \%$ & $100 \%$ & $100 \%$ \\
\hline \multicolumn{5}{|l|}{ Mike } \\
\hline Mean & $56 \%$ & $92 \%$ & $100 \%$ & $89 \%$ \\
\hline Range & $20 \%-100 \%$ & $80 \%-100 \%$ & $100 \%$ & $60 \%-100 \%$ \\
\hline \multicolumn{5}{|l|}{ Ricky } \\
\hline Mean & $69 \%$ & $84 \%$ & $80 \%$ & $93 \%$ \\
\hline Range & $20 \%-100 \%$ & $80 \%-100 \%$ & $80 \%$ & $60 \%-100 \%$ \\
\hline
\end{tabular}

apost Intervention refers to cessation of intervention. 
Table 11

Generalization Word Accuracy: Group Means

\begin{tabular}{|c|c|c|c|c|}
\hline Vowel Pattern & Baseline & intervention & Post Interv & Follow-up \\
\hline & \multicolumn{4}{|c|}{ Novel Words } \\
\hline Magic e & $4 \%$ & $41 \%$ & $83 \%$ & $91 \%$ \\
\hline Double Vowels & $22 \%$ & $55 \%$ & $90 \%$ & $88 \%$ \\
\hline \multirow[t]{2}{*}{ Closed } & $55 \%$ & $88 \%$ & $96 \%$ & $91 \%$ \\
\hline & \multicolumn{4}{|c|}{ Nonsense Words } \\
\hline Magic e & $2 \%$ & $31 \%$ & $78 \%$ & $88 \%$ \\
\hline Double Vowels & $17 \%$ & $55 \%$ & $89 \%$ & $88 \%$ \\
\hline Closed & $47 \%$ & $82 \%$ & $93 \%$ & $90 \%$ \\
\hline
\end{tabular}


The intervention for the Magic e vowel pattern was implemented on Day 7 and continued until Day 22. Between Days 7 and 22, the results were notable. The overall mean score for novel words was $41 \%$ (compared to $4 \%$ during baseline) and $31 \%$ for nonsense words (compared to $2 \%$ during baseline).

During magic e intervention, Eddie's mean score for novel words was $16 \%$ (range of $0 \%$ to $60 \%$ ). For nonsense words, his mean score was $20 \%$ (0\% to $80 \%$ ). Christie's mean score for novel words was $20 \%$ (0\% to $60 \%$ ). For nonsense words, her mean score was $17 \%$ (0\% to 60\%). Laurie's mean score for novel words was $44 \%(0 \%$ to $100 \%)$. For nonsense words, her mean score was $38 \%(0 \%$ to $100 \%)$. Mike's mean score for novel words was $64 \%(0 \%$ to $100 \%)$. For nonsense words, his mean score was $47 \%$ (0\% to 100\%). Ricky's mean score for novel words was $59 \%$ (0\% to 100\%). For nonsense words, his mean score was $34 \%(0 \%$ to $80 \%)$.

When the intervention with the magic e vowel pattern was discontinued, the intervention for the subsequent pattern (i.e., double vowel) was implemented. This allowed the instruction to focus on a single vowel pattern, decreasing potential confusion with the previous vowel pattern. Data continued to be collected to assess possible maintenance effects. This phase was referred to as post-intervention. In general, all five students continued to recognize the magic e pattern. The overall results from Day 23 through 41 were notable. The mean score for novel words was $83 \%$ (compared to $4 \%$ during baseline) and $78 \%$ for nonsense words (compared to $2 \%$ during baseline).

During the post-intervention observations, Eddie's mean score for novel words was $69 \%$ (range of $0 \%$ to $100 \%$ ). For nonsense words, his mean score was $67 \%$ (0\% to $100 \%$ ). Christie's mean score for novel words was $76 \%$ (40\% to $100 \%$ ). For nonsense words, her mean score was $68 \%$ ( $40 \%$ to $100 \%)$. Laurie's 
mean score for novel words was $96 \%$ ( $80 \%$ to $100 \%$ ). For nonsense words, her mean score was $89 \%$ (60\% to $100 \%)$. Mike's mean score for novel words was $84 \%(40 \%$ to $100 \%)$. For nonsense words, his mean score was $78 \%$ ( $40 \%$ to $100 \%$ ). Ricky's mean score for novel words was $92 \%$ (60\% to $100 \%)$. For nonsense words, his mean score was $88 \%(60 \%$ to $100 \%)$.

Finally, follow-up probes were collected and analyzed after intervention for all three vowel patterns was discontinued. This included seven probes spread across seven weeks. The first three probes were collected the two weeks immediately following the end of intervention and the remaining four probes after a two week winter vacation. The overall results during the follow-up period were notable. The mean score for novel words was $91 \%$, and $88 \%$ for nonsense words.

During the follow-up phase, Eddie's mean score for novel words was $80 \%$ (range of $60 \%$ to $100 \%$ ). For nonsense words, his mean score was $77 \%$ (20\% to $100 \%$ ). Christie's mean score for novel words was $86 \%$ (60\% and $100 \%$ ). For nonsense words, her mean score was $80 \%$ (60\% to $100 \%)$. Laurie's mean score for novel words was $97 \%$ ( $80 \%$ to $100 \%$ ). For nonsense words, her mean score was $94 \%$ ( $80 \%$ to $100 \%$ ). Mike's mean score for novel words was $91 \%$ ( $80 \%$ to $100 \%$ ). For nonsense words, his mean score was $89 \%$ (20\% to $100 \%)$. Ricky's mean score for novel and nonsense words was $100 \%$.

Double vowel pattern. The individual and group results are presented in Tables 9 and 11 respectively. Daily student performance on the double vowel words is found on the middle graphs of Figures $6-10$. Overall, the five students showed a low, variable level during baseline (Days 1 - 22). Nonsense words were generally lower than novel words. The individual means varied from $5 \%$ to $55 \%$, 
with an overall mean score of $22 \%$ for novel words, and from $1 \%$ to $53 \%$, with an overall mean of $17 \%$ for nonsense words.

During baseline, Eddie's mean score for novel words was $5 \%$ (range of $0 \%$ to $40 \%)$. For nonsense words, his mean score was $1 \%(0 \%$ to $20 \%)$. Christie's mean score for novel words was $16 \%$ ( $0 \%$ to $40 \%$ ). For nonsense words, her mean score was $6 \%(0 \%$ to $40 \%$ ). Laurie's mean score for novel words was $55 \%$ (0\% to $100 \%)$. For nonsense words, her mean score was $53 \%(0 \%$ to $80 \%)$. Mike's mean score for novel words was $5 \%$ (0\% to $20 \%$ ). For nonsense words, his mean score was $8 \%$ ( $0 \%$ to $40 \%$ ). Ricky's mean score for novel words was $31 \%(0 \%$ to $100 \%)$. For nonsense words, his mean score was $19 \%$ (0\% to $60 \%$ ).

The intervention for the double vowel pattern was implemented on Day 22 and continued until Day 33. Between Days 23 and 33, the results were positive. The overall mean score for novel words was $55 \%$ (compared to $22 \%$ during baseline) and $55 \%$ for nonsense words (compared to $17 \%$ during baseline).

During the double vowel pattern intervention, Eddie's mean score for novel words was $8 \%$ (range of $0 \%$ to $60 \%$ ). For nonsense words, his mean score was $16 \%(0 \%$ to $60 \%)$. Christie's mean score for novel words was $47 \%(0 \%$ to $80 \%)$. For nonsense words, her mean score was $40 \%(0 \%$ to $100 \%)$. Laurie's mean score for novel words was $88 \%$ (60\% to $100 \%)$. For nonsense words, her mean score was $88 \%$ (60\% to $100 \%$ ). Mike's mean score for novel words was $64 \%(0 \%$ to $100 \%$ ). For nonsense words, his mean score was $76 \%(20 \%$ to $100 \%)$. Ricky's mean score for novel words was $67 \%$ (20\% to $100 \%)$. For nonsense words, his mean score was $56 \%(0 \%$ to $100 \%)$.

When the intervention with the double vowel pattern was discontinued, the intervention for the subsequent pattern (i.e., closed) was implemented. This allowed the instruction to focus on a single vowel pattern, decreasing potential 
confusion with the previous vowel patterns. Data continued to be collected to assess possible maintenance effects. This was referred to as the postintervention phase. The results from Day 34 through 41 were notable. The overall mean score for novel words was $90 \%$ (compared to $22 \%$ during baseline) and $89 \%$ for nonsense words (compared to $17 \%$ during baseline).

During the post-intervention observations, Eddie's mean score for novel words was $75 \%$ (range of $40 \%$ to $100 \%$ ). For nonsense words, his mean score was $73 \%$ (40\% to $100 \%$ ). Christie's mean score for novel words was $88 \%$ (40\% to $100 \%$ ). For nonsense words, her mean score was $85 \%$ ( $40 \%$ to $100 \%$ ). Laurie's mean score for both novel and nonsense words was $100 \%$. Mike's mean score for novel words was $96 \%$ ( $80 \%$ to $100 \%$ ). For nonsense words, his mean score was $88 \%$ (60\% to $100 \%$ ). Ricky's mean score for novel words was $93 \%$ ( $80 \%$ to $100 \%)$. For nonsense words, his mean score was $97 \%(80 \%$ to $100 \%)$.

Finally, follow-up probes were collected and analyzed after intervention for all three vowel patterns was discontinued. This included seven observations spread over seven weeks. The first three probes were collected the two weeks immediately following the end of intervention and the remaining four probes after a two week winter vacation. The results during the follow-up period were notable. The overall mean score for novel and nonsense words was $88 \%$.

During the follow-up phase, Eddie's mean score for novel words was $71 \%$ (range of $60 \%$ to $100 \%$ ). For nonsense words, his mean score was $89 \%$ (60\% to $100 \%)$. Christie's mean score for novel words was $89 \%$ (60\% to $100 \%)$. For nonsense words, her mean score was $71 \%$ (40\% to 100\%). Laurie's mean score for novel words was $97 \%$ ( $80 \%$ to $100 \%$ ). For nonsense words, her mean score was $100 \%$. Mike's mean score for novel words was $86 \%$ ( $40 \%$ to $100 \%$ ). For nonsense words, his mean score was $86 \%$ (40\% to $100 \%$ ). Ricky's mean score 
for novel words was $97 \%$ ( $80 \%$ to $100 \%$ ). For nonsense words, his mean score was $93 \%(80 \%$ to $100 \%)$.

Closed vowel pattern. The individual and group results are presented in Tables 10 and 11 respectively. Daily student performance on the closed vowel pattern words is found on the bottom graphs of Figures $6-10$. Overall, the five students showed a variable and inconsistent level during baseline (Days 1 - 33). Nonsense words were generally lower than novel words. The individual means varied from $36 \%$ to $78 \%$, with an overall mean score of $55 \%$ for novel words, and from $19 \%$ to $70 \%$, with an overall mean of $47 \%$ for nonsense words.

During baseline, Eddie's mean score for novel words was $36 \%$ (range of $0 \%$ to $80 \%)$. For nonsense words, his mean score was $19 \%(0 \%$ to $80 \%)$. Christie's mean score for novel words was $36 \%$ (0\% to $80 \%$ ). For nonsense words, her mean score was $19 \%(0 \%$ to $60 \%)$. Laurie's mean score for novel words was $78 \%$ (40\% to $100 \%$ ). For nonsense words, her mean score was $70 \%$ ( $20 \%$ to $100 \%$ ). Mike's mean score for novel words was $61 \%(20 \%$ to $100 \%)$. For nonsense words, his mean score was $56 \%$ (20\% to 100\%). Ricky's mean score for novel words was $64 \%$ ( $40 \%$ to $100 \%)$. For nonsense words, his mean score was $69 \%(20 \%$ to $100 \%)$.

The intervention for the closed vowel pattern was implemented on Day 33 and continued until Day 38, when all intervention ceased. Between Days 33 and 38 , the results were positive. The overall mean score for novel words was $88 \%$ (compared to $55 \%$ during baseline) and $82 \%$ for nonsense words (compared to $47 \%$ during baseline).

During the closed vowel pattern intervention, Eddie's mean score for novel words was $68 \%$ (range of $40 \%$ to $80 \%$ ). For nonsense words, his mean score was $64 \%$ (0\% to $100 \%)$. Christie's mean score for novel words was $92 \%$ (60\% to 
$100 \%$ ). For nonsense words, her mean score was $72 \%$ (20\% to $100 \%$ ). Laurie's mean score for novel words was $92 \%$ ( $80 \%$ to $100 \%$ ). For nonsense words, her mean score was $96 \%$ ( $80 \%$ to $100 \%$ ). Mike's mean score for novel words was $100 \%$. For nonsense words, his mean score was $92 \%$ ( $80 \%$ to $100 \%$ ). Ricky's mean score for novel words was $88 \%$ ( $40 \%$ to $100 \%$ ). For nonsense words, his mean score was $84 \%$ ( $80 \%$ to $100 \%)$.

Once the intervention with the closed vowel pattern was discontinued, data collection continued to assess possible maintenance effects. This was referred to as the post-intervention phase. The overall results from Day 39 through 41 were positive. The mean score for novel words was $96 \%$ (compared to $55 \%$ during baseline) and $93 \%$ for nonsense words (compared to $47 \%$ during baseline).

During the post-intervention observations, Eddie's mean score for novel words was $80 \%$ (range of $40 \%$ to $100 \%$ ). For nonsense words, his mean score was $87 \%$ ( $80 \%$ to $100 \%$ ). Christie's mean score for novel and nonsense words was $100 \%$. Laurie's mean score for novel and nonsense words was also $100 \%$. Mike's mean score for novel and nonsense words was $100 \%$ as well. Ricky's mean score for novel words was $100 \%$. For nonsense words, his mean score was $80 \%$ (only one score was obtained due to absences).

Finally, follow-up probes were collected and analyzed after intervention for all three vowel patterns was discontinued. This included seven observations spread across a total of seven weeks. The first three probes were collected the two weeks immediately following the end of intervention and the remaining four probes after a two week winter vacation. The overall results during the follow-up period were notable. The mean score was $91 \%$ for novel words, and $90 \%$ for nonsense words. 
During the follow-up phase, Eddie's mean score for novel words was $80 \%$ (range of $60 \%$ to $100 \%$ ). For nonsense words, his mean score was $80 \%$ (60\% to $100 \%)$. Christie's mean score for novel words was $94 \%$ ( $80 \%$ to $100 \%)$. For nonsense words, her mean score was $89 \%$ (60\% to $100 \%)$. Laurie's mean score for novel words was $94 \%$ ( $80 \%$ to $100 \%$ ). For nonsense words, her mean score was $100 \%$. Mike's mean score for novel words was $97 \%$ ( $80 \%$ to $100 \%$ ). For nonsense words, his mean score was $89 \%$ (60\% to 100\%). Ricky's mean score for novel words was $90 \%$ ( $80 \%$ to $100 \%$ ). For nonsense words, his mean score was $93 \%(60 \%$ to $100 \%)$.

Effects on Standardized Test Measures

Three subtests of the Woodcock Reading Mastery Tests - Revised were used as pre- and posttest measures for this study (Forms $\mathrm{G}$ and $\mathrm{H}$ respectively). The subtests were (a) word identification, (b) word attack, and (c) passage comprehension. Age-based norms were used to obtain standard scores. Individual raw scores, standard scores, age-equivalents, and differences are provided in Table 12. The time between pre- and posttest was 16 weeks.

Word identification. All five students made positive gains in all measures. Overall, the mean score gain was 12.8 (raw score), 6.4 (standard score), 5.6 months (actual age equivalent), and 1.6 months (corrected age-equivalent). Raw score means increased from 21.4 (pretest) to 34.2 (posttest), while actual raw scores ranged from 5 to 29 (pretest) and from 26 to 42 (posttest). Standard score means increased from 76 (pretest) to 82.4 (posttest), while actual scores ranged from 61 to 84 (pretest) and from 77 to 92 (posttest). Difference scores were calculated for each student. For raw scores and standard scores, this figure represents posttest minus pretest scores. However, to correct for the length of the study, 4 months was subtracted from each student's age-equivalent gain, 
Table 12

Effects on Standardized Test Measures: Woodcock Reading Mastery Tests - Revised

\begin{tabular}{|c|c|c|c|c|c|c|c|c|c|}
\hline \multirow[t]{2}{*}{ Student } & \multicolumn{3}{|c|}{ Word Identification } & \multicolumn{3}{|c|}{ Word Attack } & \multicolumn{3}{|c|}{ Passage Comp } \\
\hline & RS & SS & $A E$ & RS & SS & $\mathrm{AE}$ & RS & SS & $\mathrm{AE}$ \\
\hline \multicolumn{10}{|l|}{ Eddie } \\
\hline Pretest & 22 & 80 & $6-9$ & 2 & 77 & $6-1$ & 12 & 83 & $6-9$ \\
\hline Posttest & 28 & 81 & $6-11$ & 7 & 83 & $6-7$ & 16 & 82 & $7-0$ \\
\hline Difference & 6 & 1 & -2 & 5 & 6 & +2 & 4 & -1 & -1 \\
\hline \multicolumn{10}{|l|}{ Christie } \\
\hline Pretest & 23 & 74 & $6-9$ & 2 & 65 & $6-1$ & 9 & 71 & $6-7$ \\
\hline Posttes: & 33 & 75 & $7-1$ & 11 & 80 & $6-11$ & 18 & 79 & $7-2$ \\
\hline Difference & 10 & 1 & 0 & 9 & 15 & +6 & 9 & 8 & +3 \\
\hline \multicolumn{10}{|l|}{ Laurie } \\
\hline Pretest & 28 & 84 & $6-11$ & 13 & 93 & $7-0$ & 15 & 87 & $7-0$ \\
\hline Posttest & 42 & 92 & $7-6$ & 17 & 94 & $7-5$ & 18 & 84 & $7-2$ \\
\hline Difference & 14 & 8 & +3 & 4 & 1 & +1 & 3 & -3 & -2 \\
\hline \multicolumn{10}{|l|}{ Mike } \\
\hline Pretest & 5 & 61 & $6-2$ & 3 & 76 & $6-2$ & 8 & 72 & $6-6$ \\
\hline Posttest & 26 & 77 & $6-10$ & 16 & 90 & $7-4$ & 15 & 79 & $7-0$ \\
\hline Difference & 21 & 16 & +4 & 13 & 14 & +10 & 7 & 7 & +2 \\
\hline \multicolumn{10}{|l|}{ Ricky } \\
\hline Pretest & 29 & 81 & $6-11$ & 10 & 86 & $6-10$ & 14 & 79 & $6-11$ \\
\hline Posttest & 42 & 87 & $7-6$ & 16 & 89 & $7-4$ & 21 & 85 & $7-5$ \\
\hline Difference & 13 & 6 & +3 & 6 & 3 & +2 & 7 & 6 & +2 \\
\hline
\end{tabular}

Note. Time between pre- and posttest $=16$ weeks.

Standard scores derived from age-based norms.

Difference for RS (raw score) and SS (standard score) = posttest minus pretest scores.

Difference for $\mathrm{AE}$ (age equivalent) = $\mathrm{AE}$ gain minus 4 months (length of study). 
resulting in a corrected age-equivalent (age-equivalent difference figure on Table 12). Differences in raw scores (range of 6 to 21), standard scores (range of 1 to 16), and actual age-equivalents (range of 2 to 8 months) were notable. Even the corrected age-equivalents (range of -2 to +4 months) deserve mention considering norms are based on an average population and this study included five students with reading disabilities. Mike demonstrated the most obvious difference score (21 for raw score, 16 for standard score, +8 for actual ageequivalent, and +4 months for corrected age-equivalent), while Eddie displayed the smallest difference scores ( 6 for raw score, 1 for standard score, +2 for actual age-equivalent, and -2 for corrected age-equivalent). Overall, these gains were substantial given the fact that the words used in the intervention were regular (linguistic patterns) and monosyllabic, whereas many of the words in this subtest were irregular and multisyllabic.

Word attack. All five students made substantial gains in all measures. In fact, the greatest gains were observed in this subtest. The overall mean score gain was 7.4 (raw score), 7.8 (standard score), 8.2 months (actual ageequivalent), and 4.2 (corrected age-equivalent in months). Raw score means increased from 6 (pretest) to 13.4 (posttest), while actual raw scores ranged from 2 to 13 (pretest) and from 7 to 17 (posttest). Standard score means increased from 79.4 (pretest) to 87.2 (posttest), while actual scores ranged from 65 to 93 (pretest) and from 80 to 94 (posttest). Difference scores for RS, SS, and AE were calculated using the same procedure as the word identification subtest. Differences in raw scores (range of 5 to 14), standard scores (range of 1 to 15), and actual age-equivalents (range of 5 to 14 months) were notable. The corrected age-equivalents (range of +1 to +10 months) are especially significant considering the reading difficulties of these children. Individually, Mike 
demonstrated the most obvious difference scores (13 for raw score, 14 for standard score, +14 months for actual age-equivalent, and +10 months for corrected age-equivalent). Christie showed similar difference gains ( 9 for raw score, 15 for standard score, +10 months for actual age-equivalent, and +6 months for corrected age-equivalent). Laurie displayed the smallest difference scores ( 4 for raw score, 1 for standard score, +5 months for actual ageequivalent, and +1 month for corrected age-equivalent). Although this subtest is usually considered the most difficult (it contains mono- and multisyllabic nonsense words and students must rely on their phonetic ability alone to decode them), the greatest overall gains were demonstrated by this group of children. Of course, this may be attributed to the fact that the intervention focused on regular, phonetic patterns. However, the ability to generalize to unknown, nonsense words was encouraging. These findings support the belief that with direct, explicit instruction involving the alphabetic code, students with reading disabilities can learn to apply and transfer decoding skills.

Passage comprehension. Overall increases were also demonstrated in this subtest. The mean score gain was 6 (raw score), 3.4 (standard score), 4.8 months (actual age-equivalent), and .8 month (corrected age-equivalent). Raw score means increased from 11.6 (pretest) to 17.6 (posttest), while actual raw scores ranged from 8 to 15 (pretest) and from 15 to 21 (posttest). Standard score means increased from 78.4 (pretest) to 81.8 (posttest), while actual scores ranged from 71 to 87 (pretest) and from 79 to 85 (posttest). Difference scores were calculated using the same procedure as in the two previous subtests. Differences ranged from 3 to 9 (raw score), from -3 to 8 (standard scores), and from 2 to 7 months (actual age-equivalents). The corrected age-equivalent differences ranged from -2 to +3 months. Again, these differences are noteworthy 
considering the reading disabilities of the five students. This subtest follows a cloze procedure and students are required to read sentences silently. These activities were not familiar to the children. In addition, many sentences contained irregular, unfamiliar words that were not the focus of the intervention. 


\section{CHAPTER V}

\section{Discussion}

The overall results of this study demonstrate that children with reading disabilities can benefit from an intervention that integrates holistic and graphophonic components. All five participants substantially increased their word reading accuracy after the intervention was implemented. Positive changes were seen with all three vowel patterns, for training words in isolation and in context, as well as for novel and nonsense words. In addition, the gains were maintained throughout the post-intervention and follow-up phases of the study. It is important to realize that these changes occurred within a relatively short period of time. There were only 22 actual intervention sessions throughout the study, even though data collection occurred daily (except holidays and weekends) for the entire study (approximately four months, including the follow-up phase). Another significant aspect of this study is that the intervention occurred within a reading class, using whole group instruction (as opposed to an individualized program). These results were promising and encouraging for both this study and for possible future research.

Currently, there is a paucity of research that combines holistic (including whole language) and traditional (e.g., phonics) approaches. (McKenna, Robinson, \& Miller, 1990; Pressley \& Rankin, 1994; Stahl, McKenna, \& Pagnucco, 1994; Stahl \& Miller, 1989). Perhaps this is due to the fact that staunch advocates of each approach are not in agreement with each other concerning the possible benefits of studying a more comprehensive approach to reading instruction. Some proponents believe in an "all or nothing" philosophy, rejecting the idea of eclecticism. Others, however, agree with Robinson (1994) as he urges, "It is up to those of us in the middle who have supported balance all along to regain our 
voices and speak out against the unreasoning extremism of the purists from both the right and the left in the literacy debate" (p. 63).

This study supports neither a "top-down" nor a "bottom-up" model of reading instruction in a "purist" sense, but rather, extends the research to include a systematic integration of both models. Therefore, to provide a research base for this study, certain elements from each model were analyzed. The result was an approach to teaching reading that balances meaning and structure, stories and skills. It is based on holistic and graphophonic principles. It is contextually-based and strategy-driven. It follows a whole-part-whole understanding of the reading process. It includes the "romance, precision, and generalization" (Whitehead, 1929) aspects of learning to read (Poplin, 1988a). Therefore, to understand and support this integration of approaches, a discussion of two broad bases of research (i.e., whole language and phonics) follows.

The research in whole language has been analyzed and the results have been controversial and somewhat negative. (Stahl, McKenna, \& Pagnucco, 1994; Stahl \& Miller, 1989). Because the philosophy it values rejects assessment procedures used in traditional research, comparative quantitative studies are scarce. Instead, reports of positive experiences, testimonials, or case studies of whole language teachers have been the basis of the research. However, the use of whole language with emergent or beginning readers has been explored. Positive effects have been found using whole language with kindergarten, first grade, and emergent readers (Reutzel \& Cooter, 1990; Ribowsky, 1985). In addition, support exists for some elements of whole language instruction. For example, the use of quality literature to introduce children to the concept of reading for meaning, repeated readings, and the integration of reading and writing have contributed positively to reading instruction. Some proponents of whole 
language accept the teaching of skills within the context of real reading (Goodman, 1986; Newman, 1985). This inclusion of skill teaching is usually indirect and for short periods of time. The present study supports the principle of teaching skills in context; however, the emphasis is on direct and repeated instruction.

Phonics, or the code-based approach to teaching reading is the second area of research that is part of this study. The literature is filled with research confirming the fact that early and systematic instruction in decoding leads to better reading achievement (Chall, 1983; Felton, 1993; Foorman, Novy, Francis, \& Liberman, 1991; Liberman \& Liberman, 1989; Stahl, McKenna \& Pagnucco, $1994 ;$ ) and that phonological awareness combined with explicit phonics instruction is effective in developing beginning reading and spelling skills (Alexander, Andersen, Heilman, Voeller, \& Torgesen, 1991; Ball \& Blachman, 1991; McGuinness, McGuinness, \& Donohue; Spector, 1995). This study supports the research on phonics in general, and analytic phonics specifically, by focusing on the graphophonic patterns, or vowel positions, within words. This strategy follows an analytic phonics approach (whole to part), as opposed to a synthetic phonics approach (part to whole). By recognizing the vowel pattern within a word, students are encouraged to use what they know about the pattern, to help them decode the word. For example, in the word goat, the position of the oa combination (double vowel pattern) suggests the long o sound (vowel says its name). This is very different from sounding out (as in synthetic phonics) the individual sounds of the word, especially if students do not know which vowel sound (long or short) to use. This idea is supported by Morrison (1984). He examined rule-based and word-specific views of decoding. He suggests that "children need to learn that pronunciation of some English orthographic units 
depends on the graphemic environment or position of the unit in the word, called conditional correspondence" (p. 21). He states further that short and long vowels belong to this category and that, "acquisition and use of rule knowledge in word decoding may be important in the early stages of learning to read, but their importance diminishes in later years as word decoding becomes more automatic" (p. 23).

The third, and most important, program of research that this study extends is a combination and integration of meaning-based strategies that are consistent with the philosophy of whole language, and code-based strategies that focus on phonics or graphophonics (Cunningham, Hall, \& DeFee, 1991; Eldredge, 1991; Mather, 1992; Pressley \& Rankin, 1994). According to Stahl, McKenna, \& Pagnucco (1994), whole language approaches seem to improve children's attitudes toward reading, but eclectic programs that also stress phonics instruction, seem to improve achievement and attitude (p. 175). They add, "It also could be that combining an explicit phonics program that stresses the use of authentic learning tasks and literature might be the best of both worlds" (p. 181). Interesting innovative instruction based on this synthesis of approaches is gradually finding its way into recent literature (Freppon \& Dahl, 1991; Mills, O'Keefe, \& Stephens, 1990).

This study also extends the research on the use of context cues in reading instruction. The increase in accuracy of decoding for all words was clear. However, greater gains were found with the training words, both in isolation and in context. This finding is understandable since the training words were the foundation of the intervention. These were the words the students encountered in the stories, constructed with the alphabet chips, and used in the guided spelling and writing activities. Within this set, all the participants were able to read the 
words in context (sentences from the stories used for intervention) more easily and automatically than the words in isolation. This may be attributed to the fact that the stories were both interesting and meaningful. For example, the word "nice" was more easily recognized in the context of the sentence, "My sloppy tiger thought the teacher was nice," than when it was presented in isolation. In addition, other words in the sentences provided clues about the target words. Students were able to use all four reading cueing systems (i.e., semantics, syntax, schema, and graphophonics) to decode the training words. For the words in isolation, however, the students had to depend on the graphophonic cueing system alone. This finding supports previous research on reading in context (Allington, 1979; Goodman, 1965; Mudre \& McCormick, 1989). Goodman (1965) found that reading accuracy improved significantly in context, compared to reading words in an isolated list. Allington (1979) discovered that some poor readers were able to use contextual information to identify words. In 1991, Nicholson reevaluated the Goodman study and found that only poor readers and the younger average readers made significant gains in context. He concluded that the original study was overly optimistic and that the use of context clues as a major strategy (as in whole language) needs further consideration.

Additionally, this study supports the transfer or generalization of decoding skills. In the generalization set, novel words were recognized more easily than nonsense words. This was understandable since the novel words were real and had real meaning (although they were unknown). The nonsense words, of course, had no meaning. Since these words were used to assess generalization of the vowel patterns, and, therefore, not part of the intervention, they remained more difficult to decode for most of the students throughout the study. In addition, both novel and nonsense words were presented in isolation. Therefore, the 
students had to rely on the graphophonic cueing system alone, once again. In spite of this, however, results were notable and very encouraging. These findings confirm the fact that children can learn to transfer and apply decoding skills to unfamiliar words when provided with appropriate instruction and powerful strategies. This extends and supports a recent study by Lovett et al. (1994). One group of children with dyslexia was trained in phonological analysis, blending skills and letter-sound correspondences. Another group was trained in the use of four metacognitive decoding strategies. The results indicated positive effects for transfer and generalization for both groups of children. Previous research in this area by Lovett, Warren-Chaplin, Ransby, and Borden (1990), however, contradicted these findings. Although word reading skills improved in speed and accuracy, generalization did not occur. A possible explanation for the discrepancy is that the 1990 study did not emphasize patterns or strategies. The focus of the1994 study, however, was strategy-based (as was this study). Lovett et al. (1994) emphasize the significance of positive effects of generalization, stating, "The attainment of transfer and documented generalization of training gains is necessarily the true test of efficacy for any intervention" (p. 820).

The differential use of strategies seems to be an important component of the decoding process. Although all five children increased their decoding accuracy during this study, the various strategies used to process and respond to the decoding tasks were indeed unique. For example, while Eddie used the "decoding by analogy" strategy (e.g., "I know tail, so this must be mail."), Christie and Mike repeated the "vowel pattern rule" with almost every word (e.g., "One lonely vowel squooshed in the middle, says its special sound, just a little, /ĕ/, wet."), Ricky recited the rule only when the word seemed difficult (He stated on many occasions, "I won't waste my time saying the rule if I know the word."), and 
Laurie responded almost automatically (once she learned the pattern). This was not totally unexpected, however, since the use of strategies was encouraged during the intervention. Suggestions such as, "Say the rule if it will help you read the word," "Use your eyes to find the vowel pattern," or, "What does that vowel pattern tell your brain about the sound?" were repeated frequently during the intervention phases of the study.

Since the primary purpose of single subject experimental research is to examine individual differences, the following observations are significant. Although three children responded rapidly to the intervention, Eddie and Christie required extra "booster sessions" throughout the intervention phases, due to the variability of their responses. Both children experienced severe reading problems, including visual perception difficulties (e.g., reversals and transpositions). Many of their errors did not reflect vowel miscues, but rather errors with consonant blends, consonant digraphs, or reversals and transpositions. For example, Eddie read "tain" for train, "wish" for with, and "flo" for foal. Christie's miscues included, "paint" for pate, "blue" for plue, and "sky" for sike. Even though the vowel sounds were correct, the words were scored as incorrect due to other types of errors.

The transition from one vowel pattern to the next was also worth noting. Once the students learned the magic e pattern with its corresponding long vowel sounds, the double vowel pattern was fairly easy (also long vowels). On the other hand, the transition to the closed vowel pattern (short vowels) was more difficult, even though most of the children knew some short vowel sounds at the beginning of the study. To expedite this vowel sound shift, a strong association between the visual position of the vowel pattern (grapheme) and its accompanying sound (phoneme) must exist. To foster this sound-symbol association, guided spelling activities were helpful. For example, during the written activity part of the 
intervention, when asked to spell a word, the teacher would draw the appropriate number of lines on the board corresponding to the correct number of letters in the word (white lines for consonants and red for vowels), and ask the child to "feel it in your mouth," "what sounds do you hear," or "what sound comes next?" This recoding of sound to symbol is supported by the recent research of McGuinness, McGuinness and Donohue (1995) that suggests, " ... the method of reading instruction is critical for reading success. Phoneme awareness must be connected in a coherent way to graphemes for a child to grasp the logic of the alphabet principle and learn accurate and fluent decoding skills" (p. 851).

Another interesting observation was the way these students transferred learning to other situations. For example, at various times throughout the day, many words were recognized and read correctly based on the vowel patterns taught during the reading intervention. Comments such as, "I know that word; it's a magic e word," became commonplace in our classroom. Transfer of learning is an expected learning outcome for most children, but for students with learning and reading disabilities, it is an exciting occurrence.

Still another positive effect of the study was the way all the students read and reread the books used during the intervention. This was evidenced by the number of times the children requested to read certain books as well as their appropriate reactions to them. It seems reasonable to believe that once decoding becomes automatic, fluency follows, and reading becomes an enjoyable experience.

Despite these encouraging findings, there are several limitations and concerns that need to be addressed. There exists a portion of reading enthusiasts who discount the demonstration of decoding without comprehension. Even though real books were used as the source of the training words, and the 
stories were read, discussed and reacted to, daily measures of understanding were not included for analysis. Therefore, to increase social validity, the addition of daily probes to measure comprehension might be considered. In this way, the "reading for meaning" aspect of the reading process would be emphasized. The one measurement of comprehension (i.e., the passage comprehension subtest of the Woodcock Reading Mastery Tests - Revised) provided a pre- and posttest evaluation of this skill. Although moderate gains were noted (see Table 12), daily repeated measures (using the stories read), might have provided a more realistic assessment of actual comprehension. Since this was a study of limited scope, with the focus on decoding, systematic replication of this study may provide additional information in the area of comprehension.

The total number of daily probes $(60)$ needs to be examined. A reduction of words would decrease the length of time necessary to assess each child. At times, the element of "test fatigue" seemed to interfere with individual responses. Comments such as, "Are we almost finished?" or "How many more words are left?" were heard on occasion. With encouragement, however, all the children completed all the probes every day.

In addition, the selection of certain words used in both the training and the generalization sets needs further thought. For example, if words containing blends and digraphs, "soft" $\mathrm{c}$ and g, or other more difficult combinations are included in the study, direct teaching should occur before the study begins. In this way, errors other than "vowel pattern" errors might be kept at a minimum. Another option might include a scoring procedure that controls for errors that are not directly related to the vowel pattern. In this study, for example, words that included b/d reversals were scored correct (ben/den). This was the only type of 
visual discrimination error that was accepted, even though many others occurred throughout the study.

Another concern is teacher expertise. To insure effective intervention procedures, the teacher needs to understand the integration of holistic and graphophonic components, both in theory and in practice. In addition, previous experience teaching children with reading disabilities would be beneficial.

Future studies are necessary to confirm and expand the present findings. The next logical study might be a systematic replication focusing on comprehension. For example, it would be interesting to investigate (a) the effect of this intervention on comprehension skills, and (b) any co-varying relationships between decoding and comprehension that may occur as a result of the intervention.

In conclusion, this study has demonstrated that an integrated holistic graphophonic intervention is an effective instructional approach to increase the decoding performance of children with reading disabilities. The increases were observed in training words as well as generalization words. In addition, these increases maintained well after the intervention was concluded. The use of this systematic intervention bridges the gap between meaning and code; it offers teachers a practical and effective approach to meet the needs of their students, especially those with reading disabilities. "When good teachers try to meet students' needs, what they will do will usually transcend philosophy and politics. This is the way it has been as long as we have been teaching; it is the way it should be" (Stahl, McKenna, \& Pagnucco, 1994, p. 183). By reaching beyond philosophy and politics, an integrated intervention can help students with reading disabilities conquer the code, in order to master the meaning, thereby, linking the "romance, precision, and generalization" (Whitehead, 1929) of reading. 


\section{References}

Adams, M. J. (1990). Beginning to read: Thinking and learning about print. Cambridge, MA: MIT Press.

Alexander, A. W., Anderson, H. G., Heilman, P. C., Voeller, K. K., \& Torgesen, J. K. (1991). Phonological awareness training and remediation of analytic decoding deficits in a group of severe dyslexics. Annals of Dyslexia, 41. 193-206.

Allington, R. L. (1979). Word identification abilities of severely disabled readers: A comparison in isolation and context. Journal of Reading Behavior. 10. 409-416.

Ball, E. W., \& Blachman, B. A. (1991). Does phoneme awareness training in kindergarten make a difference in early word recognition and developmental spelling? Reading Research Quarterly, 26, 49-66.

Bergeron, B. S. (1990). What does the term whole language mean? Constructing a definition from the literature. Journal of Reading Behavior, 22. 301-329.

Brooks, J. G., \& Brooks, M. G. (1993). In search of understanding: The case for constructivist classrooms. Alexandria, VA: Association for Supervision and Curriculum Development.

Caine, R. N., \& Caine, G. (1991). Making connections: Teaching and the human brain. Alexandria, VA: Association for Supervision and Curriculum Development.

Chall, J. S. (1967; 1983). Learning to read: The great debate. New York: McGraw-Hill. 
Chall, J. S. (1989). Learning to read: The great debate 20 years later - a response to "Debunking the Great Phonics Myth." Phi Delta Kappan, 70,521 538.

Chiang, B., \& Ford, M. (1990). Whole language alternatives for students with learning disabilities. LD Forum, 16, 31-34.

Cunningham, P. M., Hall, D. P., \& Defee, M. (1991). Non-ability grouped, multilevel instruction: A year in a first-grade classroom. The Reading Teacher. 44. $566-571$.

Dechant, E. (1993). Whole-language reading. Lancaster, PA: Technomic.

Eldredge, J. L. (1991). An experiment with a modified whole language approach in first-grade classrooms. Reading Research and Instruction, 30, 21-38.

Eldredge, J. L., \& Butterfield, D. (1986). Alternatives to traditional reading instruction. The Reading Teacher, 40, 32-37.

Felton, R. H. (1993). Effects of instruction on the decoding skills of children with phonological-processing problems. Journal of Learning Disabilities, 26. 583589.

Fleischner, J. E. (1995). Educational management of students with learning disabilities. Journal of Child Neurology. 10. (Supplement 1), 81-85.

Foorman, B. R., Novy, D. M., Francis, D. J., \& Liberman, D. (1991). How letter-sound instruction mediates progress in first-grade reading and spelling. Journal of Educational Psychology, 83, 456-469.

Freppon, P. A., \& Dahl, K. L. (1991). Learning about phonics in a whole language classroom. Language Arts, 68, 190-197.

Gardner, H. (1991). The unschooled mind: how children think and how schools should teach. New York: Basic Books. 
Gaskins, R. W., Gaskins, J. C., \& Gaskins, I. W. (1991). A decoding program for poor readers - and the rest of the class, too! Language Arts, 68, 213225.

Goodman. K. S. (1965). A linguistic study of cues and miscues in reading. Elementary English, 42, 639-643.

Goodman, K. S. (1986). What's whole in whole language? Portsmouth, NH: Heinemann.

Goodman, K. S. (1993). Phonics Phacts. Portsmouth, NH: Heinemann.

Goswami, U., \& Mead, F. (1992). Onset and rime awareness and analogies in reading. Reading Research Quarterly, 27, 153-162.

Gunning, T. G. (1995). Word building: A strategic approach to the teaching of phonics. The Reading Teacher, 48, 484-488.

Hoiland Publications. (1985). Crazy syllables [Posters]. Bloomington, MN.

Hollingsworth, P., \& Reutzel, D. (1988). Whole language with LD children. Academic Therapy, 23, 477-488.

Liberman, I. Y., \& Liberman, A. M. (1990). Whole language vs. code emphasis: Underlying assumptions and their implications for reading instruction. Annals of Dyslexia, 40, 51-76.

Lovett, M. W., Borden, S. L., DeLuca, T., Lacerenza, L., Benson, N. J., \& Brackstone, D. (1994). Treating the core deficits of developmental dyslexia: Evidence of transfer of learning after phonologically- and strategy-based reading training programs. Developmental Psychology, 30, 805-822.

Lovett, M. W., Warren-Chaplin, P. M., Ransby, M. J., \& Borden, S. L. (1990).Training the word recognition skills of reading disabled children: Treatment and transfer effects. Journal of Educational Psychology, 82, 769-780. 
Majsterek, D. J., \& Ellenwood, A. E. (1995). Phonological awareness and beginning reading: Evaluation of a school-based screening procedure. Journal of Learning Disabilities, 28 , 449-456.

Manzo, A. V., \& Manzo, U. C. (1993). Literacy disorders: Holistic diagnosis and remediation. Fort Worth: Harcourt Brace Jovanovich.

Mather, $N$. (1992). Whole language reading instruction for students with learning disabilities: Caught in the cross fire. Learning Disabilities Research \& Practice. 7. 87-95.

May, F. B. (1986). Reading as communication. Columbus, OH: Merrill. McCormick, S. (1990). A case for the use of single-subject methodology in reading research. Journal of Research in Reading. 13, 69-81.

McCormick, S. (1995). What is single-subject experimental research? In S. B. Neuman \& S. McCormick (Eds.), Single-subject experimental research: Applications for literacy (pp. 1-31). Newark, DE: International Reading Association.

McGuinness, D., McGuinness, C., \& Donohue, J. (1995). Phonological training and the alphabet principle: Evidence for reciprocal causality. Reading Research Quarterly, 30, 830-852.

McKenna, M. C., Robinson, R. D., \& Miller, J. W. (1990). Whole language: A research agenda for the nineties. Educational Researcher. 19, 3-6.

McKenna, M. C., Robinson, R. D., \& Miller, J. W. (1994). Whole language and research: The case for caution. In C. B. Smith (Moderator), Whole language: The debate (pp. 17-42). (Report No. CS 011 581). Bloomington, IN: ERIC Clearinghouse on Reading, English, and Communication. (ERIC Document Reproduction No. ED 366 905) 
Mills, H., O'Keefe, T., Stephens, D. (1990). Looking closer: The role of phonics in a whole language classroom. Urbana, IL: National Council of Teachers of English.

Morrison, F. J. (1984). Word decoding and rule-learning in normal and disabled readers. Remedial and Special Education, 5, 20-27.

Mudre, L. H., \& McCormick, S. (1989). Effects of meaning-focused cues on underachieving readers' context use, self-corrections, and literal comprehension. Reading Research Quarterly, 24, 89-113.

Newman, J., Ed. (1985). Whole language: Theory in use. Portsmouth, NH: Heinemann.

Nicholson, T. (1991). Do children read words better in context or in lists? A classic study revisited. Journal of Educational Psychology, 83, 444-450.

Phinney, M. Y. (1988). Reading with the troubled reader. Portsmouth, NH: Heinemann.

Poplin, M. S. (1988a). Holistic/constructivist principles of the teaching/learning process: Implications for the field of learning disabilities. Journal of Learning Disabilities, 21, 401-416.

Poplin, M. S. (1988b). The reductionist fallacy in learning disabilities: Replicating the past by reducing the present. Journal of Learning Disabilities. 21. $389-400$.

Pressley, M., \& Rankin, J. (1994). More about whole language methods of reading instruction for students at risk for early reading failure. Learning Disabilities Research \& Practice. 9 . 157-168.

Reid, D. K. (1988). Reflections on the pragmatics of a paradigm shift. Journal of Learning Disabilities. 21, 417-420. 
Reutzel, D. R., \& Cooter, R. B. (1990). Whole language: Comparative effects on first-grade reading achievement. Journal of Educational Research, 83. 252-257.

Reutzel, D. R., Hollingsworth, P. M., \& Eldredge, J. L. (1994). Oral reading instruction: The impact on student reading development. Reading Research Quarterly, 29, 41-62.

Rhodes, L., \& Dudley-Marling, C. (1988). Readers and writers with a difference; a holistic approach to teaching learning disabled and remedial students. Portsmouth, NH: Heinemann.

Ribowsky, H. (1985). The effects of a code emphasis approach and a whole language approach upon emergent literacy of kindergarten children. (Report No. CS-008-397). (ERIC Document Reproduction Service No. ED 269 720)

Richardson, E., \& DiBenedetto, B. (1985). Decoding skills test. Parkton, MD: York Press.

Robinson, R. (1994). "Let us not permit ourselves to be forced into bitterly polarized positions..." In C. B. Smith (Moderator), Whole language: The debate (pp. 62-64). (Report No. CS 011 581). Bloomington, IN: ERIC Clearinghouse on Reading, English, and Communication. (ERIC Document Reproduction Service No. ED 366 905)

Samuels, S. J. (1986). Why children fail to learn and what to do about it. Exceptional Children, 53, 7-16.

Spector, J. E. (1995). Phonemic awareness training: Application of principles of direct instruction. Reading and Writing Quarterly: Overcoming Learning Difficulties, $11,37-51$. 
Stahl, S. A. (1992). Saying the "p" word: Nine guidelines for exemplary phonics instruction. The Reading Teacher, 45, 618-625.

Stahl, S. A., McKenna, M. C., \& Pagnucco, J. R. (1994). The effects of whole-language: An update and a reappraisal. Educational Psychologist. 29.175185.

Stahl, S. A., \& Miller, P. D. (1989). Whole language and language experience approaches for beginning reading: A quantitative research synthesis. Review of Educational Research, 59, 87-116.

Stanovich, K. E. (1988). Explaining the differences between the dyslexic and the garden-variety poor reader: The phonological-core variable-difference model. Journal of Learning Disabilities, 21, 590-604.

Stanovich, K. E. (1990). A call for an end to the paradigm wars in reading research. Journal of Reading Behavior. 22, 221-231.

Tawney, J. W., \& Gast, D. L. (1984). Single subject research in special education. New York, NY: Macmillan.

Trachtenberg, P. (1990). Using children's literature to enhance phonics instruction. The Reading Teacher, 43, 648-652.

Vellutino, F. R. (1991). Introduction to three studies on reading acquisition: Convergent findings on theoretical foundations of code-oriented versus wholelanguage approaches to reading instruction. Journal of Educational Psychology. 83. $437-443$.

Whitehead, A. N. (1929). The aims of education and other essays. New York: The Free Press.

Woodcock, R. W. (1987). Woodcock reading mastery tests-revised. Circle Pines, MN: American Guidance Service. 
Wright Group (1980). The story box books [Literature collection]. San Diego, CA: The Wright Group.

Wright Group (1987). Sunshine books [Literature collection]. San Diego, CA: The Wright Group. 
Bibliography

(For additional reading)

Adams, M. J. (1991). Why not phonics and whole language? in W. Ellis (Ed.), All language and the creation of literacy (pp. 40-53). Baltimore, MD: The Orton Dyslexia Society.

Adams, M. J. (1994). The progress of the whole-language debate. Educational Psychologist. 29, 217-222.

Adams, M. J., \& Bruck, M. (1995). Resolving the 'great debate'. American Educator $19.7,10-20$.

Anderson, R. C., Hiebert, E. H., Scott, J. A., \& Wilkinson, I. A. (1985). Becoming a nation of readers: The report of the Commission on Reading. Washington, DC: National Institute of Education.

Beck, I. L., \& Juel, C. (1992). The role of decoding in learning to read. In S. J. Samuels \& A. E. Farstrup (Eds.), What research has to say about reading instruction. Newark, DE: International Reading Association.

Clay, M. (1985). The early detection of reading difficulties. (3rd ed.) Auckland, New Zealand: Heinemann.

Cousin, P. T., Prentice, L., Aragon, E., Leonard, C., Rose, L. A., \& Weekley, T. (1991). Redefining our role as special educators: Understandings gained from whole language. In S. Stire (Ed.), With promise: Redefining reading and writing for special students (pp. 165-171). Portsmouth, NH: Heinemann.

Cunningham, P. M. (1995). Phonics they use: Words for reading and writing (2nd ed.). New York, NY: Harper Collins College Publishers.

Deegan, D. H. (1995). The necessity of debate: A comment on commentaries. The Reading Teacher. 48, 688-695. 
Dudley-Marling, C. (1995). Whole language: It's a matter of principles. Reading \& Writing Quarterly: Overcoming Learning Difficulties, 11, 109-117.

Ehri, L. C., \& Robbins, C. (1992). Beginners need some decoding skill to read words by analogy. Reading Research Quarterly, 27.13-26.

Fernald, G. (1943). Remedial techniques in basic school subjects. New York: McGraw-Hill.

Gersten, R., \& Dimino, J. (1993). Visions and revisions: A special education perspective on the whole language controversy. Remedial and Special Education. 14, 5-13.

Gillingham, A., \& Stillman, B. W. (1973). Remedial training for children with specific disability in reading, spelling, and penmanship. Cambridge, MA: Educators Publishing Service.

Heymsfeld, C. R. (1989). Filling the hole in whole language. Educational Leadership, 46(6), 65-68.

Hynd, G., \& Cohen, M. (1983). Dyslexia: Neuropsychological theory. research, and clinical differentiation. Orlando, FL: Grune \& Stratton.

Johns, J. L. (1991). Helping readers at risk: Beyond whole language, whole word, and phonics. Reading. Writing, and Learning Disabilities. 7 , 59-67.

Lenz, B. K., \& Hughes, C. A. (1990). A word identification strategy for adolescents with learning disabilities. Journal of Learning Disabilities. 23, 149158.

Macinnis, C., \& Hemming, H. (1995). Linking the needs of students with learning disabilities to a whole language curriculum. Journal of Learning Disabilities, 28, 535-544.

Mann, V. A. (1993). Phoneme awareness and future reading ability. Journal of Learning Disabilities, 26, 259-269. 
Neuman, S., \& McCormick, S. , Ed. (1995). Single-subject experimental research: applications for literacy. Newark, DE: International Reading Association.

Orton, S. T. (1937). Reading, writing, and speech problems in children. New York: W. W. Norton.

Pressley, M. (1994). Commentary on the ERIC whole language debate. In C B. Smith (Moderator), Whole language: The debate (pp. 187-217). (Report No. CS 011 581). Bloomington, IN: ERIC Clearinghouse on Reading, English, and Communication. (ERIC Document Reproduction Service No. ED 366 905)

Reid, D. K. (1988). Teaching the learning disabled: a cognitive developmental approach. Boston: Allyn and Bacon, Inc.

Reutzel, D. R., Hollingsworth, P. M., \& Eldredge, J. L. (1994). Oral reading instruction: The impact on student reading development. Reading Research Quarterly, 29, 41-62.

Routman, R. (1988). Transitions: From literature to literacy, Portsmouth, NH: Heinemann.

Routman, R. (1991). Invitations. Portsmouth, NH: Heinemann.

Sawyer, D. J. (1991). Whole language in context: Insights into the current great debate. Topics in Language Disorders. 11, 1-13.

Spear-Swerling, L., \& Sternberg, R. J. (1994). The road not taken: An integrative theoretical model of reading disability. Journal of Learning Disabilities. 27. $91-103$.

Spiegel, D. L. (1992). Blending whole language and systematic direct instruction. The Reading Teacher, 46, 38-44. 
Stanovich, K. E. (1986). Matthew effects in reading: Some consequences of individual differences in the acquisition of literacy. Reading Research Quarterly, 21, 360-406.

Stephens, D. (1991). Research on whole language: Support for a new curriculum. Katonah, NY: Richard C. Owen.

Weaver, C. (1991). Whole language and its potential for developing readers. Topics in Language Disorders. 11, 28-44. 


\section{APPENDIX A}

List of Words Used in Study Arranged by Vowel Patterns Alphabetical by Phonogram (Rime) 
TRAINING SET WORDS

\begin{tabular}{|c|c|c|}
\hline Closed & Magic e & Double Vowel \\
\hline back & face & jail \\
\hline had & race & mail \\
\hline $\mathrm{am}$ & space & nail \\
\hline can & grade & sail \\
\hline Dan & made & snail \\
\hline man & bake & tail \\
\hline $\operatorname{ran}$ & cake & brain \\
\hline and & flake & gain \\
\hline at & make & main \\
\hline cat & snake & pain \\
\hline fat & take & rain \\
\hline bed & came & train \\
\hline red & flame & paint \\
\hline went & game & gray \\
\hline get & name & hay \\
\hline let & same & May \\
\hline wet & cane & play \\
\hline pick & crane & stay \\
\hline did & plane & sea \\
\hline big & care & tea \\
\hline pig & scare & read \\
\hline hill & share & cream \\
\hline will & date & scream \\
\hline swim & gate & team \\
\hline in & late & bean \\
\hline skin & skate & mean \\
\hline tin & here & dear \\
\hline sing & mice & fear \\
\hline ship & nice & hear \\
\hline fish & rice & near \\
\hline it & hide & eat \\
\hline with & ride & meat \\
\hline dog & side & neat \\
\hline $\log$ & slide & seat \\
\hline song & bike & see \\
\hline got & hike & three \\
\hline hot & like & tree \\
\hline not & crime & creep \\
\hline pot & dime & jeep \\
\hline spot & lime & keep \\
\hline tub & time & sleep \\
\hline duck & dive & key \\
\hline tuck & drive & tried \\
\hline mud & five & boat \\
\hline gum & hive & coat \\
\hline jump & home & goat \\
\hline fun & close & float \\
\hline sun & hose & blue \\
\hline up & nose & clue \\
\hline just & rose & glue \\
\hline
\end{tabular}




\section{NOVEL WORDS}

\begin{tabular}{|c|c|c|}
\hline Closed & Magic e & Double Vowel \\
\hline$c a b$ & male & maid \\
\hline crab & pale & paid \\
\hline$l a b$ & sale & raid \\
\hline tab & scale & bait \\
\hline bag & tale & gait \\
\hline $\mathrm{rag}$ & whale & wait \\
\hline tag & brave & beak \\
\hline cap & cave & weak \\
\hline clap & gave & sneak \\
\hline flap & pave & deal \\
\hline gap & save & meal \\
\hline nap & shave & real \\
\hline fell & wave & seal \\
\hline sell & eve & steal \\
\hline shell & life & bleed \\
\hline well & wife & feed \\
\hline hen & fine & need \\
\hline men & line & seed \\
\hline ten & mine & speed \\
\hline end & nine & weed \\
\hline send & pine & creek \\
\hline spend & shine & meek \\
\hline fib & spine & peek \\
\hline rib & vine & week \\
\hline milk & bite & feel \\
\hline silk & kite & heel \\
\hline pink & mite & peel \\
\hline $\sin k$ & site & reel \\
\hline hint & spite & steel \\
\hline $\operatorname{mint}$ & white & green \\
\hline job & broke & seen \\
\hline rob & joke & teen \\
\hline clock & poke & beet \\
\hline lock & smoke & feet \\
\hline rock & spoke & meet \\
\hline sock & woke & sweet \\
\hline $\operatorname{cod}$ & dole & die \\
\hline nod & hole & lie \\
\hline rod & mole & pie \\
\hline hop & pole & tie \\
\hline mop & role & load \\
\hline stop & stole & road \\
\hline top & bone & toad \\
\hline hug & cone & soak \\
\hline rug & lone & croak \\
\hline bus & stone & coal \\
\hline cut & tone & foal \\
\hline hut & hope & goal \\
\hline nut & rope & fruit \\
\hline shut & scope & suit \\
\hline
\end{tabular}




\section{NONSENSE WORDS}

\begin{tabular}{|c|c|c|}
\hline Closed & Magic e & Double Vowel \\
\hline gack & dace & cail \\
\hline nad & gace & dail \\
\hline fam & stace & kail \\
\hline gan & brade & lail \\
\hline han & nade & stail \\
\hline $\operatorname{lan}$ & dake & vail \\
\hline san & gake & crain \\
\hline fand & hake & frain \\
\hline gat & nake & hain \\
\hline lat & slake & jain \\
\hline tat & smake & lain \\
\hline jed & crame & sain \\
\hline ped & hame & maint \\
\hline fent & pame & blay \\
\hline $\operatorname{det}$ & rame & cray \\
\hline fet & stame & fay \\
\hline het & chane & flay \\
\hline vick & fane & tay \\
\hline nid & rane & fea \\
\hline hig & nare & nea \\
\hline sig & slare & mead \\
\hline liil & tare & bream \\
\hline rill & clate & gream \\
\hline stim & pate & leam \\
\hline hin & sate & fean \\
\hline $\min$ & wate & rean \\
\hline slin & pere & jear \\
\hline fing & bice & lear \\
\hline fip & fice & mear \\
\hline lish & hice & vear \\
\hline rit & jide & jeat \\
\hline mith & lide & keat \\
\hline kog & nide & leat \\
\hline $\operatorname{mog}$ & stide & reat \\
\hline hong & rike & cree \\
\hline bot & sike & ree \\
\hline kot & wike & shee \\
\hline mot & clime & breep \\
\hline sot & hime & cleep \\
\hline smot & nime & feep \\
\hline fub & stime & heep \\
\hline huck & mive & ney \\
\hline nuck & nive & gried \\
\hline pud & pive & foat \\
\hline fum & stive & noat \\
\hline sump & forne & poat \\
\hline dun & bose & sloat \\
\hline Iun & gose & plue \\
\hline sup & mose & slue \\
\hline nust & stose & stue \\
\hline
\end{tabular}


APPENDIX B

Sample Data Sheets 
Student:

Date

Observer:

Day:

\section{DATA SHEET}

Vowel

Reading Accuracy

Pattern

Training Words
Isolation Context

Closed

\begin{tabular}{|l|l|l|l|r|r|r|r|}
\hline 1 & & 1 & & 1 & & 1 & \\
\hline 2 & & 2 & & 2 & & 2 & \\
\hline 3 & & 3 & & 3 & & 3 & \\
\hline 4 & & 4 & & 4 & & 4 & \\
\hline 5 & & 5 & & 5 & & 5 & \\
\hline \multicolumn{2}{|c|}{$15=\%$} & & & & \\
\hline
\end{tabular}

Magic e

\begin{tabular}{|c|c|c|c|c|}
\hline 1 & 1 & 1 & 1 & \\
\hline 2 & 2 & 2 & 2 & \\
\hline 3 & 3 & 3 & 3 & \\
\hline 4 & 4 & 4 & 4 & \\
\hline 5 & 5 & 5 & 5 & \\
\hline
\end{tabular}

Double

Vowels

\begin{tabular}{|c|c|c|c|c|}
\hline 1 & 1 & 1 & 1 & \\
\hline 2 & 2 & 2 & 2 & \\
\hline 3 & 3 & 3 & 3 & \\
\hline 4 & 4 & 4 & 4 & \\
\hline 5 & 5 & 5 & 5 & \\
\hline
\end{tabular}

$\log$

Event:

Student Reaction:

Observer Reaction: 
Student

Date

CONSONANT TEST

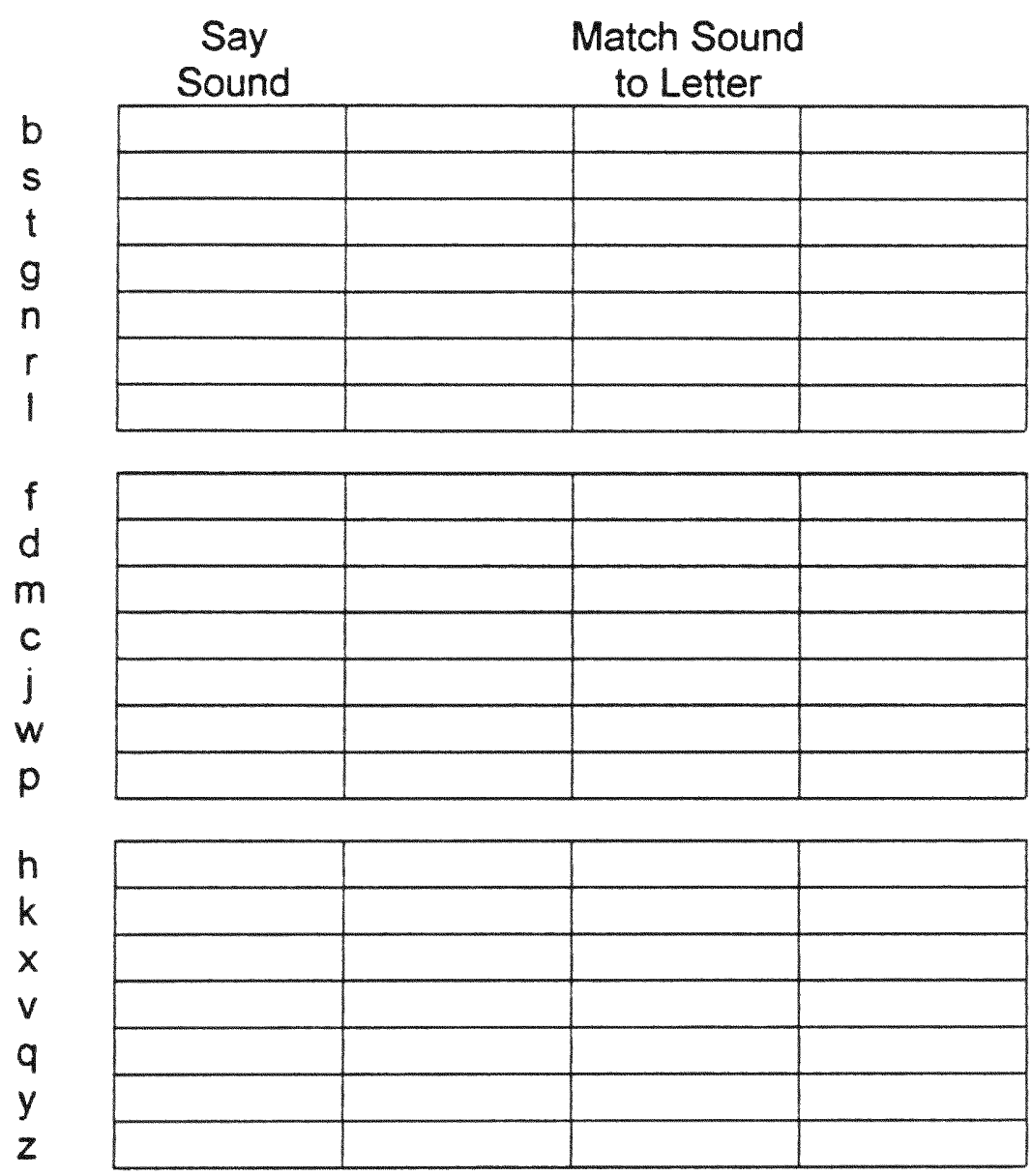



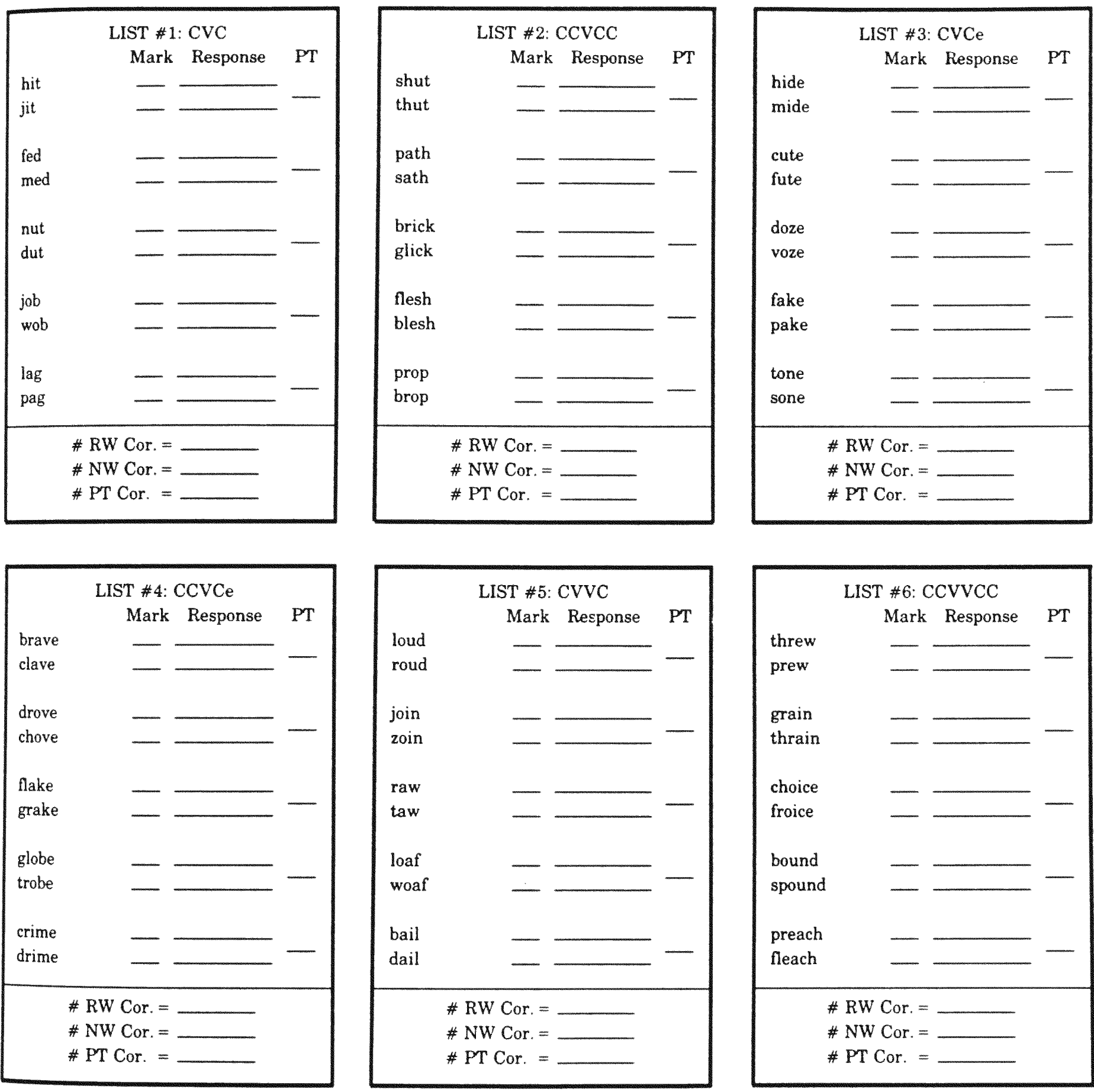

Monosyllabic Score Summary

Section 1: $\mathrm{RW}_{\mathrm{MS}}$

$$
\begin{aligned}
& \mathrm{PT}_{\mathrm{MS}} \\
& \mathrm{PTI}_{\mathrm{MS}}=\frac{}{\mathrm{PT}_{\mathrm{MS}}} / \frac{}{\mathrm{RW}_{\mathrm{MS}}}=
\end{aligned}
$$




\section{APPENDIX C}

List of Literature Books Used in Intervention 
The Story Box Collection: The Wright Group

The Jigaree

The Red Rose

Meanies

Dan, the Flying Man

Grandpa, Grandpa

Mrs. Wishy-Washy
Joy Cowley $\quad x$

Joy Cowley $\quad x$

Joy Cowley

Joy Cowley

Joy Cowley

Joy Cowley

Sunshine Books Collection: The Wright Group

Space Race

The Terrible Tiger

My Sloppy Tiger Goes to School

My Boat
Joy Cowley $\quad x$

Joy Cowley $\quad x$

Joy Cowley $\quad x$

Joy Cowley $x$

$x$ $x$

$x$

$x$




\section{APPENDIX D}

Vowel Patterns Classified by Literature Books Used in Intervention 
Vowel Pattern

a

e

0

u

The Jigaree

Closed

can

it

jump

swim

with

Magic e

skate

here

ride

home

take

Double Vowel

see

The Red Rose

Closed

cat
and
back

red
went

in

pick

it

Magice

side

rose

home

Double Vowel

see

dear

Space Race

Closed

ship

fun

in

sun

Magic e

space

five

race

made

Double Vowel

stay

three

(table continues) 
(continued)

Vowel Pattern

a

e

0

u

The Terrible Tiger

Closed

back

hill

not

$\log$

Magic e

scare

home

snake

Double Vowel

tail

creep

My Sloppy Tiger Goes to School

Closed

and

get

it

got

not

up

ran

$\begin{array}{ll}\text { race } & \text { nice } \\ \text { came } & \text { time }\end{array}$

Magic e

take

face

made

Double Vowel

$\begin{array}{ccc}\text { paint } & \text { key } & \text { tried } \\ \text { play } & \text { read } & \\ & \text { eat }\end{array}$

\section{Meanies}

Closed

$\begin{array}{ll}\text { tin not } & \text { mud } \\ \text { in } & \text { gum }\end{array}$

Magic e

bake

drive

Double Vowel

mean

eat

sleep

bean 
(continued)

Vowel Pattern

a

e

0

u

My Boat

Closed

had

went

it

skin

not

up

with

got

gum

Double Vowel

sail

sea

boat

blue

float

Dan, the Flying Man

Closed

Dan

man

am

can

ran

Magic e crane

Double Vowel train tree

sea

\section{Grandpa - Grandpa}

Closed

fat

$$
\text { let }
$$

wet

with

fish

will

big

did

Double Vowel

sea

tea

three 
(continued)

Vowel Pattern

a

e

0

U

Mrs. Wishy-Washy

Closed

and
at

went

in

it

mud

pig

jump duck tub just

Magic e

came

Double Vowel

scream 


\section{APPENDIXE}

Intervention Procedure 


\section{INTERVENTION PROCEDURE}

HOLISTIC: Understanding

- Pictured Reading Book

- Semantic mapping

- Reading, rereading, choral reading

- Guided questioning

- Illustrating parts of story

- Writing response (cloze)
GRAPHOPHONIC: Accuracy

- Vowel Pattern Sheet

- Tracing vowels in red

- Signing vowels

- Analyzing words on vowel pattern sheet

- Constructing words with letter chips

- Guided spelling 
APPENDIX F

Vowel Patterns Chart 
VOWEL PATTERNS

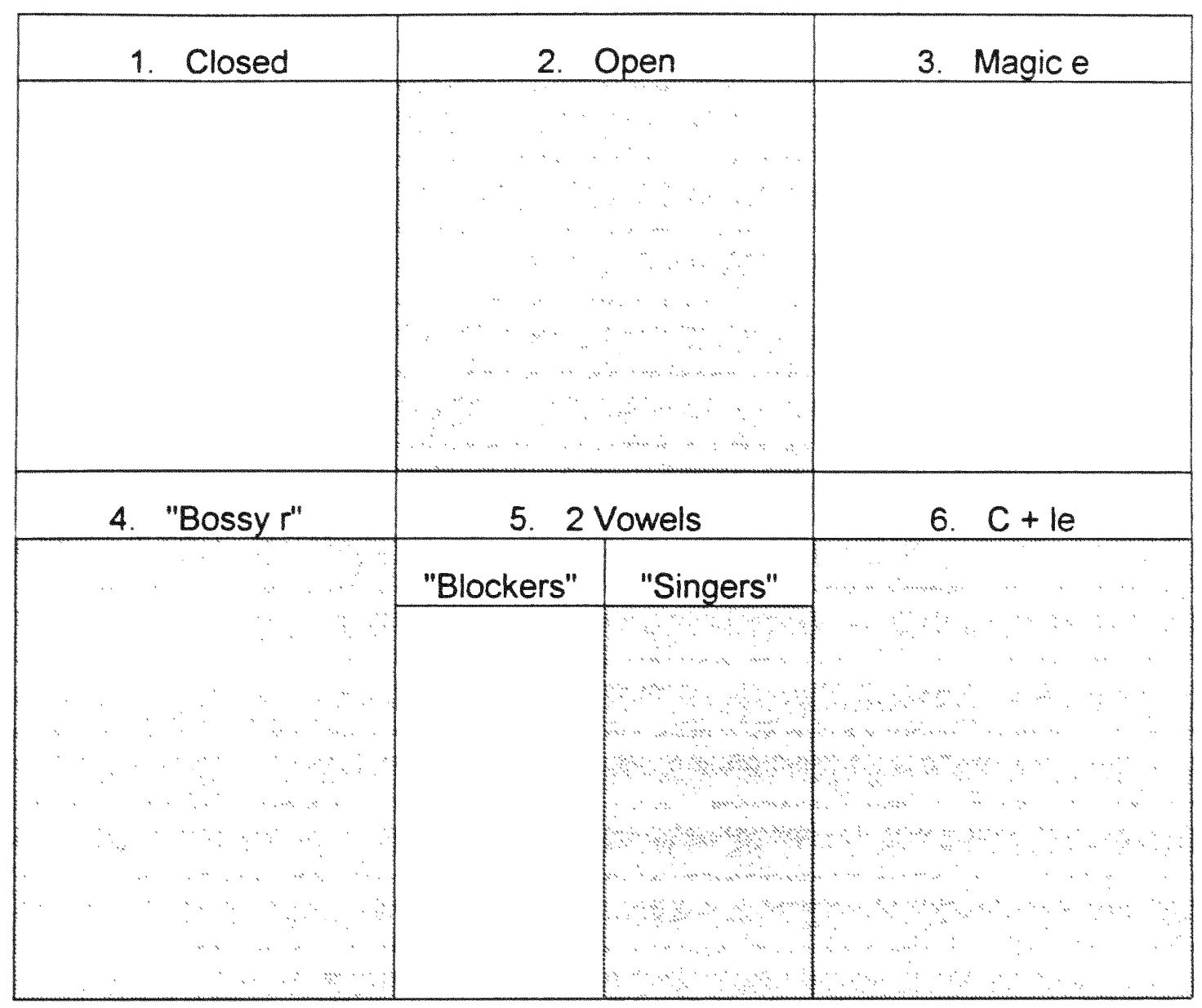




\section{APPENDIX G}

Florida International University

Institutional Review Board Approval Form 
JNSTITUTIOMAL REVIEW BOARO

\section{APPROVAB FOR日}

\section{FLORIDA INTERNATIONAL UNIVERSITY \\ University Park Campus \\ Miami, Florida 33199}

This is to certify that the program listed below has been reviewed and approved by the Institutional Review Board (IRB) in accordance with the requirements of 45 CFR 46, including its relevant subparts.

Principal Investigator/Project Director: E. Judith Krisman Cohen

Title of Application: Effects of a Holistic-Graphophonic Intervention on the Decoding Performance of Children with Reading Disabilities

Agency Submitted to:

Proposal Identification Number (if available):

Certificate of IRB:

September 21, 1995 - Date of IRB Review and Approval

X_ Full Board Review __ Expedited Review

Comments:

Council found no risk to the subjects but did caution the investigator to protect the anonymity of the subjects.

Any problems should be immediately brought to the attention of the IRB Council.

The Official signing below certifies that the information provided on this form is correct and the institution assumes responsibility for assuring future reviews, approvals, and submissions of certification.

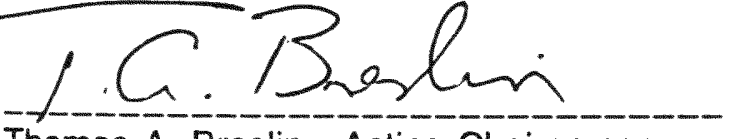

Thomas A. Breslin, Acting Chairperson

IRB Committee

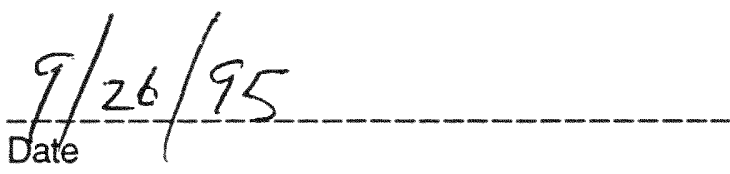

IRB FORM 09/91 [ma] 


\section{APPENDIXH}

Parental Consent Forms 


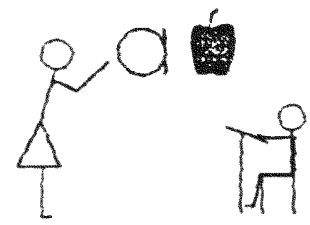

October 2, 1995

\section{Dear Parents:}

As you may know, I am currently working on my doctoral dissertation at Florida International University in the Department of Educational Psychology and Special Education. I am studying the effects of the strategies used in our reading program on the reading performance of children with reading disabilities.

I would greatly appreciate your permission so that your child may participate in this study. If you agree to allow your child to participate, we will examine his/her daily reading performance. We will also administer an additional reading test before and after the study.

The curriculum and teaching methods of the reading class will not be any different than we have used before, and I will continue to be the reading class teacher.

No student names will be used and all results will be kept completely confidential. If you give your permission and then change your mind, you have the right to withdraw your consent without any consequence to your son or daughter.

If you desire any further information about this research, you may contact Dr. Michael Brady at F.I.U. at 348-2286. You will receive a copy of this consent form. Your cooperation will be greatly appreciated. Thank you for considering this request.

Sincerely,

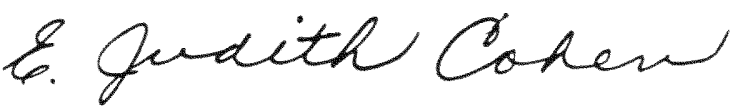

E. Judith Cohen, M.S.

271-3550 (home) or 274-2208 (school)

Permission IS IS NOT granted for my child, (circle one)

to participate in the Reading Study. 
Mc Glannan School

September 20,1995

Dear Parents:

Judy Cohen is in the process of completing her doctorate in Exceptional Student Education.

We have been asked to cooperate with the Department of Educational Psychology and Special Education at Florida International. University in a study being conducted by Judy for her dissertation. The curriculum, teaching methods and teacher will remain the same for your child's class.

We have found that our students like to participate and seem to enjoy the recognition and attention of a special project. Needless to say, the information gained is usually valuable.

Please return the enclosed form in the stamped addressed envelope as soon as possible as Judy is looking forward to finalizing her research.

Thank you for your cooperation.

Sincerely,

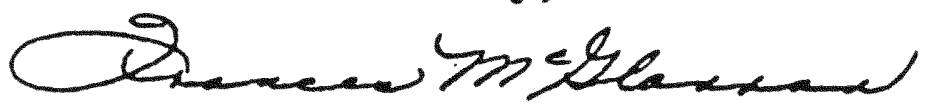

Frances MCGlannan

$F M: i j$

Encls. 
May 27, 1949

Born, Jackson Heights, New York

1974

B.S., Specific Learning Disabilities

Florida International University

Miami, Florida

$1974-1979$

Special Education Teacher

McGlannan School

Miami, Florida

1974 to Present Educational Consultation and Therapy

Private Practice

Miami, Florida

1977

M.S., Diagnostic Teaching

Florida International University

Miami, Florida

1984 to Present Special Education Teacher

McGlannan School

Miami, Florida

1988

Kennedy Grant Dyslexia Research Project

Florida International University

Miami, Florida

1994 to Present

Adjunct Professor

Department of Educational Psychology \& Special Education Florida International University

Miami, Florida

\section{PRESENTATIONS}

Cohen, E.J., (March 1995). Solving the Dyslexic Dilemma - A True Holistic Approach to Reading. Paper presented at the Learning Disabilities Association, International Conference, Orlando, Florida.

Cohen, E.J., (November 1995). Solving the Dyslexic Dilemma - A True Holistic Approach to Reading. Paper presented at the Learning Disabilities Association of Florida, Regional Conference, Sarasota, Florida. 